DIANA MARIA DA CAMARA GORAYEB

GESTÃO DE CONTINUIDADE DE NEGÓCIOS APLICADA NO ENSINO PRESENCIAL MEDIADO POR RECURSOS TECNOLÓGICOS 
DIANA MARIA DA CAMARA GORAYEB

GESTÃO DE CONTINUIDADE DE NEGÓCIOS APLICADA NO ENSINO PRESENCIAL MEDIADO POR RECURSOS TECNOLÓGICOS

Dissertação de mestrado em Engenharia Elétrica apresentada à Escola Politécnica da Universidade de São Paulo para obtenção do título de Mestre em Engenharia Elétrica.

São Paulo 
DIANA MARIA DA CAMARA GORAYEB

\title{
GESTÃO DE CONTINUIDADE DE NEGÓCIOS APLICADA NO ENSINO PRESENCIAL MEDIADO POR RECURSOS TECNOLÓGICOS
}

\author{
Dissertação de mestrado em Engenharia Elétrica \\ apresentada à Escola Politécnica da Universidade de São \\ Paulo para obtenção do título de Mestre em Engenharia \\ Elétrica.
}

Área de concentração:

Sistemas digitais.

Orientador: Prof. Dr. Edison Spina.

São Paulo 
Este exemplar foi revisado e alterado em relação à versão original, sob responsabilidade única do autor e com a anuência de seu orientador.

São Paulo, 13 de março de 2012.

Assinatura do autor

Assinatura do orientador

FICHA CATALOGRÁFICA

Gorayeb, Diana Maria da Camara

Gestão de continuidade de negócios aplicada ao ensino presencial mediado por recursos tecnológicos / D.M.C. Gorayeb. ed.rev. -- São Paulo, 2012.

$153 \mathrm{p}$.

Dissertação (Mestrado) - Escola Politécnica da Universidade de São Paulo. Departamento de Engenharia de Computação e Sistemas Digitais.

1. Avaliação de risco 2. Gestão da segurança em sistemas computacionais I. Universidade de São Paulo. Escola Politécnica. Departamento de Engenharia de Computação e Sistemas Digitais II. t. 


\section{DEDICATÓRIA}

Ao meu pai Ernani Villar Parente da Camara (in memorian) e minha mãe, Dalva Maria Oliveira da Camara, que foram responsáveis pelos alicerces que hoje sustentam o meu ser, oferecendo renúncias inimagináveis e todos os sacrifícios necessários para minha educação, incutindo valores e uma abordagem positiva da vida. Hoje, a vida está aberta para mim. 


\section{AGRADECIMENTOS}

À Superintendência da Zona Franca de Manaus - SUFRAMA pelo patrocínio financeiro do Minter.

À Fundação de Amparo à Pesquisa do Estado do Amazonas - FAPEAM pelas bolsas para cumprimento do estágio obrigatório.

À Coordenação de Aperfeiçoamento de Pessoal de Nível Superior - CAPES pela criação e regulamentação do Minter.

À Universidade do Estado do Amazonas - UEA por gerar condições e propiciar o oferecimento do programa de Pós da Escola Politécnica da Universidade São Paulo - EPUSP em Manaus.

Ao caríssimo Professor Dr. Edison Spina não só pelas inestimáveis e insubstituíveis ajuda e colaboração para esse trabalho, mas principalmente, pela generosidade humana que me possibilitou concluí-lo. 
"So these princes of ours, whose power had been established many years, may not blame fortune for their losses. Their own indolence was to blame, because, having never imagined when times were quiet that they could change (and this is a common failing of mankind, never to anticipate a storm when the sea is calm), when adversity came their first thoughts were of flight and not of resistance." (MAQUIAVEL, 1513, apud CHAMBERS, 2005). 


\section{RESUMO}

Este trabalho propõe diretrizes de Gestão de Continuidade de Negócios (GCN) para a tecnologia de Ensino Presencial Mediado por Recursos Tecnológicos (EPMRT), que conta, para a realização de suas atividades acadêmicas, com um sistema complexo para transmissão de aulas e exige um grande esforço para o controle das suas operações e das respostas coordenadas diante de erros, falhas e defeitos, ou quaisquer incidentes que resultem na interrupção das suas atividades. A manutenção deste ambiente tecnológico está relacionada com a implantação de processos eficientes de gestão de risco e do ciclo de melhoria contínua em ambiente de TI com a adoção do ITIL $₫$ e através da construção das diretrizes de um Plano de Continuidade de Negócios (PCN), documentado por meio de elementos da UML, utilizando a Análise de Impacto nos Negócios (BIA), a Avaliação dos Riscos (RA) e os atributos de Dependabilidade para os elementos tecnológicos: disponibilidade, confiabilidade, segurança, confidencialidade, integridade e manutenibilidade.

Palavras chaves: Gestão de Continuidade de Negócios, Plano de Continuidade de Negócios, Ensino Presencial Mediado por Recursos Tecnológicos, ITIL $\circledast$, Dependabilidade, Análise de Impacto nos Negócios, Avaliação dos Riscos, disponibilidade, confiabilidade, segurança, confidencialidade, integridade, manutenibilidade, GCN, PCN, UML, BIA, RA, EPMRT. 


\begin{abstract}
This paper proposes guidelines for Business Continuity Management (BCM) that uses a technology called Education System Mediated Classroom Resources Technology (SPMRT), which needs, for the achievement of their academic activities, a complex system for transmission of lessons and requires a great effort to control their operations and coordinated fast responses in case of errors, faults, attacks and defects, or any incidents that result in the disruption of their activities. Maintaining this technological environment is related to the implementation of efficient processes of risk management and continuous improvement cycle in the IT environment with the adoption of ITIL $₫$ and through the construction of a Business Continuity Plan (BCP), documented by elements of the UML using the Business Impact Analysis (BIA), Risk Assessment (RA) and the attributes of Dependability: availability, reliability, security, confidentiality, integrity and maintainability.
\end{abstract}

Key words: Business Continuity Management, Business Continuity Plan, Face Teaching Mediated by Technology Resources, ITIL $®$, Dependability, Business Impact Analysis, Risk Assessment, availability, reliability, security, confidentiality, integrity, maintainability, BCM, BCP, UML, BIA, RA, SPMRT. 


\section{LISTA DE FIGURAS}

Figura 1 - Ciclo de vida da Gestão de Continuidade de Negócios (GCN). Fonte:

(NBR 15999-1, 2007).

Figura 2: Processo de disponibilidade da informação. Fonte: (SMITH; SHIELDS, 2007).

Figura 3: Fases de recuperação do sistema. Fonte: Cornish (2007).................. 40

Figura 4: Detalhe das atividades de preparação do programa de GCN. ............. 44

Figura 5: Matriz de risco. Fonte: NIST SP 800-30, (2002)............................. 53

Figura 6: Elementos macro do plano de continuidade de negócio.................... 65

Figura 7: Entradas, ferramentas e técnicas utilizadas pela GCN. Fonte: NBR

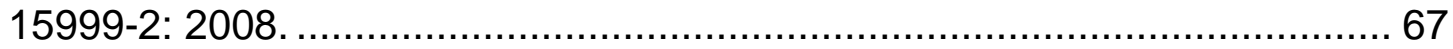

Figura 8: Ciclo de Vida do ITIL $₫$ V3. Fonte: ITIL $₫$ V3 ................................... 75

Figura 9: Ciclos e processos do ITIL $₫$ V3 .................................................. 76

Figura 10: Modelo 'V' para validação e teste de serviço. Fonte: (Arnold et al:

"Systems Engineering - coping with complexity", 1998 apud Holwell, 2009).

Figura 11: Fórmula do Cálculo da Disponibilidade

Figura 12: Fórmula do cálculo para do Tempo Médio entre Falhas. .................... 85

Figura 13: Fórmula para o cálculo do Tempo Médio entre Incidentes.................. 86

Figura 14: Fórmula para o cálculo do Tempo Médio para Restaurar o Serviço. .. 86

Figura 15: Modelo ensino-aprendizagem do EPMRT ................................... 106

Figura 16: Modelo tecnológico utilizado no EPMRT. Fonte: Pereira, (2010)..... 109

Figura 17: Diagrama de componentes da GCN. ......................................... 114

Figura 18: Representação do PCN composto de1 ou vários SOP através do diagrama de casos de uso da UML................................................... 119

Figura 19: SOP documentado através de caso de uso (1 de 3)....................... 121

Figura 19: SOP documentado através de caso de uso (2 de 3) ....................... 122

Figura 19: SOP documentado através de caso de uso (3 de 3)....................... 123

Figura 20: Template do caso de teste da GCN. ........................................ 125

Figura 21: Diagrama de classes da diretriz do PCN....................................... 126

Figura 22: Representação das áreas envolvidas no EPMRT......................... 129

Figura 23: Diagrama de caso de uso da atividade crítica - Executar failover para o banco de dados secundário. ............................................................... 134

Figura 24: Instância do diagrama de componentes para o caso de uso Plano de desastre e recuperação BD corporativo.................................................. 135

Figura 25: SOP - Plano de desastre e recuperação do banco de dados corporativo. (1 de 2)........................................................................ 136

Figura 25: SOP - Plano de desastre e recuperação do banco de dados corporativo. (2 de 2) ..................................................................... 137

Figura 26: Caso de teste do SOP - Plano de desastre e recuperação do banco de dados corporativo. (1 de 2)............................................................... 139

Figura 26: Caso de teste do SOP - Plano de desastre e recuperação do banco de dados corporativo. (2 de 2)....

Figura 27 - Diagrama de objetos do serviço transmissão de aula pelo IP.TV para o EPMRT. 
Figura 28: Ferramentas utilizadas para desenvolver a GCN....................... 145 


\section{LISTA DE QUADROS}

Quadro 1: Matriz de Risco e avaliação do impacto. Fonte: Rittinghouse e

Ransome (2005).

Quadro 2: Ameaças em TI. Fonte: Whitman (apud OLIVEIRA, 2006)................ 48

Quadro 3: Categoria de freqüência.Fonte: Whitman (apud OLIVEIRA, 2006)..... 51

Quadro 4: Categoria de gravidade.Fonte: Whitman (apud OLIVEIRA, 2006)...... 51

Quadro 5: Nível da probabilidade. Fonte: Ferreira (2003)................................ 52

Quadro 6: Categorias de impacto. Fonte: Ferreira (2003)................................... 53

Quadro 7: Exemplo de questionário aplicado pelo BIA. ................................... 55

Quadro 8: Questionário do BIA segundo a visão do impacto causado por evento crítico. 56

Quadro 9: Cenário anterior versus Panorama atual. Fonte: Magalhães e Pinheiro (2007)

Quadro 10: Template para primeira etapa do PCN.

Quadro 11: Descrição Template para descrever as funções críticas da empresa.

Quadro 12: Abertura do PCN para o EPMRT.....

Quadro 13: Descrição das atividades críticas (1 de 3) 129

Quadro 13: Descrição das atividades críticas (2 de 3)

Quadro 13: Descrição das atividades críticas (3 de 3)

Quadro 14: Contribuição do ITIL $®$ na aplicação da GCN 


\section{LISTA DE TABELAS}

Tabela 1 - Avaliação FMEA. Kardec e Nascif (2001).

.50 


\section{LISTA DE SIGLAS E ABREVIAÇÕES}

AVA - Ambiente Virtual de Aprendizagem.

BIA - Business Impact Analysis.

BPO - Business Process Outsourcing.

BRP - Business Recovery Plan.

CIO - Chiefs Informatio Officer

CKO - Chief Knowledge Officer.

COOP - Continuity of Operation Plan.

DIKW - Data, Information, Knowledge, Wisdom.

EPMRT - Ensino Presencial Mediado por Recursos Tecnológicos.

FEMEA - Failure Mode and Effect Analysis

GCN - Gestão da Continuidade do Negócio.

IC - Item de ConFiguração.

ITIL® - Information Technology Infraestructure Library.

KPO - Knowledge Process Outsourcing.

LDS - Linha de Serviço.

MTBF - Mean Time Between Failures.

MTRS - Mean Time to Restore Service.

MTBSI - Mean Time Between Service.

PAN - Padrão de Atividade do Negócio.

PCN - Plano de Continuidade de Negócios.

PDCA - Plan (Planejar), Do (Fazer), Check (Verificar), Act (Agir).

RA - Risk Assessment.

RPO - Recovery Point Objective.

RTO - Recovery Time Objective. 
SaaS - Software as a Service.

SOP - Standard Operation Procedures.

TE - Tecnologia Educacional.

TI - Tecnologia da Informação.

TMPR - Tempo Médio para Reparo. 


\section{SUMÁRIO}

FICHA CATALOGRÁFICA ........................................................................ 4

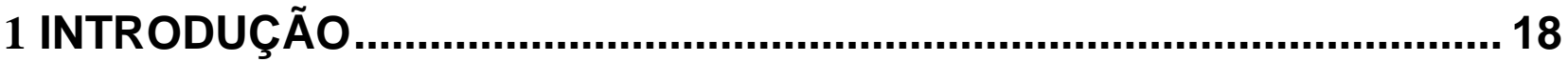

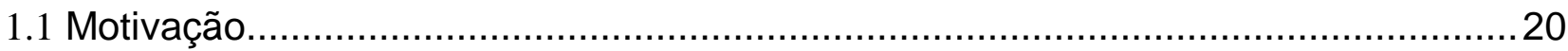

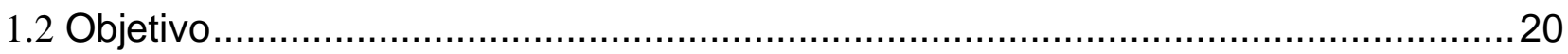

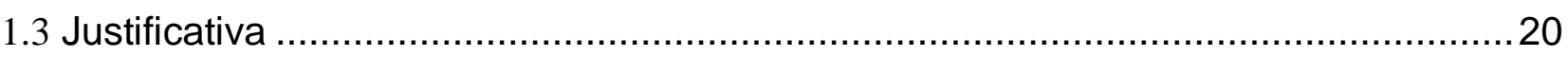

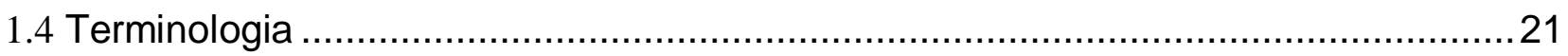

2 GESTÃO DE CONTINUIDADE DE NEGÓCIOS .................................... 28

$2.1 \mathrm{O}$ ciclo de vida da Gestão de Continuidade de Negócios ........................................40

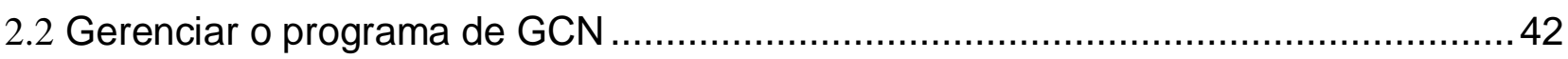

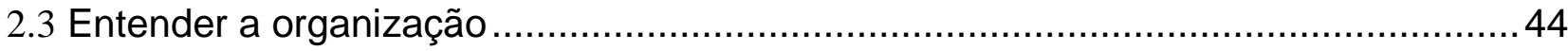

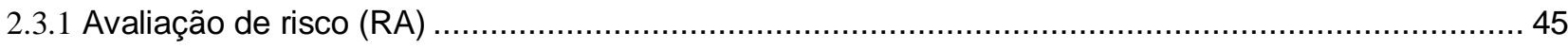

2.3.2 Análise de impacto nos negócios ou Business Impact Analysis (BIA) ......................................... 54

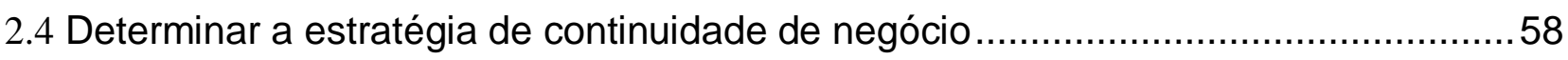

2.5 Desenvolver e implantar uma resposta de GCN.................................................. 63

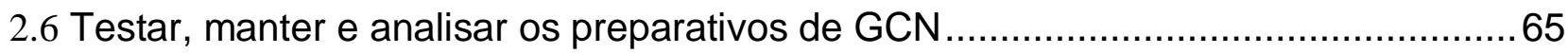

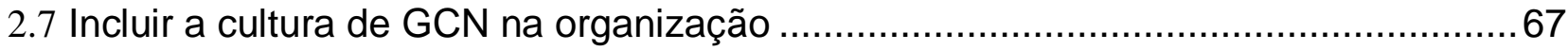

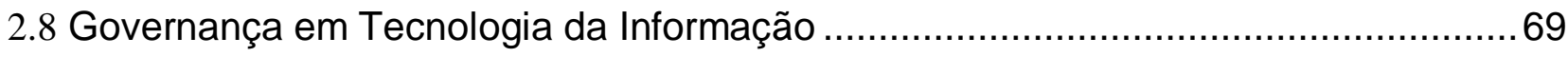

2.8.1 O ITIL $\mathrm{V}_{3}($ Information Technology Infrastructure Library) ....................................................... 71

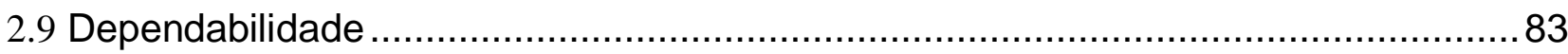

3 SISTEMAS DE ENSINO........................................................................ 90

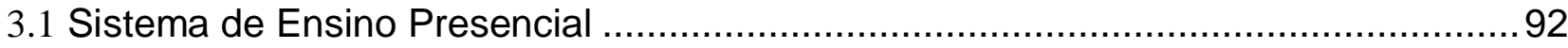

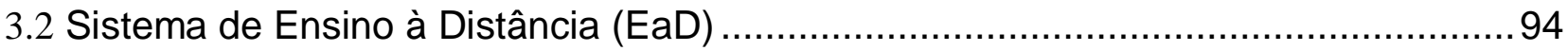

3.3 Sistema de Ensino Presencial Mediado por Recursos Tecnológicos ..................... 102

4 PROPOSTA DAS DIRETRIZES DE CONSTRUÇÃO DO PLANO DE CONTINUIDADE DE NEGÓCIOS ...................................................... 114

4.1 Diretrizes para a construção do Plano de Continuidade de Negócios ..................... 115

5 APLICAÇÃO DAS DIRETRIZES DO PROGRAMA DE CONTINUIDADE DE NEGÓCIO AO EPMRT.......................................... 128

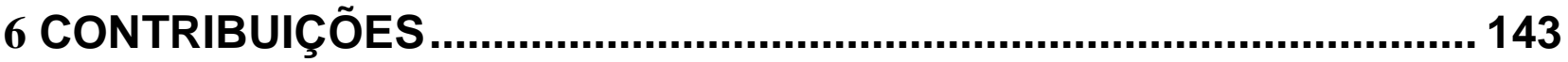

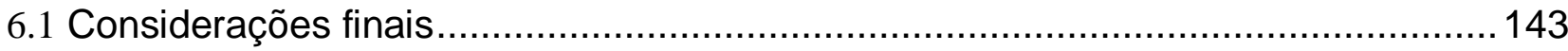


6.2 Trabalhos futuros 


\section{INTRODUÇÃO}

A Gestão de Continuidade de Negócios (GCN) é uma técnica utilizada para proteger, recuperar e manter a entrega dos sistemas em momentos de crise com um desempenho pré-estabelecido.

Os processos do GCN consideram como elementos fundamentais: os recursos existentes em um sistema, o ambiente técnico, as atividades críticas do negócio, os produtos e serviços entregues pela empresa e as políticas aplicadas para a gestão da organização. Estes elementos estarão reunidos e organizados em um Plano de Continuidade de Negócio (PCN) como objetivo de estabelecer a resiliência do sistema, isto é, a capacidade de um sistema de resistir aos efeitos de um incidente.

De forma geral, o programa de Gestão de Continuidade de Negócios envolve o alinhamento estratégico da empresa na área de Tecnologia da Informação ( $\mathrm{TI}$ ) com a política de continuidade de negócios; com a análise dos riscos e impactos gerados no ambiente em caso de crises e interrupções dos serviços; com a definição de alternativas para o gerenciamento das crises; com a avaliação do custo benefício da implantação das soluções e por fim, com a introdução e os melhoramentos constantes.

O Ensino Presencial Mediado por Recursos Tecnológicos (EPMRT) é uma tecnologia educacional dependente de aplicações e do ambiente da Tecnologia da Informação (TI) que distribui conhecimento entre regiões distantes e, em especial, utilizado entre os municípios do Estado do Amazonas. Atualmente o EPMRT é considerado como presencial, mas, apresenta também todas as características da educação à distância, tornando-se um modelo híbrido e sustentado por pilares essenciais: a forma de transmissão de aula, os métodos pedagógicos e o pessoal especializado. As aulas acontecem em um estúdio de televisão, utilizando um meio tecnológico que inclui hardware, software, ambiente físico, procedimentos, pessoas treinadas, legislação e normatização específica.

A elaboração de diretrizes paraa continuidade de negócios ao Ensino Presencial Mediado por Recursos Tecnológicos deve contemplar as 
atividades envolvidas na plataforma para ensino à distância, integração do professor-aluno, integração dos municípios, nos serviços de rede de comunicação baseada em protocolo IP, nos suportes de serviços de acesso a Internet e vídeo conferência multiponto e colaborativa entre outros.

Este ambiente específico de tecnologia educacional foi utilizado para adotar as diretrizes de continuidade de negócio propostas neste trabalho, pois admite o planejamento estratégico do negócio, a definição dos modelos de processo educacional, a agregação de valor ao sistema, o controle dos riscos, a redução dos custos e a melhoria contínua do projeto.

Uma das principais tarefas do planejamento da continuidade de negócio na área de TI é garantir que os incidentes que afetam a infra-estrutura de TI não afetem a disponibilidade dos recursos e dos processos de negócios dependentes além da medida aceitável pelo BCP. Segundo Laurindo apud Zorello (2005) uma integração da estratégia de TI com a estratégia do negócio vai além da proposta de uma ferramenta produtiva para a empresa, sendo muitas vezes o fator de sucesso nos negócios. Muitas organizações têm implementado sistemas de qualidade integrando a totalidade das atividades da empresa, com processos controlados para a obtenção de melhoria contínua dos seus serviços. São "boas práticas" elaboradas a partir de metodologias de governança de TI. Neste trabalho a metodologia ITIL® Information Technology Infrastructure Library contribui com as perspectivas de alinhamento estratégico porque tem o objetivo de criar de maneira sistemática processos eficientes para: avaliar o risco, validar o tempo objetivado de recuperação nos incidentes, criar os procedimentos operacionais padrão para utilização durante o gerenciamento de crise, entre outros.

O ITIL® - Information Technology Infrastructure Library aplica de maneira integrada o uso de processos, pessoas e ferramentas e permite a definição dos responsáveis e dos controles eficientes sobre os elementos da dependabilidade (dependability) como segurança, confiança, integridade, disponibilidade, confidencialidade e manutenibilidade, assegurando que a cultura de continuidade de negócios seja absorvida pela instituição. 


\subsection{Motivação}

Utilizar a GCN, o ITIL $®$, a Dependabilidade, o PDCA e outras ferramentas como componentes do planejamento estratégico da empresa de forma a:

- O aumento da resiliência do ambiente tecnológico;

- O atendimento das expectativas dos envolvidos no programa estratégico dos negócios;

- A garantia das responsabilidades legais, sociais e morais das instituições que empregam este modelo continuidade de serviços; e

- Contribuir para estabilidade e consolidação do sistema educacional denominado de Ensino Presencial Mediado por Recursos Tecnológicos através da elaboração de diretrizes de continuidade de negócio.

\subsection{Objetivo}

Este trabalho propõe diretrizes para a construção de um Plano de Continuidade de Negócios utilizando os processos da Gestão de Continuidade de Negócios e de governança em Tecnologia da Informação para proteger, recuperar e manter o ambiente tecnológico que sustenta o Ensino Presencial Mediado por Recursos Tecnológicos dentro das propriedades de dependabilidade de um sistema computacional.

\subsection{Justificativa}

As atividades necessárias para a realização do processo ensinoaprendizagem no modelo de Ensino Presencial Mediado por Recursos Tecnológicos exigem um alto grau de eficiência dos recursos envolvidos. Segundo Barbosa e Ramos (2008) estes recursos estão divididos em quatro segmentos fundamentais: equipamentos, equipe técnica, corpo docente e corpo discente. O domínio da plataforma tecnológica de transmissão de aulas, a produção dos objetos educacionais, a aquisição e distribuição de 
livros e manuais, a produção de roteiros de aulas, a manutenção do ambiente virtual de aprendizagem e a manutenção do ambiente físico das salas de aulas são exemplos de elementos importantes que influenciam o processo educacional.

Imaginando que todos os elementos participem na medida exata para a realização do sistema de ensino, ainda assim, não há garantias de que os resultados sejam os esperados no que diz respeito à aprendizagem, à formação e ao ganho real para o investimento da sociedade.

Para a efetiva formação, concomitantemente às participações dos quatro segmentos do sistema, novas competências e habilidades são exigidas e a educação deixa de ser um processo fechado professor-aluno, para se transformar em um ensino democrático, compreendendo processos colaborativos e participativos, e altamente dependentes de suporte tecnológico.

Assim é preciso criar estratégias de controle, proteção e manutenção, com procedimentos definidos e documentados para estes fins, que eliminem a improvisação no decidir e agir, os atrasos ou perdas nos serviços e nos recursos liberando os quatro segmentos fundamentais para a realização de suas competências.

\subsection{Terminologia}

A finalidade dessa seção é familiarizar o leitor com os temas a seguir apresentados, o que irá contribuir para a correta compreensão da metodologia proposta no próximo capítulo, bem como para o entendimento da relevância das técnicas escolhidas para integrar a referida metodologia.

- Atividade: é um processo ou um conjunto de processos executados por uma organização (ou em seu nome) que produzem ou suportem um ou mais produtos ou serviços. 
- Atividades críticas: atividades que devem ser executadas para entregar os produtos e os serviços fundamentais da empresa buscando atingir aos seus objetivos mais importantes e sensíveis no tempo. Em geral estão associadas aos ativos críticos da empresa e devem ser identificadas corretamente para análise de suas vulnerabilidades.

- Incidente: é uma situação que pode representar ou levar a uma interrupção de negócios, perdas, emergências ou crises.

- Análise de impacto nos negócios (BIA - Business Impact Analysis): é o processo de análise das atividades e funções do negócio e o efeito que uma interrupção pode ter sobre as mesmas. Essa avaliação do impacto deve ser realizada considerando o quanto os atributos da dependabilidade foram afetados. Podem ser considerados ainda, durante a análise, os impactos financeiros e na imagem da organização.

- Gestão de risco: é o desenvolvimento estruturado e aplicação de uma cultura de gestão, políticas, procedimentos e práticas às tarefas de identificação, análise e controle dos riscos.

- Continuidade de negócio: é a capacidade estratégica e tática da empresa de se planejar e responder a incidentes e interrupções de negócios, para conseguir continuar suas operações em um nível aceitável previamente estabelecido.

- Plano de continuidade de negócio (PCN): é a documentação de procedimentos e informações desenvolvida, consolidada e mantida de forma que esteja pronta para uso caso ocorra um incidente, de forma a permitir que a organização mantenha suas atividades críticas em um nível aceitável previamente definido.

- Contingência de negócios: é a prática de preparar formalmente um ambiente de negócios para uma possível variação.

- Tempo objetivado de recuperação (RTO): é o tempo alvo; período de tempo necessário para recuperar sistemas ou aplicações. Deve ser sempre melhor que o Ponto Objetivado de Recuperação. 
- Ponto objetivado de recuperação (RPO): intervalo de tempo em que se admite que haja perda de dados tolerável para o negócio, sistema ou aplicação. Também é conhecido como período máximo de interrupção tolerável, a partir do qual a viabilidade de um negócio será ameaçada de forma inevitável, caso a entrega dos produtos ou dos serviços não possa ser reiniciada.

- Produtos e serviços: resultados benéficos que uma organização, ou parte da organização, fornece a seus clientes e partes interessadas.

- Organização: grupo de pessoas e instalações com uma série de responsabilidades, autoridades e relacionamentos.

- Risco: de acordo com D'Andrea apud Oliveira(2006) o risco pode ser classificado e tratado como uma oportunidade, uma incerteza ou uma ameaça.

- O risco como oportunidade está centrado no investimento e tem base em iniciativas estratégicas. Quanto maior for o risco, maior o potencial de retorno, e, paralelamente, maior pode ser o potencial de perda. Nesta visão, onde o risco é compreendido como uma oportunidade, ações pró-ativas e ofensivas (não defensivas) são adotadas pelos gestores, com o propósito de que sejam obtidos resultados positivos.

- O risco como incerteza está relacionado à eficiência operacional; neste caso, o gerenciamento do risco consiste em adotar técnicas que equilibrem a variação entre o resultado projetado e o real obtido. Neste cenário, em geral, é difícil estimar o risco existente; na realidade, os gestores trabalham com intervalos de valores, dentro dos quais são feitas as previsões.

- O risco como ameaça, escopo deste trabalho, referese à abordagem mais tradicional, na qual a preocupação está atrelada à ocorrência de efeitos 
negativos, por exemplo, perda financeira, fraude, roubo, comprometimento da imagem e reputação, infração legal, falhas tecnológicas, dentre outros. Nas situações em que o risco é visualizado como uma ameaça, os gestores atuam fortemente de maneira preventiva, a fim de minimizar o impacto causado para a organização caso o risco se materialize. Numa abordagem conceitual, o risco pode ser definido como a probabilidade de uma ameaça específica explorar uma vulnerabilidade existente. Riscos são eventos futuros incertos que podem influenciar a organização no alcance dos seus objetivos, sejam estes estratégicos, financeiros ou operacionais. De modo mais amplo, o risco é um conceito fundamental que alcança todos os processos da organização nos mais diversificados setores da empresa.

\section{RISCO = AMEAÇA * VULNERABILIDADE}

- Ameaça: é uma atividade deliberada ou não intencional, com o potencial de causar danos aos ativos. Elas se dividem em ameaças humanas (intencional e não-intencional); ameaças ambientais (hardware, software, dispositivos tecnológicos, rede elétrica, etc.); e ameaças naturais (desastres naturais como terremotos, incêndios, enchentes, etc.).

- Vulnerabilidade: é definida como circunstância que aumenta a probabilidade de materialização de uma ameaça, contribuindo para que ela ocorra com maior freqüência, maior impacto, ou ambos concomitantemente. As vulnerabilidades podem ser decorrentes de fraquezas existentes nos controles de segurança (sejam estes procedimentos, controles tecnológicos ou físicos).

- Impacto: o impacto refere-se ao dano causado no ambiente tecnológico ou ao negócio devido à exploração de uma vulnerabilidade por uma ameaça. Esse impacto deve ser analisado considerando o quanto os 
atributos da dependabilidade foram afetados. Durante uma análise de risco, outros tipos de impacto também são considerados, dentre eles o financeiro e de imagem/reputação da organização. O impacto causado pela exploração de uma vulnerabilidade deve ser analisado tanto quantitativamente como qualitativamente e deve levar em consideração todo o contexto em que o evento está inserido.

- Ativos: o termo ativo possui significado bastante amplo, e pode englobar recursos tangíveis e intangíveis. São considerados ativos: dados e informações, hardware, software, documentação, dispositivos de infra-estrutura, mídias magnéticas e até mesmo a imagem e reputação da empresa. Os ativos são os principais afetados por uma ameaça. Em função disso, os ativos críticos do negócio devem ser corretamente identificados e suas vulnerabilidades mapeadas para permitir que medidas de controle e proteção sejam adotadas.

- Avaliação de risco (RA - Risk Assessment): processo geral de identificação, análise e estimativa dos riscos. É parte da disciplina de gerenciamento dos riscos.

- Probabilidade: possibilidade de algo acontecer que seja determinada, medida ou estimada, objetiva ou subjetivamente, em termos gerais (como raro, pouco provável, provável, quase certo, etc.), freqüências ou probabilidades matemáticas.

- Gestão de continuidade de negócio (GCN): processo abrangente de gestão que identifica ameaças potenciais para uma organização e os possíveis impactos nas operações de negócio caso estas ameaças se concretizem. A gestão de continuidade de negócio envolve gerenciar a recuperação ou a continuidade dos negócios em caso de uma interrupção nestes, e gestão de todo o programa ou meio de treinamento, testes e análises críticas, a fim de garantir que o plano de continuidade de negócio esteja atualizado e operacional.

- Governança corporativa: proporciona à empresa a transparência na gestão estratégica e efetiva monitoração dos gestores, através da adoção de boas práticas para alcançar aumento da rentabilidade, 
redução do risco, integridade e confiabilidade das informações financeiras e alinhamento entre os objetivos da empresa e as práticas operacionais, definindo responsabilidades claras e objetivos de controle.

- Governança de TI: são práticas de gestão de TI realizadas para garantir o alinhamento de TI às iniciativas de Governança corporativa.

- Dependabilidade (Dependability): é a capacidade de um sistema computacional de entregar serviços que possam ser justificadamente confiáveis.

- Confiabilidade (Reliability): demonstra a capacidade de um sistema em trabalhar sem interrupções, de maneira com o combinado nos acordos de níveis de serviços (ANS).

- Disponibilidade (Availability): é a capacidade em que os serviços, os componentes ou os itens de conFiguração estejam disponíveis para os usuários conforme estabelecido nos acordos de níveis de serviços (ANS).

- Segurança (Safety): é a existência simultânea da disponibilidade de um sistema, isto é, não apresentar defeitos que levem a conseqüências graves para o ambiente e para o usuário, e da confidencialidade e integridade de um sistema, isto é, permite o acesso aos serviços apenas por usuários autorizados.

- Confidencialidade (Confidentiality): é a capacidade que as informações estejam seguras, ou seja, apenas são disponibilizadas para quem tem direito.

- Integridade (Integrity): é a capacidade que as informações sejam precisas e atuais, e que ninguém que não possua permissão poderá alterar o conteúdo.

- Manutenibilidade (Maintainability): é a capacidade de um item, componente ou serviço voltar a funcionar normalmente após uma falha, e o mais rapidamente possível. 
- Alta disponibilidade: é a capacidade de um serviço de TI em minimizar ou mascarar os efeitos de falha em componentes de TI para os usuários do serviço.

- Falha (Failure): execução incorreta de alguma função, mau funcionamento causado pelo erro.

- Erro (Error): manifestação do defeito, comprometimento das informações internas.

- Defeito (Fault): problema físico ou imperfeição que ocorre dentro de um determinado componente.

- Resiliência: capacidade de uma organização de resistir aos efeitos de um incidente.

- Educomunicador: um novo modelo de ensino aprendizagem calcado no professor como mediador dos conhecimentos, onde se valoriza a participação, utilizando os produtos da mídia como catalisador para a busca de mais conhecimentos sobre um determinado tema.

- Cliente: destinatário de um serviço, neste trabalho, serviço de TI, sendo normalmente responsável pela alocação dos recursos financeiros para o seu pagamento, diretamente, mediante cobrança, ou indiretamente, pela demonstração em termos de necessidades do negócio.

- Usuário: pessoa que utiliza o serviço, neste trabalho, serviço de TI, diretamente.

- Fornecedor: entidade responsável pela prestação do serviço, neste trabalho, do serviço de $\mathrm{TI}$.

- Funcionalidade (Serviceability): é a habilidade que tem o provedor de serviço de TI em manter a disponibilidade do serviço.

- Processos: conjunto estruturado de atividades elaborado para alcançar um objetivo. 


\section{GESTÃO DE CONTINUIDADE DE NEGÓcIOS}

A Gestão de Continuidade de Negócios (GCN) ou Business Continuity Management (BCM) é uma metodologia que permite às organizações estabelecerem estratégias operacionais para melhorar a resiliência de seus processos de negócio diante de possíveis falhas e interrupções nos momentos de crise e eventos não planejados, recuperando a capacidade de entregar produtos ou serviços, dentro de nível e de prazos prédeterminados. Seu principal objetivo é criar, manter e incorporar na empresa um plano de ação denominado Plano de Continuidade de Negócios (PCN).

O Plano de Continuidade de Negócio (PCN) é composto por um conjunto de procedimento operacional padrão - Standart Operation Procedures (SOP) e medidas que devem ser executados perante um evento não esperado de risco que provoca a inatividade dos sistemas.

As ações em momentos de crise são dirigidas para retomada dos processos de negócios críticos da empresa procurando diminuir os danos e estabelecer um ambiente de operação alternativo, até que as normalidades dos processos e do ambiente possam ser alcançadas.

Lawer e Szygenda (2007) descrevem as mudanças na tecnologia aplicada, na elaboração dos processos de recuperação de desastres - disaster recovery e de tolerância à falha, denominado disaster preparedness are outlined, de acordo com eventos que comprometem o tempo máximo de indisponibilidade do processo de negócio (o tempo que o negócio pode ficar inoperante). Neste caso, qualquer evento desta natureza é considerado, um desastre a ser contido através do Plano de Continuidade de Negócios.

Os desastres podem ser classificados de acordo com os efeitos:

- Falha de um elemento de infra-estrutura individual (ponto único de falha ou Single Points of Failure);

- Interrupção de longo-prazo de um fluxo de informação crítica;

- Interrupção de longo-prazo de uma cadeia de atividades críticas ou de um processo de negócio crítico; 
- Interrupção total dos negócios.

Para Lawer e Szygenda (2007), a dependência das empresas sobre as informações críticas das aplicações tecnológicas exige do nível gerencial executivo uma compreensão do valor da informação e da adoção de mecanismos apropriados de mitigação do risco para aplicações de TI através de redundância e de infra-estrututura de componentes distribuídos considerando a relevância do custo da solução e do benefício adquirido.

Cornish (2007) explica que os benefícios, ao adotar GCN e padrões de continuidade de negócios, como a NBR 15999-1 "Gestão de continuidade de negócios, Parte 1: Código de Prática (2007)" e NBR 15999-2 "Gestão da continuidade de negócios, Parte 2: Requisitos (2008)", serão completos dependendo do envolvimento do nível gerencial executivo, dependendo do planejamento, da correta avaliação das necessidades da empresa, do treinamento exaustivo e testes operacionais, exercício, manutenção, revisão e auditoria contínuos e não somente através da escrita de um plano de continuidade de negócios.

A Figura 1 apresenta o ciclo de vida do GCN e seus elementos chaves que serão detalhados a partir da seção 2.1:

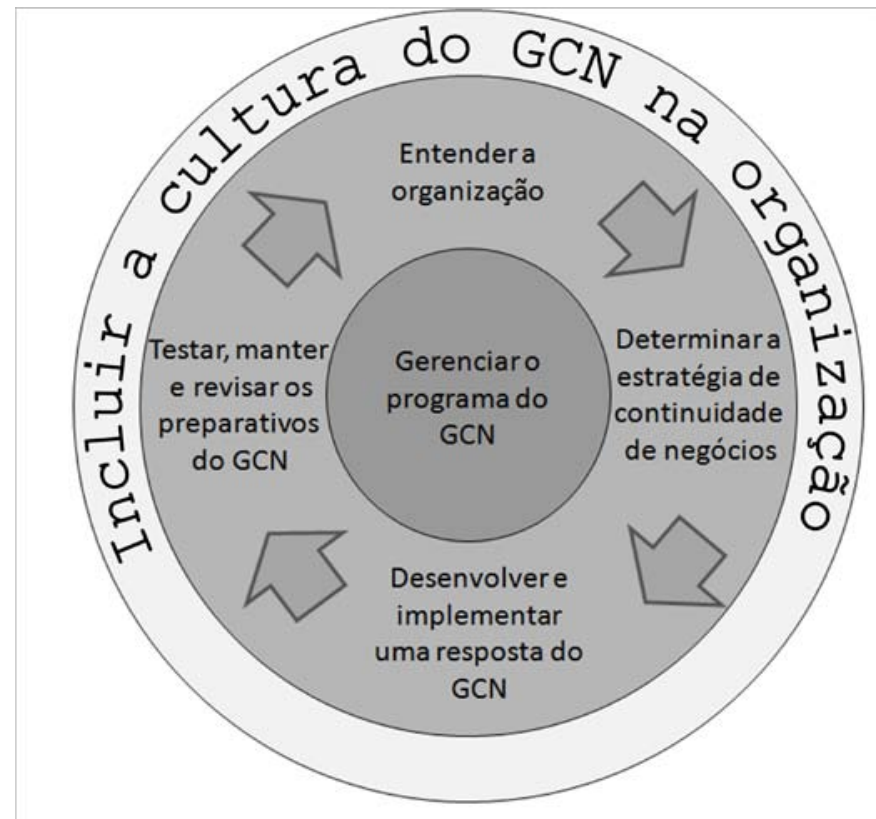

Figura 1 - Ciclo de vida da Gestão de Continuidade de Negócios (GCN). Fonte: NBR 15999-1 (2007). 
A estratégia da GCN, segundo O'Hehir (2007) é a identificação e proteção das atividades críticas, e dos recursos necessários para manter um nível aceitável de operação através dos procedimentos operacional padrão (SOP) garantindo a sobrevivência da empresa no período de crise e interrupção dos negócios.

A estratégia compreende um plano técnico baseado no conhecimento da empresa, nas ferramentas que suportam a operação dos negócios, na avaliação das perdas dessas ferramentas, e nos recursos humanos disponíveis para tratar a situação de crise.

Três importantes questões são avaliadas durante a ausência de um plano de continuidade de negócios: a interrupção da capacidade produtiva e de servir clientes que compromete as oportunidades de negócios; a queda do fluxo de recebíveis, as penalidades, mora e vendas perdidas que influenciam perdas financeiras; e as responsabilidades legais pela não observância de obrigações contratuais que trazem danos a imagem da empresa.

Para O'Hehir (2007) os objetivos da estratégia de um plano de continuidade de negócios (PCN) são:

- Estabelecer um framework para avaliação dos processos de negócio da empresa que permita uma abordagem voltada a desenvolver o PCN;

- Desenvolver um plano de recuperação econômico e operacional que permita à organização concluir seus processos críticos no caso de crise;

- Buscar meios de minimizar o impacto e o dano de uma ameaça concreta na organização;

- Ter um plano eficaz de recuperação através de seguros como uma forma terceirizada e relativamente barata assumido como custo necessário para as empresas atualmente;

- Garantir gestão eficaz dos riscos.

Esses objetivos são alcançados através da governança corporativa.

A necessidade de gerenciamento inclui avaliação da exposição da empresa, no meio externo (economia, ambiente, legislação, entre outros) e interno (poder econômico da empresa, natureza de operação da empresa, tipo de 
produto, sistemas de controle, entre outros); a definição das áreas de risco da empresa (TI, garantia da qualidade, operacional, gestão de ativos, gestão de mudanças, relações de trabalho, entre outros); a definição dos elementos chaves do controle: acompanhamento, avaliação, escopo, mitigação, entre outros.

Vancoppernolle (2007) e O'Hehir (2007) afirmam que as organizações trabalham impulsionadas pelo tempo curto, sob alta pressão para cortar custos e aumentar a eficiência e estão organizadas em torno dos processos de negócio para entregar a um cliente um produto ou serviço. Processo de negócio é uma cadeia de atividades que deve ser realizada de forma lógica e pré-determinada e dirigida por fluxos de informação contínua.

A empresa integra três componentes do processo de negócio:

- Atividades ou fluxos de atividade:

- Participantes (quem participa da execução das atividades); e

- Infra-estrutura e recursos (usados na execução das atividades), internos ou externos e que envolvem: finanças, marketing, área de estoque, carga/descarga, arquitetura de recursos de $\mathrm{TI}$, fornecedores, bancos, entidades públicas, recursos como eletricidade, água, gás, telecomunicações, entre outros.

Cada processo de negócio possui vulnerabilidades e dependências de um número crítico de elementos: recursos, elementos da logística, utilitários, infra-estrutura empresarial, infra-estrutura operacional, TI, entre outros. Quando um componente ou recursos fica indisponível muitos ou todos os fluxos de informação crítica são interrompidos comprometendo a execução dos processos de negócio.

Uma cadeia de atividades possui um número de sub-processos vulneráveis e dependentes de recursos; a estratégia do planejamento de continuidade de negócio não é duplicar cada processo, nem prever backup para cada elemento, isso seria insuficiente para recuperar efetivamente o processo completo, segundo Vancoppernolle (2007). A estratégia deve contemplar o tempo de retomada das atividades e o nível de serviço a ser entregue. 
O autor define ainda "quando um acontecimento inesperado interrompe a cadeia de atividades, o plano de continuidade de negócios terá que reorganizar o processo de negócio de forma diferente, usando uma infraestrutura alternativa, limitada e temporária, redefinindo os tempos de ciclos e prazos".

O autor Roberts (2006) apresenta fatores essenciais para determinar o envolvimento da organização para o desenvolvimento de um programa de continuidade de negócios:

- Quando a organização sente a necessidade de um plano de continuidade de negócios;

- Quando a organização admite eventos não planejados críticos para o processo de negócio e relevante para a continuidade de suas operações;

- Quando algum regulamento específico determina esta necessidade;

- Quando há orçamento destinado ao desenvolvimento do plano de continuidade de negócio como parte do plano estratégico da empresa;

- Quando a empresa está interessada na implantação do plano e sente que é a maior beneficiária do programa;

- Quando há recursos humanos selecionados para participar do programa; e

- Quando existe um método de gestão e governança na empresa, utilizado para que o programa alcance o sucesso esperado.

O desenvolvimento de estratégias de continuidade de negócios depende do método de contingência escolhido pela empresa, e da área de recuperação - work área recovery. Contingências referem-se às substituições previstas para quaisquer recursos que podem se tornar indisponíveis de forma inesperada ou em um momento inesperado.

O tipo de contingência é classificado a partir da decisão da empresa em assumir sozinha os riscos de operação; ou terceirizar através de contratos 
de seguro; ou buscar parceiros para desenvolver ações conjuntas; ou simplesmente reagir aos riscos quando eles, por ventura, vierem a ocorrer.

O autor Courtney (2007) especifica os quatro tipos de contingências que podem ser usadas na estratégia de recuperação, são elas:

- In house: última das opções de contingência por apresentar alto custo, adquirindo recursos duplicados e bens adicionais que serão adotados e colocados disponíveis imediatamente em qualquer crise. Necessitam de manutenção, testes, especificações, etc. São adotados em empresas que devem estar de standby para imediatamente suprir os serviços aos clientes.

- Contrato com terceiros: onde a contingência é assegurada através de uma fonte externa, conhecida como terceirização. Os fornecedores terceirizados mais comuns são relacionados com a tecnologia da informação e dispõem de: servidores, computadores em rede, telecomunicações, work area recovery, web services, entre outros.

- Acordos recíprocos: quando a empresa entre em acordo para apoiar uma parte de, ou outra empresa totalmente independente. O contrato pode prever disponibilidade de work area recovery, equipamentos, entre outros.

- Reativa: a empresa pode garantir uma re-alocação no momento de crise, entretanto, esta decisão pode afetar a disponibilidade da linha atual de recursos disponíveis para a empresa; o acesso aos registros vitais e documentação em papel da empresa; a recuperação dentro do tempo e limite estabelecidos; entre outras considerações.

A Gestão de Continuidade de Negócios se aplica a qualquer natureza de atividade, ou produtos e serviços. Todas elas acabam por envolver a infraestrutura tecnológica empregada em seus negócios e amplamente difundida hoje.

$\mathrm{Na}$ área financeira a Gestão de Continuidade de Negócios demanda bons recursos humanos na sua liderança com conhecimento específico para direcionar a equipe e o esforço para proteger a organização através das 
abordagens regulatórias (questões legais, de regulamentação, etc.) de forma a estabilizar o sistema financeiro da empresa. Segundo Simms (2007) há outra questão envolvendo a tecnologia empregada pelo sistema financeiro que essencialmente impulsiona o trabalho e que deve ser alvo também de proteção e recuperação.

Na área de produção e logística, Musson (2007) descreve um plano de recuperação para área de produção e logística (manufatura) e que envolve diferentes questões: de ambiente, de planejamento de recuperação dos dados processados, de processos de negócio, de tecnologia da informação, da produção, da logística e distribuição.

Muitos processos envolvem técnicas globalizadas de produção e venda, como: e-commerce, certificação de qualidade, obediência à regulamentação, sistemas de planejamento de recursos empresariais - enterprise resource planning (ERP), etc..

As regras para a estratégia e o plano de recuperação na manufatura são:

- Não se prender as formas tradicionais de recuperação;

- Examinar soluções para os incidentes operacionais e comparar seu uso no caso de crises mais críticas;

- Discussões com criatividade e senso comum;

- Revisar as estratégias de continuidade de negócio e recuperação;

- Considerar as interdependências, suporte às funções operacionais e a infra-estrutura de produção;

- Conhecer profundamente os riscos e seus impactos potenciais;

- Usar como uma das estratégias a mitigação dos riscos;

- Conhecer a extensão do dano no ambiente de produção;

- Educar, treinar e exercitar a equipe colaboradora.

$\mathrm{Na}$ área de telecomunicação a gestão de comunicação e tecnologia da informação fornece uma ampla escala de recursos e suporte de sistemas para manter em operação grandes empresas de todas as naturezas. Inúmeras tendências podem ser listadas nas comunicações de hoje, críticas 
para o sucesso empresarial: velocidade de transmissão através da tecnologia de protocolos, Ethernet, por exemplo; redes locais, transmissão baseada em fibra ótica; Virtual Private Networks (VPN), crescimento de sistemas de comunicação baseados em voz sobre IP (VoIP); crescimentos de sistemas que combinam transmissão de Internet via satélite dedicado, contínuo gerenciamento e controle de redes para aumentar a capacidade dos serviços.

Os requisitos para considerar a retomada dos elementos e superação da crise na área de comunicação, segundo Kirvan (2007) são muitos, é possível citar alguns deles na lista abaixo:

- Determinar o valor da infra-estrutura de rede, equipamentos específicos, etc;

- Determinar perdas potenciais no caso de uma crise atingir a infraestrutura de rede;

- Estabelecer planos e estratégias para contingenciar a área de comunicação;

- Desenvolver estratégia de hardware e software para recuperar a capacidade de comunicação dos sistemas;

- Fazer backup dos dados e armazená-los off-site (em outro ambiente alternativo);

- Duplicar e utilizar a redundância dos elementos críticos de processamento, links de rede, etc.;

- Estabelecer práticas de segurança dos sistemas de rede (senha, programas de controle de fluxo, programas de controle de conteúdos como firewalls e roteadores, etc.);

- Identificar fornecedores para componentes de reposição imediata, confiáveis, no caso de manutenção preventiva e corretiva;

- Desenvolver estratégia para reduzir equipe de trabalho, de maneira a deixar o ambiente o mais privativo possível; 
- Trabalhar com dados criptografados, com anti-vírus, anti-spam, antispyware e com proteção up-to-date;

- Determinar o volume de tempo que a empresa pode ficar sem comunicação;

- Estabelecer redundância do sistema on-site e off-site (detalhamento será realizado na seção do ciclo de continuidade de negócio);

$\mathrm{Na}$ área de tecnologia da informação o grande desafio é a segurança da informação e a recuperação da informação, mantendo todos da organização conectados por todo o tempo (24 (vinte e quatro) horas por 7 (sete) dias).

Nessas organizações, segundo Magalhães e Pinheiro (2007) os gerentes da área de informação - Chiefs Informatio Officer (CIO) trabalham para atender aos seus clientes (área de negócio) com produtos e serviços da área de TI não como simples prestador de serviços, mas integrado com a estratégia do negócio, assumindo o que se denominada um agente facilitador do negócio. Atingir a disponibilidade da informação para a continuidade de negócios é, segundo o autor, um processo de 3 etapas apresentado na Figura 2 a seguir:

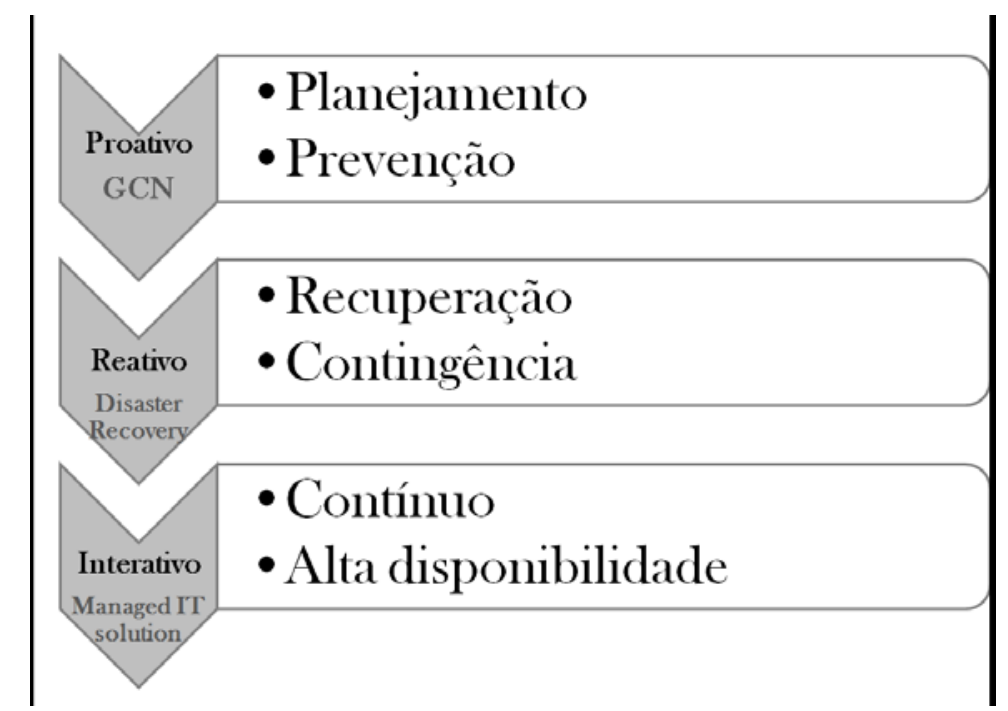

Figura 2: Processo de disponibilidade da informação. Fonte: (SMITH; SHIELDS, 2007).

O objetivo de cada uma das etapas do processo pode ser ainda mais detalhado: 
- Proativa: análise e decisão que irá alimentar o planejamento e a estratégia para assegurar a continuidade de negócios. Compreende as dependências e relacionamentos (internos e externos); prioriza-os pelo tempo que o negócio suporta a inatividade, entre outros.

- Reativo: os elementos reativos da disponibilidade da informação são geralmente denominados de "recuperação de desastres" e geralmente entram em operação quando ocorre o chamado "downtime" ou tempo de inatividade. Os elementos reativos determinam alternativas de áreas de trabalho "work area" que são: hot-site (praticamente uma cópia fiel da localidade principal, dispondo de recursos como hardware, software, rede de comunicação e telefonia, segurança física e ambiental, com profissionais disponíveis 24 (vinte e quatro) horas po 7 (sete) dias assim que o plano de contingência é ativado), cold-site (ambiente com recursos mínimos de infra-estrutura e telecomunicações, desprovido de recursos de processamento de dados e telefones), warm-site (parcialmente equipado com alguns recursos de hardware, software e equipamentos de telecomunicações. Esta localidade deverá ser previamente preparada para receber os profissionais que realizarão configurações e operações).

- Interativo: soluções para alguns requisitos do negócio que representam a força motriz da organização e que precisam de alta disponibilidade e tolerância à falhas através do gerenciamento das soluções de tecnologia da informação.

Obter a disponibilidade plena da informação através da continuidade de negócios inclui a aplicação de ferramentas indispensáveis para a compreensão dos processos de negócio e avaliação dos riscos (RA) como a análise de impacto dos negócios (BIA) e a avaliação de riscos. Barnes (2007) explica que a aplicação do BIA permite uma abordagem top-down dos negócios e atividades da empresa e possibilita que, mesmo as operações mais complexas sejam investigadas. A interpretação dos seus resultados consiste em uma das estratégias da continuidade de negócios 
A avaliação dos riscos (RA) é uma parte chave do $\mathrm{GCN}$, que busca identificar os riscos potenciais para o negócio. Nesta fase, Rittinghouse e Ransome (2005) destacam que todas as possibilidades de incidentes e cada um dos seus impactos, devem ser considerados. Os autores destacam os elementos no processo de avaliação do risco:

- Identificar as ameaças que podem causar danos e quais adversidades que afetam a operação e os ativos críticos;

- Estimar a probabilidade que de cada ameaça se materializar, baseado na informação histórica, no julgamento das pessoas com conhecimento específico de cada área, atividade, e ou operação;

- Identificar e estimar o valor e a criticidade das operações e das questões que afetam na materialização das ameaças. Determinar a ordem de operações e ativos mais importantes e descrever suas características.

- Estimar perdas potenciais sobre operações e ativos importantes da empresa ou o dano que deve ocorrer se a ameaça se materializar, incluindo os custos de recuperação.

- Identificar o custo efetivo das ações de mitigação dos riscos. Essas ações podem incluir implementar novas políticas na empresa e procedimentos, bem como técnicas e controles físicos e lógicos.

Existem vários modelos e métodos para avaliação do risco, e a extensão da análise dos recursos pode variar dependendo do escopo da avaliação e da disponibilidade e confiabilidade dos dados sobre os fatores de risco. Tjoa, Jakoubi e Quirchmayr (2008) afirmam que a abordagem quantitativa do risco geralmente estima o custo do risco, e ainda, que as técnicas de redução dos riscos estão baseados em 3 fatores:

- A probabilidade de um evento não planejado e prejudicial ocorrer;

- O custo potencial das perdas; e

- O custo das ações de mitigação que devem ser feitas.

Ao definir estratégias para análise do negócio e avaliação dos riscos, o projeto para a disponibilidade da informação deve se preocupar com a 
interface dos envolvidos no desenvolvimento do GCN como: auditores, executivos do negócio e a alta administração. A prioridade é apoiar e justificar o custo para o desenvolvimento dos serviços:

- Gestão de risco: identificar e categorizar a exposição da empresa, o tipo de interrupção, obter contratos de seguro e com fornecedores para proteger os ativos e operações contra possíveis eventos não planejados e assegurar o atendimento à legislação, regulamentações, entre outros;

- Planos de contingência: identificar as interrupções de negócio em potencial e desenvolve medidas de salvaguarda contra estas interrupções com a finalidade de aplicar procedimentos de recuperação;

- Recuperação de desastres: salvaguardar as operações de processamento de dados através da identificação de áreas problemáticas e pontos únicos de falha de tecnologia da informação. Desenvolver e implementar planos de recuperação descritos em procedimentos operacional padrão (SOPs).

- Recuperação do negócio: desenvolver planos para salvaguardar e recuperar a área de trabalho, os ativos e os recursos críticos necessários a retomada do negócio.

Além de apresentar o ciclo de vida da Gestão de Continuidade de Negócios este Capítulo apresenta os conceitos de Governança corporativa, com destaque ao $\mathrm{ITIL}{ }^{1}$ - um conjunto de melhores práticas para $\mathrm{O}$ Gerenciamento de Serviços de TI, que fornece orientações para a área de TI visando melhoria contínua e envolvendo processos, pessoas e tecnologia; e da Dependabilidade - uma denominação para a computação confiável, um conceito introduzido na tecnologia da informação através da observância de seus fundamentos: as ameaças, os atributos e os meios através dos quais a Dependabilidade é alcançada.

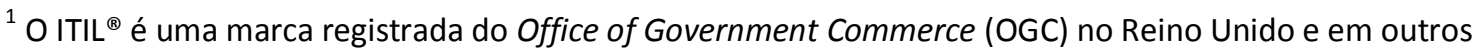
países.
} 


\subsection{O ciclo de vida da Gestão de Continuidade de Negócios}

A Gestão da Continuidade de Negócios (GCN) - Business Continuity Management é um sistema de gerenciamento que ajuda uma organização a melhorar seus controles de segurança e a sua resiliência para assegurar uma resposta imediata e efetiva em momentos de crise. A resiliência é a capacidade de um sistema de resistir aos efeitos de um incidente, (NBR15999-1, 2007), e envolve três fases distintas:

- Uma resposta emergencial para a proteção dos ativos do sistema;

- O gerenciamento da crise para restabelecer as operações do sistema; e

- A recuperação do negócio da organização e superação da crise.

A Figura 3 apresenta as atividades desenvolvidas ao longo do tempo em um sistema quando atingido por uma crise:

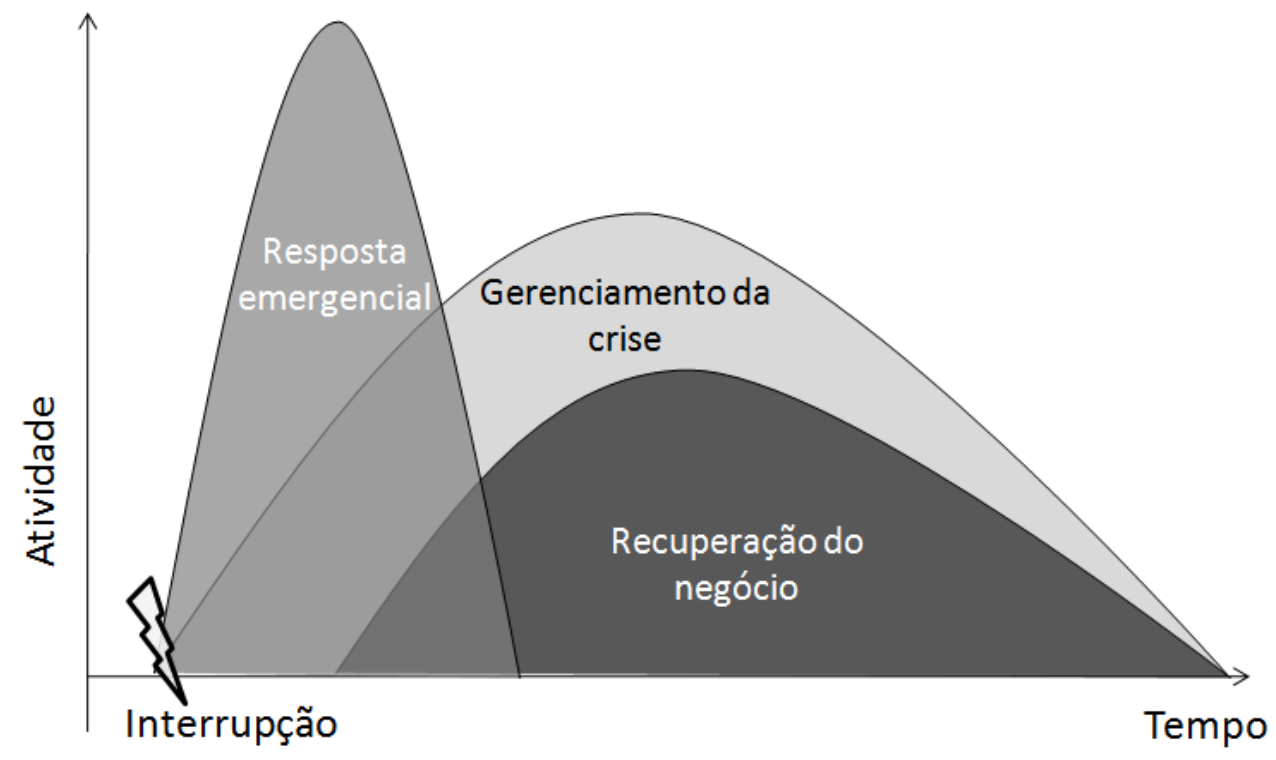

Figura 3: Fases de recuperação do sistema. Fonte: Cornish (2007).

Atualmente, as empresas estão adotando estratégias de continuidade como solução para o gerenciamento dos riscos de qualquer natureza e de qualquer proporção. O objetivo é assegurar perdas mínimas, garantir os contratos e obrigações com parceiros e manter o bem-estar e segurança dos seus recursos humanos e físicos. Este novo comportamento agrega valor à imagem da organização, tornando-a forte diante do mercado e sociedade, 
demonstra que ela está preparada para lidar com adversidades e que pode superar, sem perdas significativas, a ocorrência de um evento de risco.

[...] proteção contra eventos grandes e improváveis como atos de terrorismo, fogo, inundação ou qualquer outro desastre natural. Porém, nos dias atuais, a adoção de continuidade de negócio conta com estratégias contra as interrupções de minutos ou interrupção de horas para traumas em sistemas críticos, projetos sensíveis, produtos ou serviços elementares e vitais para a vida financeira da empresa, cujo choque potencial pode causar conseqüências sérias e traumáticas para suas expectativas e cuja origem pode considerar também: atos de vandalismos, suspensão de serviços públicos, falhas humanas e tecnológicas. Wan e Chan(2008).

A Gestão de Continuidade de Negócios é implementada efetivamente em uma organização através da aplicação dos elementos compreendidos no ciclo de vida do GCN (Figura 1). São eles:

- Gerenciar o programa de GCN;

- Entender a organização;

- Determinar a estratégia de continuidade de negócios;

- Desenvolver e implementar uma resposta de GCN;

- Testar, manter e revisar os preparativos de GCN; e

- Incluir a cultura de GCN na organização.

Os elementos Gerenciar o programa de GCN, inserido no círculo central da Figura, e Incluir a cultura de GCN na organização, apresentado no círculo externo da Figura, são continuamente aplicados durante o ciclo de vida da Gestão de Continuidade de Negócios e interagem com todos os outros elementos do programa. O primeiro porque fornece instrumentos para implementar o programa como a gerência dos recursos e das atividades. $O$ segundo porque habilita toda a organização para enfrentar um momento de crise. A cada iteração do ciclo de vida do programa de GCN novas habilidades são definidas e passadas à organização, dentro do modelo de melhoria contínua.

A seguir, os conceitos e detalhes dos elementos do ciclo de vida da GCN. 


\subsection{Gerenciar o programa de GCN}

O programa de Gestão de Continuidade de Negócio, conforme a NBR 15999-1 (2007) define os seguintes passos:

- Atividades de preparação para reunir informações:

- Levantar os custos do programa: o quanto a empresa deve investir para conhecer a GCN e desenvolver o programa.

- Levantar os benefícios do programa: o quanto a empresa pode ganhar protegendo seus ativos, divulgando os seus resultados ou antecipando, às outras partes interessadas nos negócios (cliente, investidores, parceiros, etc.), que está habilitada em um programa de continuidade de negócios.

- Gerenciamento contínuo e manutenção do programa:

- Definir a composição da equipe e as responsabilidades de cada membro: quem vai ser o gerente do programa e qual o poder de decisão que ele vai possuir; quais os requisitos de comunicação da equipe.

- Estabelecer o escopo do projeto: quais as metas e objetivos que o programa irá atingir; qual o cronograma para desenvolver a GCN. O tamanho do programa de continuidade de negócio de uma organização é proporcional ao volume das suas atividades. Ele também é influenciado também pela natureza do negócio, escala geográfica, criticidade e complexidade da organização. Outro fator importante para a definição do escopo do programa de continuidade são as dependências operacionais, e 
restrições legais impostas à organização: políticas de meio ambiente, instruções, normais e padrões de trabalho e condução de atividades.

- Estabelecer as entregas: definir quais os documentos que serão entregues (avaliação dos riscos, análise de impacto, planos de emergência, recuperação de crises e continuidade de negócios, etc.). A preparação inclui também definir os requisitos da documentação, o planejamento das operações de treinamento, teste e validação do programa.

A capacidade de gestão da organização irá determinar como as atividades do programa serão integradas e incorporadas ao crescimento e desenvolvimento da empresa.

Segundo o autor Roberts (2006), uma boa gestão demanda necessidades e exigências para a sua implantação que, uma vez atendidas, integram-se na rotina da empresa melhorando a disponibilidade dos produtos e serviços e a satisfação dos seus clientes.

Outras etapas recomendadas pela NBR 15999-1 (2007) para o gerenciamento do programa de continuidade de negócios:

- Promoção e comunicação do programa de continuidade de negócio para toda a organização incluindo também os produtos e serviços promovidos por terceirizados que, perante o contexto da organização é de responsabilidade desta;

- Promoção de testes e auditorias contínuas das atividades do programa: direcionar recursos para averiguar se o projeto está seguindo o planejado. Se forem detectados desvios, será aplicada uma ação corretiva para colocar as atividades de acordo com o plano do projeto; e

- Definição dos procedimentos para controle do gerenciamento de mudanças.

Howe, (2007) descreve que os elementos mais importantes da fase inicial do projeto: estrutura, orçamento, cronograma e marcos. 
A Figura 4 apresenta o modelo de negócio para o início das atividades de continuidade de negócio e que contam inicialmente com especialistas de GCN e com a alta direção da organização:

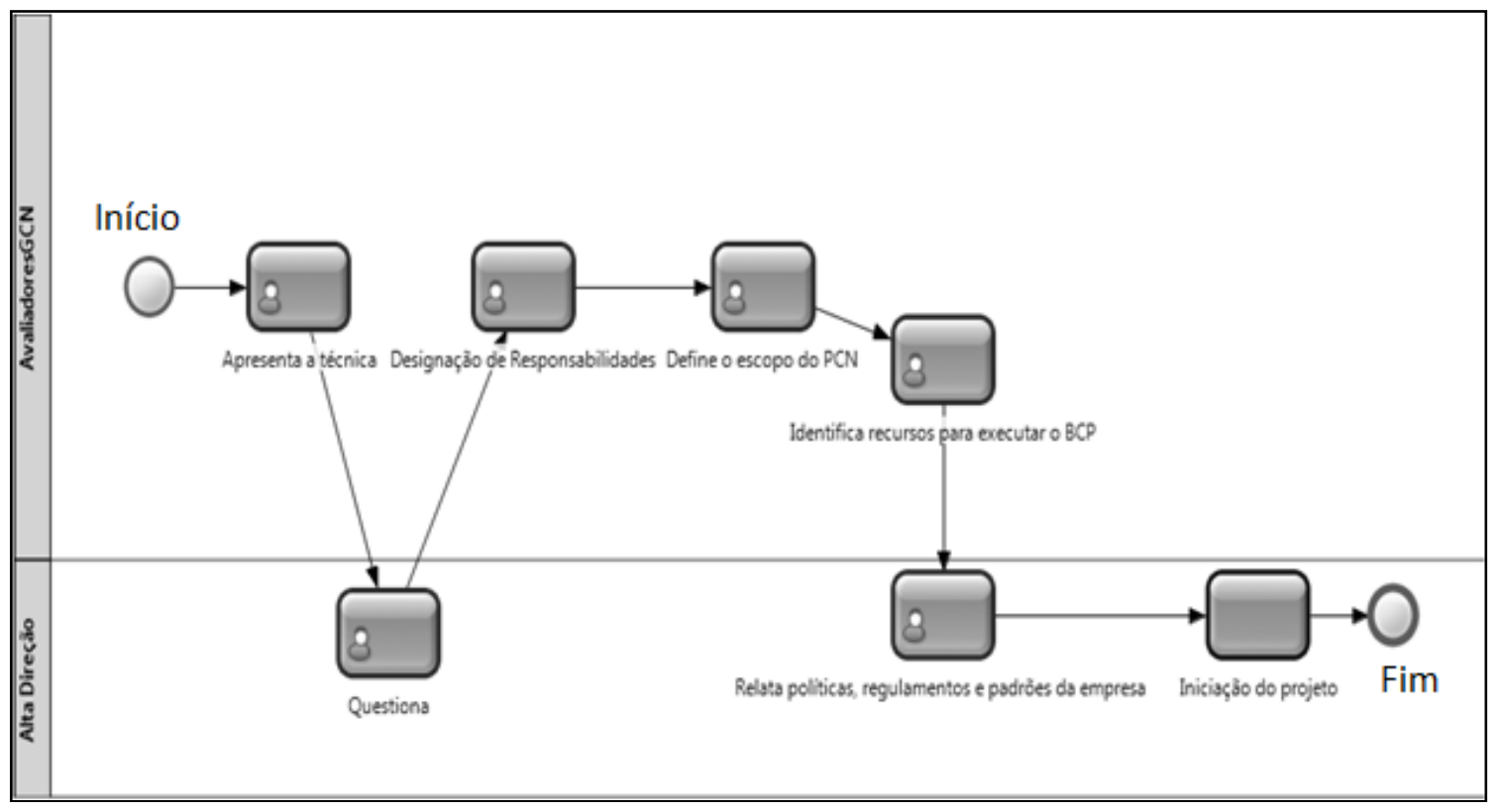

Figura 4: Detalhe das atividades de preparação do programa de GCN.

\subsection{Entender a organização}

A análise do ambiente operacional da empresa é um dos passos para compreensão da organização. É uma análise sistemática, um exame detalhado de seus produtos, atividades e dependências do meio, de outros serviços e de recursos. Esta análise inclui fases de identificação e avaliação segundo os autores Wan e Chan (2008).

A fase de identificação da organização compreende o levantamento de elementos essenciais. Vancoppenolle (2007) os define como fluxo de informação da empresa:

- Produtos e serviços;

- Atividades e recursos; e

- Encadeamentos e dependências.

A fase de avaliação deve fornecer três aspectos importantes:

- O que a organização faz; 
- Quem e o que está envolvido na criação de produtos e serviços; e

- Como as atividades estão ligadas.

Segundo o Good Practice Guidelines (2008) as ferramentas utilizadas para compreender os negócios de uma empresa são:

- Avaliação dos riscos (RA - Risk Assessment);

- Análise do impacto no negócio (BIA - Business Impact Analysis); e

- Análise dos requisitos de continuidade.

\subsubsection{Avaliação de risco (RA)}

No contexto da Gestão de Continuidade de Negócios, a avaliação de risco é o processo que identifica e avalia os riscos potenciais para o negócio, resultantes de situações de crises. Esse processo identifica as ameaças e as vulnerabilidades considerando todos os tipos de incidentes e seus possíveis impactos sobre os negócios de uma empresa.

O processo de avaliação de risco inclui a identificação e a estimativa do risco e faz parte da disciplina de gerenciamento de risco juntamente com o controle de risco (medidas de redução do risco) e gerência de risco (manutenção do programa).

Uma abordagem estruturada para a avaliação do risco em TI envolve quatro passos, segundo o autor Charters (2007):

- Bens e ameaças identificados: listar e categorizar os bens da empresa, considerando os bens tangíveis e não tangíveis, incluindo procedimentos, processos de manufatura, sistemas de informação e comunicação.

- Quantificação das perdas potenciais: representar em termos financeiros as perdas de bens, reputação, credibilidade, etc..

- Avaliação das vulnerabilidades: conduzir análise de cenários e calcular Risco = Impacto $x$ Probabilidade. Utilizar métodos quantitativos $\mathrm{e}$ qualitativos. 
- Avaliação das soluções: enquadrar as medidas de controle do risco em uma das quatro categorias: aceitar, gerenciar, reduzir e planejar a continuidade de negócios. Ver quadro 1 abaixo:

\begin{tabular}{|l|l|l|}
\hline \multicolumn{1}{|c|}{ Impacto } & Baixo & Alto \\
\hline Probabilidade & & \\
\hline Alta & Gerenciar & Reduzir \\
\hline Baixa & Aceitar & Business Continuity Plan \\
\hline
\end{tabular}

Quadro 1: Matriz de Risco e avaliação do impacto. Fonte: Rittinghouse e Ransome (2005).

Existem diferentes modelos e métodos para condução do processo de avaliação de risco de $\mathrm{TI}$ e a extensão da análise e os recursos empregados podem variar dependendo do escopo do levantamento e da disponibilidade de dados e informações confiáveis, além da experiência do profissional que conduzirá o processo de análise de risco. Para Oliveira (2006), a avaliação de risco é estruturada em três grandes etapas:

Identificação dos riscos: consiste mapear todas as potenciais ameaças aos quais os ativos estão suscetíveis, bem como as vulnerabilidades que estes possuem, a avaliação da probabilidade de materialização das ameaças e a estimativa dos impactos causados.

Mitigação dos riscos: consiste na seleção de estratégias a serem adotadas para eliminação ou minimização dos riscos.

Monitoramento dos riscos: consiste na monitoração dos riscos visto que as ameaças, vulnerabilidades e os próprios ativos alteram-se com o passar do tempo.

Westerman e Hunter (2008) descrevem o processo de avaliação de risco de forma semelhante, contando ainda com as etapas:

- Definir normas e políticas de segurança;

- Identificar e avaliar riscos;

- Priorizar os riscos e atribuir responsabilidades;

- Lidar com riscos através de ações efetivas; e

- Monitorar e rastrear riscos através de mensurações do status das ações. 
Segundo os autores Westerman e Hunter (2008) os fatores de risco para Tecnologia da Informação, são:

Agilidade: capacidade de mudar com rapidez e custos administrados. São exemplos as relações ruins entre negócios e a área de TI; gerenciamento insuficiente de projetos; falta de iniciativas para novos projetos.

Precisão: proporcionar informações corretas, oportunas e completas que atendam aos requisitos da administração, do pessoal, dos clientes, dos fornecedores e dos reguladores. São exemplos de fatores críticos as aplicações que não atendem os requisitos de negócio; integração manual de dados; implementações significativas ainda em produção ou recémconcluídas.

Acesso: assegurar o acesso apropriado a dados do sistema, de modo que as pessoas certas o tenham quando precisarem e as pessoas erradas não, a possibilidade de mau uso de informações cai nesta categoria. São exemplos de fatores críticos: dados não compartimentados; aplicações sem padronização de arquitetura; falta de controle interno ou unificado nas aplicações; rede não confiável.

Disponibilidade: propriedade que mantém os sistemas em operação, podendo recuperá-los em caso de interrupções. Alguns fatores críticos são, por exemplo: alta rotatividade do pessoal de $\mathrm{Tl}$; infra-estrutura não padronizada; gestão ineficaz de patches ou atualizações; tecnologia ultrapassada; backups e processos de recuperação ruins.

Estes autores afirmam que o controle desses fatores de risco em TI é obtido através da execução dos passos de avaliação do risco, inicialmente levantando as políticas e critérios de segurança utilizados, normas e padrões aplicados pela empresa na área de TI.

No passo de identificação e avaliação de risco é necessário definir ameaças e vulnerabilidades e ainda: analisar os controles existentes de segurança, determinar a probabilidade através de métodos quantitativos e qualitativos de avaliação de risco, fazer a análise de impacto e finalmente, determinar o risco, Ferreira (2003). 
Para Oliveira (2006) neste passo estão incluídas as tarefas de definir e caracterizar o escopo. Várias técnicas podem ser utilizadas para realizar esta tarefa, são elas: questionários, entrevistas, revisão da documentação e ferramentas existentes.

Whitman apud Oliveira (2006) apresenta nove categorias para identificar ameaças. Ver no quadro 2 abaixo:

\begin{tabular}{|l|}
\hline Categorias de ameaças \\
\hline Erro humano ou falha \\
\hline Comprometimento de propriedade intelectual \\
\hline Atos deliberados de espionagem \\
\hline Atos deliberados de sabotagem ou vandalismo \\
\hline Atos deliberados de roubo \\
\hline Ataques deliberados de software \\
\hline Falhas técnicas ou erros de hardware \\
\hline Falhas técnicas ou erros de software \\
\hline Obsolescência tecnológica \\
\hline
\end{tabular}

Quadro 2: Ameaças em TI. Fonte: Whitman apud Oliveira (2006).

A identificação das vulnerabilidades consiste em mapear as "fragilidades" existentes nos recursos e processos de Tecnologia da Informação, as quais poderiam ser exploradas por potenciais fontes de ameaças, Oliveira (2006). As vulnerabilidades, técnicas ou não, associadas com o ambiente de $\mathrm{TI}$ podem também ser identificadas por meio das técnicas para obtenção de informação apresentadas para definição do escopo, somadas aos relatórios de auditorias anteriores, relatórios de manutenção, testes e deploy (transferência para o ambiente de produção de nova aplicação), lista de ameaças e vulnerabilidade apresentada no site $\mathrm{NIST}^{2}$, especificamente na área de segurança da computação, e utilização de informações dos fabricantes de bens e ativos de TI.

A presença de uma ameaça não significa que ela irá necessariamente causar prejuízos, danos ou perdas de qualquer natureza. Para se tornar um risco, a ameaça precisa explorar vulnerabilidades existentes nos ativos, nos sistemas de segurança ou nos controles internos empregados pela

\footnotetext{
${ }^{2}$ NIST - National Institute of Standards and Technology. Disponível em <http://www.nist.gov/threatsvulnerabilities.cfm>. Acesso em 05.04.2011.
} 
organização, Oliveira (2006). Algumas situações intensificam a probabilidade da ocorrência de incidentes:

- Alto grau de mudança no ambiente;

- Ambientes informatizados em larga escala;

- Tecnologia de rede complexa;

- Maturidade das tecnologias empregadas; e

- Volume de acesso por terceiros.

A análise dos controles de segurança refere-se aos controles técnicos incorporados no hardware, software ou firmware (mecanismos de controle de acesso, identificação e autenticação, criptografia), e ainda: nos procedimentos operacionais, segurança física de pessoal e ambiental, Ferreira (2003).

Uma vez que existe a caracterização dos sistemas, a identificação das ameaças, o passo seguinte é a identificação das vulnerabilidades, feita através do check list dos controles de segurança, técnicas para levantar informação, ou testes de segurança e análise das ações de controle efetivo.

A seguir a determinação da probabilidade através de métodos quantitativos ou qualitativos:

Análise qualitativa: na análise qualitativa todas as métricas aplicadas são subjetivas por natureza, a análise final do risco é classificada em categorias e são usadas para sugerir, indicar a existência do risco. Algumas técnicas podem ser utilizadas para esta análise como:

- Análise do Modo e Efeito da Falha- Faliure Mode Effect Analysis (FMEA) é uma abordagem que ajuda a identificar e priorizar as falhas potenciais em equipamentos, sistemas ou processos e remendar ações preventivas, Kardec e Nascif (2001). FMEA é fundamentalmente a medida do risco da falha. Seus principais conceitos são:

- Causa: é o meio pelo qual um elemento particular do projeto ou processo resulta em um modo de falha; 
- Efeito: é uma conseqüência adversa para o consumidor ou usuário.

- Modos de falha: são as categorias de falha que são normalmente descritas;

- Frequência: é a probabilidade de ocorrência da falha;

- Gravidade da falha: indica como a falha afeta o usuário ou cliente;

- Detectabilidade: indica o grau de facilidade de detecção da falha;

- Índice de risco ou número de prioridade de risco (NPR): indica o resultado do produto da freqüência pela gravidade da falha pela detectabilidade da falha (facilidade de detecção da falha). Esse índice:

- $[$ NPR = FREQUENCIA $X$ GRAVIDADE $X$ DETECTABILDIADE];

- Determina a prioridade da falha. Veja a tabela 1:

Tabela 1 - Avaliação FMEA. Fonte: Kardec e Nascif (2001).

\begin{tabular}{|c|c|c|}
\hline Componente do NPR & Classificação & Peso \\
\hline \multirow{5}{*}{ Freqüência } & Improvável & 1 \\
\hline & Muito Pequena & 2 a 3 \\
\hline & Pequena & 4 a 6 \\
\hline & Média & 7 a 8 \\
\hline & Alta & 9 a 10 \\
\hline \multirow{5}{*}{ Gravidade da falha } & Apenas perceptível & 1 \\
\hline & Pouca importância & 2 a 3 \\
\hline & Moderadamente grave & 4 a 6 \\
\hline & Grave & 7 a 8 \\
\hline & Extremamente grave & 9 a 10 \\
\hline \multirow{5}{*}{ Detectabilidade } & Alta & 1 \\
\hline & Moderada & 2 a 5 \\
\hline & Pequena & 6 a 8 \\
\hline & Muito pequena & 9 \\
\hline & Improvável & 10 \\
\hline
\end{tabular}


- Estudo do Perigo e da Operabilidade (HazOp) - é uma técnica sistemática para identificar perigos e problemas operacionais dos processos. As ameaças e possíveis causas são mapeadas e qualificadas através dos quadros 3 e 4 que representam respectivamente: a categoria da freqüência, a categoria da gravidade.

\begin{tabular}{|l|l|l|}
\hline Categoria & Denominação & Freqüência \\
\hline 1 & Freqüente & 1 por ano \\
\hline 2 & Provável & 1 em cada 5 anos \\
\hline 3 & Ocasional & 1 em cada 15 anos \\
\hline 4 & Remoto & 1 em cada 30 anos \\
\hline 5 & Improvável & 1 em cada 100 anos \\
\hline
\end{tabular}

Quadro 3: Categoria de freqüência. Fonte: Whitman apud Oliveira (2006).

- O nível de risco é obtido através da combinação entre freqüência e gravidade e determina se o risco será aceitável, aceitável através de mecanismos de controle, indesejado ou inaceitável.

\begin{tabular}{|l|l|l|}
\hline Categoria & Denominação & Freqüência \\
\hline 1 & Catastrófico & Destruição de equipamentos e mortes múltiplas \\
\hline 2 & Perigoso & $\begin{array}{l}\text { Redução da margem de segurança, danos físicos, } \\
\text { lesões graves, possíveis mortes }\end{array}$ \\
\hline 3 & Moderado & Incidente grave e lesões a pessoas \\
\hline 4 & Menor & Limitações operacionais, incidentes melhores \\
\hline 5 & Insignificante & Conseqüências leves \\
\hline
\end{tabular}

Quadro 4: Categoria de gravidade. Fonte: Whitman apud Oliveira (2006).

Análise quantitativa: a análise quantitativa do impacto provê a medida da magnitude do impacto e pode ser utilizada nas análises de custo benefício dos controles. Exemplos de técnicas que apresentam resultados quantitativos:

- Avaliação Probabilística do Risco ou Probabilistic Risk Analysis (PRA) é um método que avalia as respostas de um sistema diante da perturbação de seu ambiente suas condições normais de operação. A base da avaliação de risco é desenvolver cenários contendo eventos que podem levara conseqüências indesejadas como uma situação de perigo. O início do evento pode ser: falhas em equipamentos de $\mathrm{TI}$, falhas humanas, falhas de software, falhas de processos, etc. Estes cenários são documentados através de árvore de evento - árvore de 
modo e efeito da falha. A partir de então, se investiga como cada evento pode ter ocorrido e desenha-se a árvore de falhas.

A determinação da probabilidade deve levar em consideração os fatores: motivação da ameaça e natureza da vulnerabilidade. A existência ou não de controles efetivos de segurança deve compor a definição da fonte da ameaça e sua condição para explorar ou não explorar a vulnerabilidade existente.

O quadro 5 abaixo apresentado define o nível de probabilidade em : alto, médio e baixo a partir da análise feita com as variáveis acima:

\begin{tabular}{|l|l|}
\hline Nível & Definição \\
\hline Alto & $\begin{array}{l}\text { A fonte de ameaça está altamente motivada e possui conhecimento } \\
\text { suficiente para execução do ataque. Os controles de segurança para } \\
\text { prevenir que a vulnerabilidade seja explorada são ineficazes }\end{array}$ \\
\hline Médio & $\begin{array}{l}\text { A fonte de ameaça está motivada e possui conhecimento suficiente para a } \\
\text { execução do ataque. Os controles de segurança para prevenir que a } \\
\text { vulnerabilidade seja explorada são eficazes. }\end{array}$ \\
\hline Baixo & $\begin{array}{l}\text { A fonte de ameaça não está altamente motivada e não possui conhecimento } \\
\text { suficiente para a execução do ataque. Os controles de segurança para } \\
\text { prevenir que a vulnerabilidade seja explorada são eficazes. }\end{array}$ \\
\hline
\end{tabular}

Quadro 5: Nível da probabilidade. Fonte: Ferreira (2003).

A análise do impacto determina o grau de risco quando uma ameaça é explorada por uma vulnerabilidade. Sendo assim, saber o impacto causado é conhecer exatamente a função ou as funções do sistema e conhecer a criticidade do sistema, isto é, seu valor e importância na organização, Ferreira (2003).

Para a tecnologia da informação, o impacto poderá ser contabilizado através dos critérios de valor da informação: integridade, disponibilidade e confiabildiade; ou através dos atributos da dependabildiade: segurança, disponibilidade, integridade, confiabilidade, confidencialidade e manutenibilidade (denominado também de resiliência)

Alguns impactos podem ser medidos por meio das perdas financeiras e custo para realização da manutenção. O quadro 6 apresenta categorias de impacto, segundo o autor Ferreira (2003): 


\begin{tabular}{|l|l|}
\hline Nível & Definição \\
\hline Alto & $\begin{array}{l}\text { Perda significante dos principais ativos e recursos. } \\
\text { Perda da reputação, imagem e credibilidade. } \\
\text { Impossibilidade de continuar com as atividades de negócio }\end{array}$ \\
\hline Médio & $\begin{array}{l}\text { Perda dos principais ativos e recursos. } \\
\text { Perda da reputação, imagem e credibilidade. }\end{array}$ \\
\hline Baixo & $\begin{array}{l}\text { Perda de alguns dos principais ativos e recursos. } \\
\text { Perda da reputação, imagem e credibilidade. }\end{array}$ \\
\hline
\end{tabular}

Quadro 6: Categorias de impacto. Fonte: Ferreira (2003).

.A matriz de risco apresentada por NIST SP 800-30 apresenta a determinação do risco segundo à severidade do impacto e à probabilidade de ocorrência em uma matriz 3×3 conforme Figura 5.

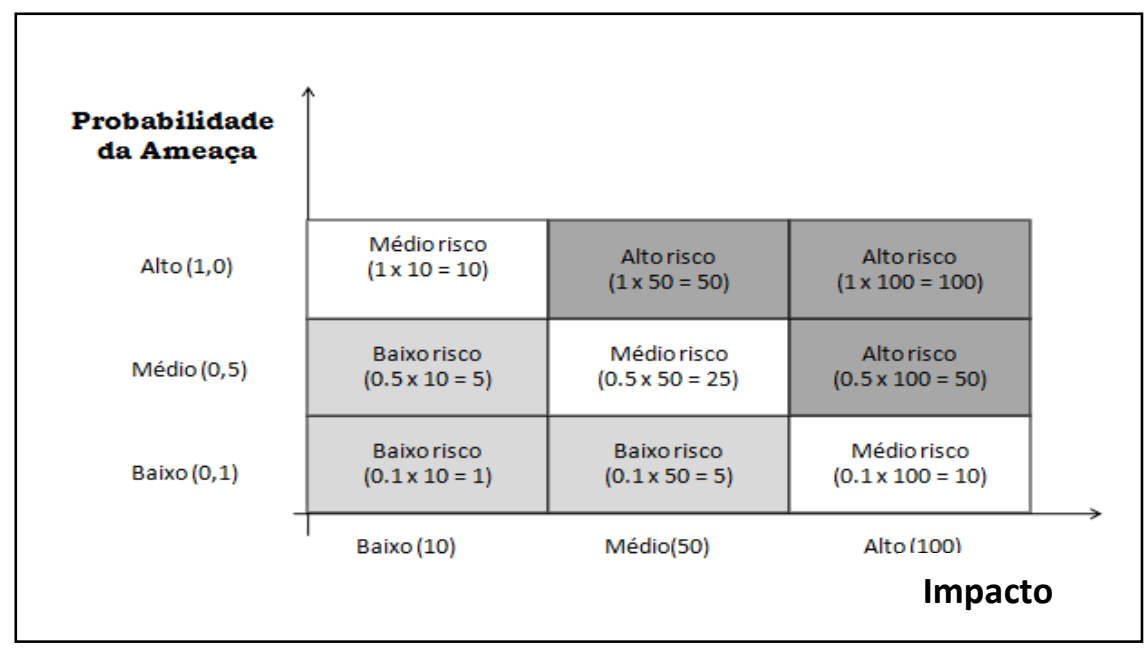

Figura 5: Matriz de risco. Fonte: NIST SP 800-30 (2002).

A determinação desses níveis de risco é subjetiva, irá depender dos requisitos especificados e a granularidade da avaliação de risco desejada. A interpretação da matriz de risco para as categorias alto risco, médio risco e baixo risco são:

- Alto risco é um risco que a organização deve certamente responder adotando medidas corretivas que devem ser iniciadas o mais breve possível

- Médio risco é um risco que a organização deve considerar responder através de ações corretivas estabelecidas em um plano de ação elaborado em um curto período de tempo;

- Baixo risco é um risco que a organização deve considerar a aceitação ou avaliar a necessidade de efetuar manutenção corretiva. 
As recomendações dos controles de segurança servem para reduzir o nível de risco que os sistemas estão expostos, até um nível aceitável. A escolha e prioridade irão depender da análise custo $x$ benefício realizada para os controles propostos. O planejamento da contingência para o ambiente de TI será apresentado na seção 2.4: Determinar a estratégia de continuidade de negócio.

\subsubsection{Análise de impacto nos negócios ou Business Impact Analysis (BIA)}

A Análise de Impacto nos Negócios é um processo de identificação das funções críticas do negócio e as perdas e efeitos se essas funções não estiverem disponíveis.

Segundo a NBR15999-1 (2007) as funções críticas do negócio são atividades que devem ser executadas de forma a entregar os produtos e serviços fundamentais da empresa e que a permita atingir seus objetivos mais importantes e sensíveis ao tempo. Em geral estão associadas aos ativos críticos da empresa e deve ser identificadas corretamente para análise de suas vulnerabilidades.

A aplicação do BIA no programa do GCN é obrigatória. Ele fornece dados coletados diretamente das partes interessadas nos processos críticos apresentando inclusive, como os responsáveis enxergam o risco, os impactos e como esses impactos poderiam ser controlados, reduzidos ou evitados:

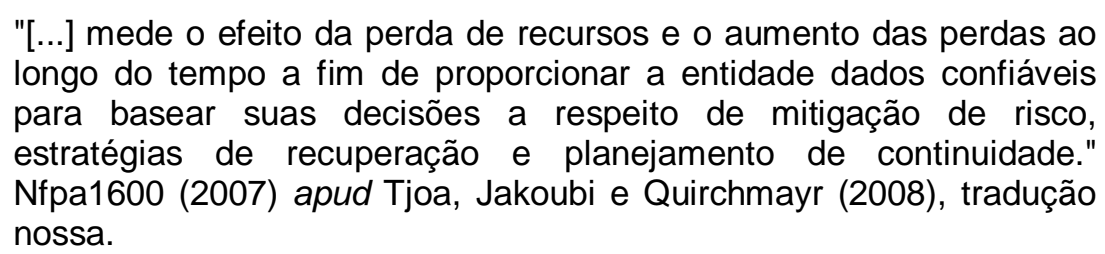

Para Wan e Chan (2008) o BIA é desenvolvido em seis passos apresentados a seguir:

- Desenvolver uma pesquisa ou questionário para levantar o máximo de informações do ambiente; 
- Identificar e notificar apropriadamente os destinatários do levantamento/pesquisa;

- Distribuir a pesquisa e receber as respostas;

- Revisar as pesquisas e conduzir entrevistas complementares com os responsáveis, se necessário;

- Analisar dados de pesquisa; e

- Preparar relatório para a decisão do gerenciamento sênior.

Os requisitos para elaborar os questionários e entrevistas do BIA devem ser:

- Quais recursos e registros são requisitos para a continuidade de negócios da empresa;

- Quais são as necessidades mínimas para manter as operações;

- Quais os recursos seriam provenientes de fontes internas, e em que medida;

- Que dependências existem com negócios externos ou fornecedores, e em que medida estão estabelecidos os ANS

- Quais são as necessidades de backup;

- Qual o tempo e o esforço necessários para recriar os dados atuais de backup; e

- Que precauções devem ser tomadas para a recuperação sem um ambiente de teste.

Algumas questões chaves incluem os itens demonstrados no quadro 7:

\begin{tabular}{|l|l|}
\hline Quando acontece uma interrupção... & Respostas \\
\hline $\begin{array}{l}\text { Torna-se evidente para um grande numero } \\
\text { de pessoas? }\end{array}$ & \\
\hline $\begin{array}{l}\text { Resulta em um grande número de de } \\
\text { reclamações ou críticas? }\end{array}$ & $\begin{array}{l}\text { Listar possíveis ações para } \\
\text { reduzir as reclamações. }\end{array}$ \\
\hline Pode aumentar ou diminuir? & $\begin{array}{l}\text { Estabelecer o período de tempo } \\
\text { e a causa. }\end{array}$ \\
\hline É prevenida por ações que reduzem efeitos? & Explicar as ações necessárias. \\
\hline
\end{tabular}

Quadro 7: Exemplo de questionário aplicado pelo BIA. 
O quadro 8 apresenta uma outra visão do questionário do BIA, utilizado para determinar o impacto de um evento crítico:

\begin{tabular}{|l|l|}
\hline Quando uma interrupção impacta... & Respostas \\
\hline Na geração da receita corrente... & \multirow{2}{*}{ Qual a fonte e o montante. } \\
\cline { 1 - 2 } Na geração da receita futura... & Estado de como isso pode ocorrer. \\
\hline Na infra-estrutura de suporte em TI... & Quantos? \\
\hline No número de empregados... & \multirow{2}{*}{ Estado de como isso pode ocorrer. } \\
\cline { 1 - 1 } Na segurança ou morte de empregados... & \\
\cline { 1 - 1 } Na imagem da empresa... & \\
\cline { 1 - 1 } No acesso à informação & \\
\hline
\end{tabular}

Quadro 8: Questionário do BIA segundo a visão do impacto causado por evento crítico.

Outras investigações devem ser feitas para detalhar a importância e dependências das atividades. Estes investigações devem descriminar:

- Informações básicas de cada atividade: nome, unidade, localização, pessoa responsável e descrição da atividade (fluxo do processo);

- Os efeitos de uma interrupção para cada atividade devem apresentadas em termos de: impactos financeiros e impactos operacionais (por exemplo: clientes que recebem os produtos ou serviços, danos na imagem e reputação da empresa, não conformidades com regulamentações), impactos na segurança dos empregados e clientes, etc.

- Os recursos exigidos para cada atividade: pessoas (que executam as atividades sob condições normais, que são necessárias para a retomada das atividades após uma interrupção e sob condições críticas), tecnologias, equipamentos, e documentação.

- O tratamento e a mitigação do risco contendo: medidas para reduzir a probabilidade de uma interrupção, medidas para reduzir o período de uma interrupção, e medidas para limitar os impactos de uma interrupção.

É importante entender como a função é vital para a estratégia da empresa. Isto exige determinar por quanto tempo a função poderia ficar inoperante sem qualquer impacto ou perdas e determinar como o restante dos negócios seria afetado por estas interrupções das funções - o impacto operacional. 
Parte deste processo deve entender o valor da receita perdida devido a interrupção da função - o impacto financeiro .

Se a interrupção resultar em violação dos acordos de nível de serviço, dos requisitos regulamentares, ou quaisquer obrigações contratuais como sanções e problemas jurídicos - os impactos legais e regulamentares.

Determinar se a interrupção da função afeta as relações com os clientes - a perda de confiança dos clientes ou se afeta as relações com o mercado redução das taxas de mercado.

Outros impactos como a perda de competitividade ou perda de oportunidades de vendas futuras também devem ser registrados no BIA.

A análise de impacto deve considerar, ao longo do tempo, os benefícios e os custos dos recursos necessários para restaurar os sistemas.

Ao final o relatório do BIA deve apresentar a priorização e a classificação das funções de negócio baseado na criticidade das atividades para a empresa. Elas podem ser divididas em funções críticas, essenciais, necessárias e desejáveis.

- Funções críticas são aquelas funções que, se interrompidas ou indisponíveis por algum período de tempo, podem causar grandes danos à empresa. Devem ser restabelecidas no período de 3 (três) a 24 (vinte e quatro) horas.

- Funções essenciais são aqueles cuja perda poderia afetar seriamente a capacidade da organização e de funcionamento da empresa. Devem ser restabelecidas entre dois a três dias.

- Funções necessárias são aquelas que não seriam necessárias para a organização continuar funcionando, mas a sua ausência limita a eficácia do negócio. Devem ser restabelecidas no período de quatro a sete dias.

- Funções desejáveis seriam aquelas que são benéficas para a organização, mas sua ausência não afeta a organização. Podem ser restabelecidas dentro de quatorze dias.

A visão do relatório do BIA para Rittinghouse e Ransome (2005) apresenta os seguintes resultados: 
- Um meio de determinar quais componentes e equipamentos são cruciais para sustentar sistemas ou infra-estruturas de comunicações. (O BIA admite que todos os componentes são importantes para o negócio e que portanto, necessitam de estratégias para minimizar os riscos aos quais estão expostos, entretanto, entende que alguns componentes são mais críticos que outros em casos de emergências de devem fazer parte de um plano de recuperação - disaster recovery);

- Um meio para estabelecer dependências e relações entre os processos de negócios;

- Uma declaração do quanto às perdas financeiras e não financeiras acontecem com o passar do tempo, o que fornece uma justificativa apropriada para gastar em continuidade;

- Uma quantificação da importância dos componentes de negócios propondo atribuição de fundos adequados como medida de proteção a esses componentes;

- Os limites de tempo e informações toleráveis dentro do qual as operações devem se recuperar (tempo objetivado de recuperação timeframe ou RTO) e (ponto objetivado de recuperação - timestamp ou RPO); e

- Uma fundação para a elaboração da estratégia de recuperação e continuidade da empresa.

\subsection{Determinar a estratégia de continuidade de negócio}

Determinar as estratégias de continuidade de negócios envolve escolher quais procedimentos serão adotados para permitir que a empresa proteja, sustente e recupere seus negócios.

Esta tarefa envolve os seguintes passos:

- Estabelecer a equipe de continuidade de negócios; 
- Estabelecer quais procedimentos operacionais padrão (SOP - Standard Operating Procedures) de gerenciamento de riscos e crises serão adotados;

- Avaliar o custo e o benefício da estratégia de continuidade considerando três tipos de recursos:

- Estabelecer estratégias tecnológicas: estratégias defensivas como redundância de hardware, software, rede, etc., contratos de manutenção e suporte, capacidade de backup e restauração (ou recuperação).

- Estabelecer estratégias de informação: recuperação da informação pelo uso de espelhamento de dados, backup de dados, storage de dados secundário (depósito de dados secundário) ou geograficamente distante.

- Estabelecer estratégias de recursos humanos: disponibilizar os recursos relacionados com pessoas chaves com conhecimentos e habilidades do negócio e se necessário, e ainda de uma equipe de trabalho stand-by, especialistas, etc.

- Desenhar um conjunto de planos de trabalho para a continuidade de negócios que envolva:

- Plano de gerenciamento de riscos;

- Plano de gerenciamento de crise;

- Plano de disaster recovery;

- Plano de continuidade de negócios.

O plano de gerenciamento de riscos pode ser alcançado através de uma das opções abaixo segundo Rittinghouse e Ransome (2005):

- Assunção de risco: isto é, manter a operação do sistema de TI aceitando o risco potencial ou implementando controles para reduzir o risco a um nível aceitável. 
- Prevenção de risco: isto é, tomar uma decisão consciente para não se envolver com ou evitar uma situação de risco através da eliminação da causa do risco e / ou conseqüência.

- Limitação do risco: isto é, aplicação de técnicas adequadas para reduzir a probabilidade de uma ocorrência e suas consequências, ou ambos, limitando o risco através da implementação de controles que permitam minimizar o impacto negativo de uma ameaça.

- Planejamento do risco: é o gerenciamento do risco através do desenvolvimento de um plano de mitigação de risco que prioriza, implementa e mantém controles.

- Reconhecimento e pesquisa: é o reconhecimento da empresa de um risco e das vulnerabilidades existentes e a pesquisa para processos apropriados de controle. É considerada uma estratégia temporária, reservada par uso durante uma fase de implantação de uma nova regra de segurança, um novo sistema de informação ou quando uma ameaça é completamente nova.

- Transferência do risco: é a transferência da responsabilidade das perdas para outra parte (terceiros) através de contratos, legislação, ou outro mecanismo de compensação. Esta opção geralmente é implementada em combinação com outras estratégias.

As medidas de prevenção de segurança da informação são parte da gestão de risco e do planejamento de continuidade de negócios.

Alguns exemplos de soluções para controle eficaz do risco e contingência das atividades do negócio são: Virtual Private Networks (VPNs) e acesso remoto, firewalls, criptografia de dados, sistemas de detecção de intrusão, antivírus, anti-spyware e anti-spam.

- Virtual Private Networks (VPNs) e aceso remoto: VPNs são túneis 'tunnels' entre duas extremidades que permitem que os dados sejam transmitidos em segurança entre os nós e em muitos casos, em uma rede privada. Uma rede privada é aquela onde os caminhos de dados estão escondidos de todos exceto, de um grupo limitado de pessoas, 
geralmente dos clientes e empregados da organização. Atualmente a VPN faz uso da infra-estrutura existente, pública ou privada através de LANs e WANs para transferência de dados usando a tecnologia conhecida como tunelamento para criptografar dados para uma transmissão segura. Vários recursos de segurança ficam disponíveis quando uma conexão VPN é criada, como por exemplo: a autorização, a autenticação, a criptografia e a filtragem de dados. O acesso remoto por usuários autorizados pela empresa deve ser controlado e restrito às máquinas seguras.

- Firewall é um sistema designado a prevenir o acesso não autorizado para ou de uma rede privada. São implementados por elementos de hardware e software e fazem um controle sobre todas as solicitações e mensagens que entram e saem da rede, examinando o conteúdo e bloqueando aqueles que não são condizentes com os critérios de segurança especificados pela segurança da informação. As várias técnicas de firewall utilizadas são:

- Packet filter: olha todos os pacotes que entram e saem da rede avaliando-os a partir de regras definidas pelo usuário. É suscetível à falsificação de IP.

- Application gateway: aplica mecanismos de segurança para protocolos específicos como servidores FTP e Telnet. Isto pode impor a degradação do desempenho.

- Circuit-level gateway: aplica mecanismos de segurança quando uma conexão TCP ou UDP é estabelecida. Uma vez que a conexão foi feita os pacotes podem fluir entre os pontos sem outras verificações.

- Proxy server: interceptam todas as mensagens que entram e saem da rede. O proxy efetivamente esconde a verdadeira rede de endereços.

- Criptografia: criptografia é a tradução de dados num código secreto, e é a forma mais eficaz para garantir a segurança de dados. Para ler um arquivo criptografado, você deve ter acesso a uma chave secreta ou passaword que permite decifrá-lo. Os dados criptografados são chamados de textos cifrados. 
- Deteç̧ão de intrusos: sistemas de detecção de intrusão são utilizados para detectar pacotes mal formados ou suspeitos quando eles viajam através da rede. Os sistemas de detecção de intrusão reúnem e analisam informações de diversas áreas dentro de um computador ou uma rede para identificar obter informação e identificar possíveis falhas de segurança, que incluem tanto os ataques de fora da organização quanto o abuso e ataques de dentro da organização:

- Acompanhar e analisar tanto as atividades do usuário quanto as do sistema;

- Analisar as conFigurações do sistema e as suas vulnerabilidades;

- Avaliar a integridade dos arquivos e aplicativos; e

- Reconhecer os padrões típicos de ataques;

- Analisar os padrões normais de atividades e acompanhar qualquer violação das políticas de usuário.

- Antivírus, anti-spyware, e anti-spam: são software que detectam uma classe de programa de computador que tenta identificar, impedir e eliminar vírus de computador e outros tipos de software em sua rede, servidores ou clientes com comportamento suspeito ou que pode indicar infecção.

Outros tipos de prevenção à propriedade intelectual, controles preventivos de segurança da informação incluem os backups de dados, gerenciamento de backups e recuperação de procedures, organização de storages. Além desses métodos preventivos existem outros elementos de prevenção dependendo do tipo de negócio, como por exemplo: sistemas de energia, sistemas contra incêndios, geradores, sistemas de refrigeração, entre outros: utilização de no-breaks (Uninterruptible Power Suplly - UPS), geradores de energia elétrica, aparelhos de ar-condicionado, detectores de fumaça, utilização de sala cofre, com cofres a prova de fogo, fumaça e água, 
armazenamento externo de backups, documentação dos sistemas, estratégias de recuperação

\subsection{Desenvolver e implantar uma resposta de GCN}

Escrever o Plano de Continuidade de Negócios (PCN) para a área de Tecnologia da Informação (TI) é contemplar a especificação detalhada da infra-estrutura, dos sistemas e da rede de comunicação. Essa documentação deve fazer isso claramente para cada atividade ou função crítica da empresa e suas dependências com esta infra-estrutura tecnológica.

Depende da natureza do negócio, do investimento pretendido, e da escolha da melhor alternativa proposta em termos do custo da medida de proteção do risco e do benefício que essa medida trás ao ser implementada na organização. O plano de continuidade de negócio deve incluir os seguintes serviços:

- Gerenciamento de risco: identificar e categorizar exposições falha que pode causar uma interrupção de negócios, então, obter contratos de seguro e de fornecedor para proteger contra um evento de desastre. garantir requisitos de negócios e regulatórios conhecidos e respeitados, e garantir recuperação implementando procedimentos e contratos.

- Plano de contingência e tolerância às falhas: identificar as interrupções de negócios em potencial e desenvolver defesas contra essas interrupções e implementar procedimentos de recuperação.

- Plano de disastre recovery: salvaguardar as operações de processamento de dados, identificando as áreas de problemas potenciais e pontos únicos de falha que podem resultar em interrupções. Desenvolver e implementar procedimentos de backup e recuperação, plano de retomada dos negócios (restabelecer os pontos mínimos de serviços, no tempo tolerável de retomada) e plano de emergência ocupacional (proteção de empregados, salvaguardar vidas, instalar em 
ambientes físicos alternativos) podem ser adicionados ao plano de continuidade de negócio

- Recuperação de negócio: desenvolver medidas de proteção e os planos de recuperação de empresas e procedimentos que regem os escritórios remotos e operações de negócios associados à organização. Assegurar que os procedimentos de proteção de ativos corporativos alcancem os recursos críticos de negócios localizados em escritórios comerciais e definir os responsáveis pelas atividades prioritárias e complementares nos planos de continuidade de operação para sustentar e manter as operações em momento de crise. Também pode ser adicionado no PCN.

Após a definição das estratégias de rede de comunicação, banco de dados, backup, recovery, software, controle e gerenciamento do fluxo de dados e dos usuários; após a definição da equipe de recuperação de negócios, notificação dos elementos chaves, planos de comunicação e ambientes alternativos de serviço, o Plano de Continuidade de Negócio deverá ser descrito na seguinte forma:

- Recuperação dos dados do negócio: definição do ponto de recuperação, definição do tempo de recuperação, alta disponibilidade, estratégia de backup, estratégia de duplicação de dados, redundância;

- Plano de recuperação da tecnologia: disponibilidade de rede, virtualização, sala cofre, licença de software e aplicativos;

- Plano de emergência de crise: impactos humanos nos negócios, na propriedade, nos recursos internos e externos, identificar procedimentos de emergência, integrar com outros planos de continuidade;

- Plano de gerenciamento da crise: estratégia de recuperação préincidente ou pós-incidente, procedimentos gerais de mitigação de risco;

- Recuperação a área de trabalho de negócio: recuperação de lugar com recursos e bens, time para transporte, recuperação dos sistemas, equipamentos requisitos de TIC; e 
- Planejamento da equipe de recuperação: time de gerenciamento da crise, suporte administrativo, time de avaliação do perigo, tipo de coordenação da recuperação, time de comunicação corporativa, time suporte aos recursos humanos.

A Figura 6 associa as etapas do plano ao alinhamento estratégico da empresa buscando especificar os procedimentos operacionais padrões da crise - SOP's.

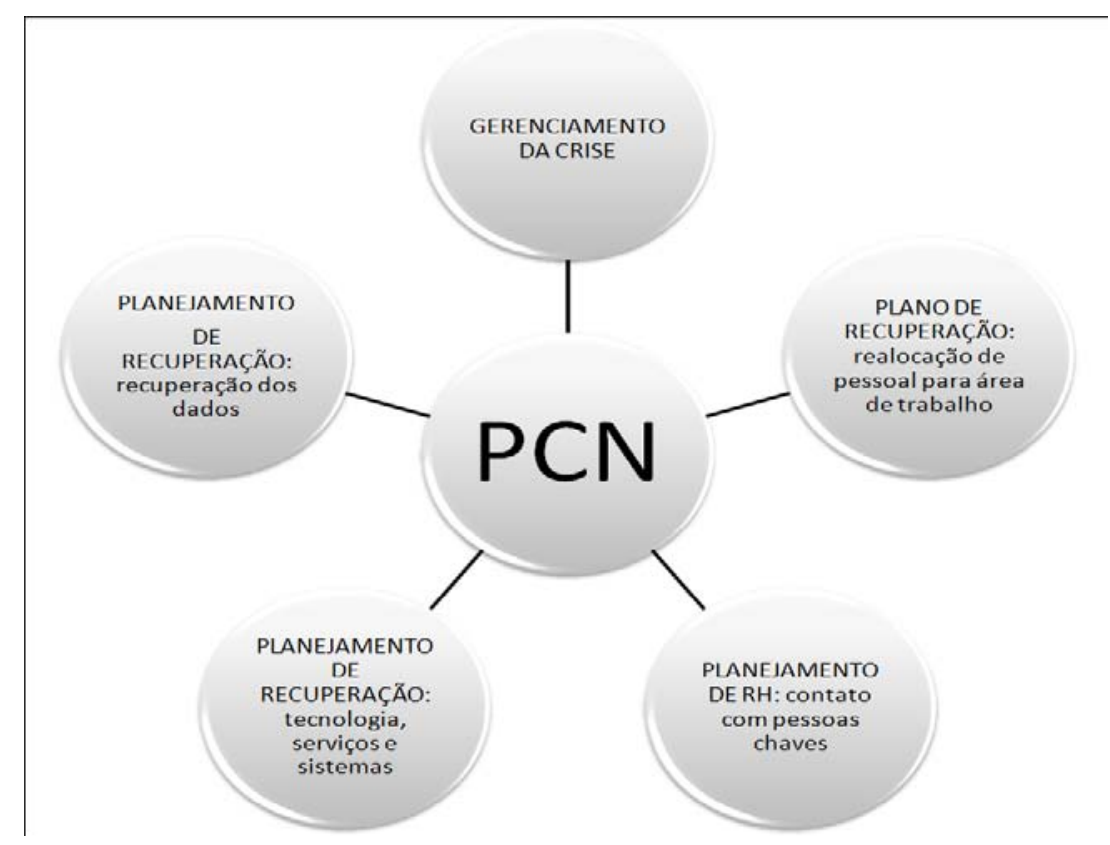

Figura 6: Elementos macro do plano de continuidade de negócio.

\subsection{Testar, manter e analisar os preparativos de GCN}

Para implantar um programa de GCN que permita desenvolver uma capacidade estratégica e tática de operação em modelos de ensino presencial com mediação tecnológica será utilizado o modelo PDCA, uma ferramenta de qualidade que trata do processo de melhoria contínua.

O PDCA é o meio de garantir o gerenciamento e aprimoramento do programa de GCN de forma eficaz. Spina (1998) apresenta os quatro estágios do PDCA ou ciclo de Deming e ressalta que os estágios devem ser repetidos continuamente e estão representados pelas letras P (Plan), D (Do), $\mathrm{C}$ (Check) e A (Act) (planejar, fazer, controlar e agir). 
Igualmente a outros sistemas de gestão, os procedimentos do SGCN são desenvolvidos na seguinte proporção:

- P (estabelecer políticas e objetivos de continuidade);

- D (implementar, criar controles e medidas para gerenciar adequadamente o risco);

- C (monitorar e analisar criticamente o desempenho e eficácia do GCN);

- A (melhoraria contínua baseada nos objetivos).

A seguir o detalhamento de cada uma das fases do programa de melhoria da qualidade:

- O planejamento compreende as fases de "Gestão do programa de GCN" e "Incluir a GCN na cultura da organização". O resultado deve apresentar: o escopo do programa, as políticas adotadas pela empresa, a provisão de recursos, a identificação das habilidades das equipes envolvidas, a conscientização e treinamento..

- O fazer compreende as fases de "Entender a organização", "Estratégias de continuidade de negócios" e "Desenvolver e implementar uma resposta de GCN". O resultado apresenta documentos que comprovem o desenvolvimento do BIA, do RA, o período máxima de interrupção suportável pelos cursos, o custo de implementação da estratégia, as conseqüências de não agir, os recursos envolvidos e os planos de resposta a incidentes.

- O controlar compreende a fase de "testar, manter e analisar criticamente os preparativos do GCN". Utiliza como ferramenta a auditoria e, entrega na saída, as recomendações para revisão do plano.

- O agir compreende a manutenção e melhoria do SGCN. Manter e melhorar a eficiência e eficácia do plano através de medidas corretivas e preventivas quando determinado pela análise crítica das auditorias e gerência.

A Figura 7, abaixo, representa o processo de qualidade do Sistema de Gestão de Continuidade dos Negócios (SGCN) como ferramenta para o 
processo de alinhamento estratégico da empresa utilizando o código de boas práticas para gestão - ITIL®:

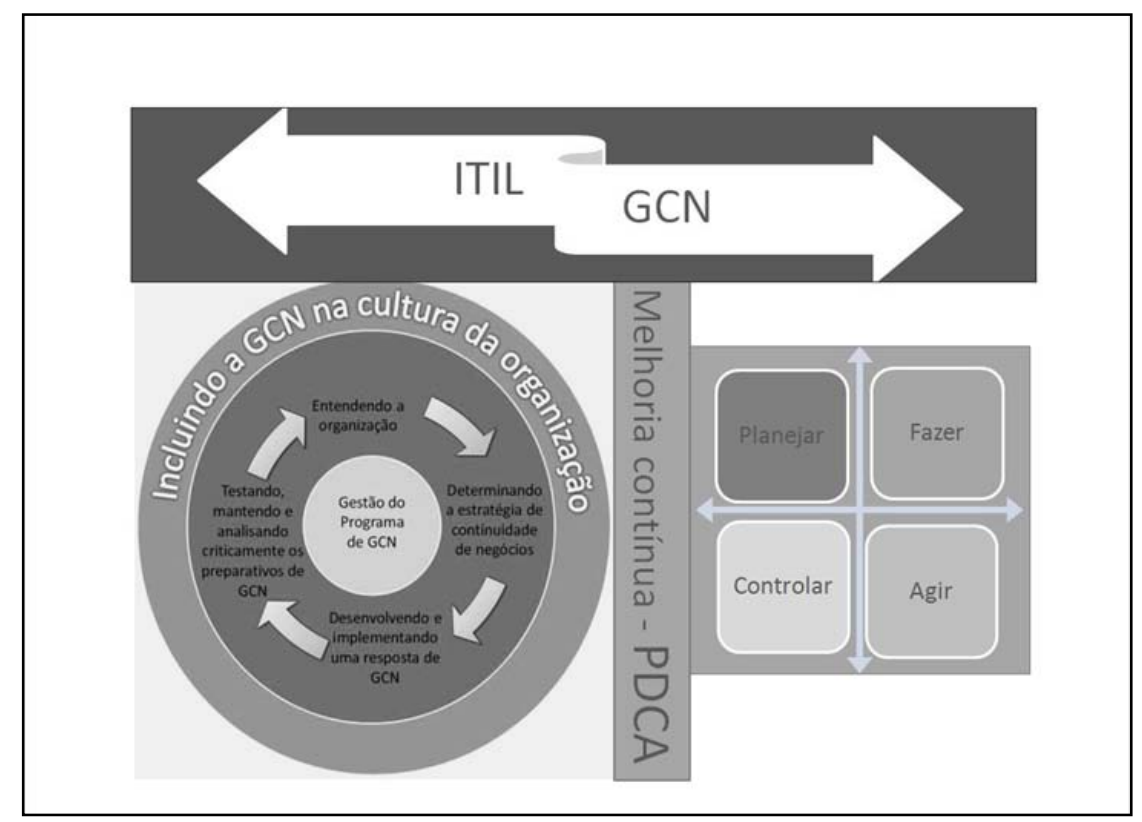

Figura 7: Entradas, ferramentas e técnicas utilizadas pela GCN. Fonte: Adaptado da NBR 15999-2 (2008).

Conforme apresenta a Figura 7, os sistemas utilizam elementos importantes para a sua execução: infra-estrutura, equipe técnica, corpo docente e corpo discente. Integrados, eles equilibram demandas como: gestão da melhoria contínua, processos eficientes na área de $\mathrm{TI}$, gestão da continuidade de negócio, gestão de risco, etc..

O desequilíbrio pode acontecer quando um desses elementos fica isolado por não conseguir interagir com o sistema. Qualquer que seja o motivo da quebra, a interrupção provoca vulnerabilidade, e potencializa a ameaça.

\subsection{Incluir a cultura de GCN na organização}

O sucesso e continuidade dos negócios precisa ser parte da gestão corporativa, independente da natureza de operação da organização. O ideal para a GCN é introduzir a cultura como um valor básico de gerencia. Desenvolver, promover e incorporar a cultura de GCN na empresa para garantir uma resposta positiva diante de uma crise em termos de: 
- Desenvolver um programa consistente e em constante evolução com o tempo e tecnologia (recursos, metas, objetivos da empresa, etc.);

- Passar confiança as partes interessadas, clientes, empregados, investidores, mídia, etc.;

- Aumentar a resiliência da organização em todos os níveis operacionais e de decisão;

- Minimizar a probabilidade de impacto e exploração de vulnerabilidade pela ação contínua de boas práticas dos empregados e gestores;

- Manutenção das responsabilidades definidas no plano de continuidade de negócios;

- Desenvolvimento de habilidades e planos de testes.

A conscientização da organização é feita por meio de educação permanente em GCN e divulgação de informações e resultados, como por exemplo:

- Informações através de boletins de segurança e programas de continuidade de negócio;

- Informações de incidentes internos e externos e tratamento do PCN com resultados;

- Informações através de reuniões ordinárias que tratam do PCN e sua evolução;

- Comunicação com a mídia para apresentar respostas e planos de continuidade;

- Aplicação de GCN aos fornecedores e outras partes envolvidas no processo de produção, financeiro, logístico, etc.;

- Treinamento contínuo das práticas e habilidades adquiridas durante a construção e aprovação do PCN. 


\subsection{Governança em Tecnologia da Informação}

A área de Tecnologia da Informação (TI) é influenciada por todo contexto administrativo e estratégico de uma organização, pela direção e necessidades do negócio, pelas expectativas dos usuários e clientes. Assim, é necessária a adoção de medidas que maximize a eficiência e efetividade do valor do serviço entregue pela área de TI, buscando o real aumento da sua produtividade.

Segundo os autores Magalhães e Pinheiro (2007) uma grande dificuldade desse setor é equilibrar o tempo de desenvolvimento dos produtos e serviços com as necessidades do mercado. Para superar essas dificuldades algumas áreas de $\mathrm{TI}$ reduzem o tempo de desenvolvimento de produtos e serviços entregando-os com baixa qualidade, sem construí-los a partir de uma arquitetura de processo e de componentes adequada à evolução da empresa e do mercado.

Nestes casos, o modelo de gestão adotado não possui um planejamento estratégico bem definido e traduzido corretamente pelos gestores em processos empresariais para serem executados pela área operacional, produzindo bens e serviços com qualidade e atendendo as necessidades dos clientes, contribuindo para a geração de lucros para os proprietários e para a melhoria da imagem da empresa no mercado.

Portanto, primeiramente, para atingir um modelo de gestão ótimo é preciso ter um planejamento estratégico bem definido e processos operacionais alinhados ao plano estratégico.

As boas práticas de gestão incluem esforços empresariais no sentido de minimizar o problema de conflito de interesses entre o planejamento e o operacional, buscando definir papéis e responsabilidades para todos os atores do ambiente empresarial: proprietários, gestores, área operacional, clientes e mercado.

A governança corporativa, originada no mercado financeiro mundial com o propósito de priorizar a transparência da gestão, diminuir os riscos e aumentar a rentabilidade do negócio de investimento, buscou definir estas 
boas práticas criando mecanismos eficientes de gestão, monitoramente e controle para garantir que decisões dos executivos e os processos empresariais estivessem alinhados com os interesses dos proprietários e/ou acionistas, Freitas (2010).

A governança corporativa proporciona à empresa a gestão estratégica, efetiva monitoração da direção executiva e transparência na prestação de contas entre proprietários, gestores, auditores independentes, governo e qualquer outro organismo envolvido direta ou indiretamente no negócio.

A governança corporativa dispõe dos recursos da tecnologia da informação (TI) para extrair e disponibilizar a informação necessária à transparência dos processos e dos resultados.

Neste contexto deve preocupar-se também com o detalhamento dos procedimentos utilizados, comprovando o grau alcançado de integridade dos processos e componentes de TI envolvidos na geração, no armazenamento e na divulgação das informações, Freitas (2010).

Sob esses aspectos estão: a continuidade dos serviços de desenvolvimento e manutenção dos sistemas, a aquisição e manutenção de ativos de $\mathrm{TI}$, as redes de comunicação e a segurança da informação.

A área de TI não deve ser tratada como uma área separada dentro da empresa. Tl é uma área de apoio aos objetivos do negócio e possui a missão de prestar serviços de TI com a qualidade requerida para atender as expectativas do negócio; a visão estratégica da área de TI é mudar e inovar auxiliando no plano estratégico da empresa, Gaspar; Gomez e Miranda (2010).

Técnicas de gerenciamento dos serviços de TI proporcionam recomendações e práticas para atender aos requisitos da governança corporativa, e o mercado mundial cunhou o termo Governança de TI para nomear as práticas de gestão de TI realizadas para garantir o alinhamento da área de tecnologia da informação às iniciativas da governança corporativa da empresa.

Segundo o autor Freitas (2010) a governança de TI possui dois aspectos fundamentais: 
- Propiciar insumos para a governança corporativa da empresa; e

- Melhorar os processos de gestão de TI da empresa.

No primeiro caso surge como componente fundamental para obtenção da governança corporativa. No segundo caso, surge como instrumento de aprimoramento e obtenção da qualidade nos serviços e nos produtos de TI.

Tanto na primeira quanto na segunda linha de ação o aumento do grau de confiança nos recursos tecnológicos tem como objetivo 'integrar as atividades da área de TI com os objetivos estratégicos das empresas'.

Boas práticas e recomendações são utilizadas atualmente no mercado para alcançar a governança de TI como, por exemplo: ISO (International Organization for Standardization) que agrega as principais normas e controles de qualidade e estabelece requisitos para certificação das empresas em seus processos operacionais; PMBOK, baseado em processos, definindo entradas e saídas através de produtos ou entregas; COBIT (Control Objectives for Information and Related Technology) modelo de referência para gestão de Tl; e o ITIL ${ }^{\circledR}$ (Information Technology Infrastructure Library) que possui a finalidade de atender à demanda por melhores práticas na área de gerenciamento de serviços de TI. .

Neste trabalho, o ITIL $®$ reúne os processos mais pertinentes ao desenvolvimento da GCN.

\subsubsection{O ITIL $® \mathrm{~V}_{3}$ (Information Technology Infrastructure Library)}

O ITIL $® V_{3}{ }^{3}$ foi desenvolvido pela Central Computer and Telecommunication Agency, agora Office of Government Commerce, com a finalidade de atender à demanda por melhores práticas na área de gerenciamento de serviços de $\mathrm{TI}$.

Os resultados esperados pela aplicação do ITIL $®$ são:

\footnotetext{
${ }^{3}$ É uma marca registrada do Office of Government Commerce (OGC) no Reino Unido e em outros países. Acessado pelo site oficial em 23-03-2011 através da URL $=$ www.ITIL ${ }^{\circledR}$-oficialsite.com
} 
- Capacitação para entrega de serviço que suportem a expansão do negócio;

- Efetividade de custos pela melhoria do desempenho e na utilização dos recursos de $\mathrm{TI}$ reduzindo o $\mathrm{TCO}^{4}$ (Total Cost of Ownership) ou custo total de propriedade;

- Disponibilidade para atingir os requerimentos dos clientes dentro dos níveis de serviço e de continuidade de negócio;

- Aumento da eficiência e efetividade de TI com medidas dos resultados;

- Alinhamento da estratégia da TI com as áreas de negócio da empresa.

O ITIL $®$ é um conjunto de melhores práticas que vem ao encontro de novo estilo de trabalho imposto a área de TI, baseado em valores em detrimento unicamente ao lucro, e habilitando o incremento da maturidade do processo de gerenciamento de $\mathrm{TI}$.

O desafio da área de $\mathrm{TI}$ de coordenar e trabalhar em parceria com as demais áreas de negócio da empresa garante o almejado alinhamento estratégico visando então a geração de valor do serviço. O quadro 9 apresenta o cenário anterior versus o panorama atual das empresas:

\begin{tabular}{|l|l|}
\hline CENÁRIO ANTERIOR & PANORAMA ATUAL \\
\hline Atendimento ao usuário & Atendimento ao cliente \\
\hline Perspectiva interna & Perspectiva externa \\
\hline Esforço pessoal & Esforço repetitivo e medido \\
\hline Foco na tecnologia & Foco no processo \\
\hline Processos ad-hoc & Processos racionalizados \\
\hline Recursos internos & Recursos internos e externos \\
\hline Comportamento reativo & Comportamento proativo \\
\hline Visão fragmentada & Visão integrada \\
\hline Sistema manual & Sistema automatizado \\
\hline Gestor de operações & Gestor de serviços \\
\hline
\end{tabular}

Quadro 9: Cenário anterior versus Panorama atual. Fonte: Magalhães e Pinheiro (2007).

O ITIL $®$ busca a melhoria contínua e o incremento da "maturidade" do processo de Gerenciamento de Serviço de TI, propiciando um caminho com

\footnotetext{
${ }^{4}$ TCO é uma metodologia desenvolvida pelo Gartner Group, Inc., é definido como todo custo associado com a aquisição, manutenção e uso de um ativo de TI durante toda a vida útil prevista para ele.
} 
procedimentos detalhados focado no atendimento ao cliente e agregação de valores aos serviços, Freitas (2010).

A realização de uma mudança na área de TI para atingir a "maturidade" inclui adotar o Gerenciamento de Serviços de TI para:

- Receber o reconhecimento da organização como uma área que cria valor, ser um agente facilitador do negócio;

- Examinar todas as opções e seus impactos sobre a organização;

- Utilizar um planejamento personalizado que atenda as necessidades da empresa;

- Estabelecer um sistema de medição do desempenho que permita controlar os custos com o Gerenciamento de Serviços de TI.

Para ajudar na compreensão do ciclo de vida do ITIL®, os principais conceitos amadurecidos na Versão 3 do ITIL $®$ serão detalhados a seguir:

- Função: pessoas, grupo, equipe, ferramentas utilizadas para conduzir processo/atividade;

- Processo: conjunto estruturado de atividades, elaborado para alcançar um objetivo. Utiliza um ou mais entradas e as transforma em saídas definidas. Para isso, pode incluir qualquer papel ou responsabilidade na equipe, ferramentas e controle gerencial para entregar o resultado esperado de maneira confiável. Pode definir políticas, normas, recomendações, atividades e instruções de trabalho. Um processo deve possuir os seguintes elementos:

- Identificação dos responsáveis pela execução das atividades do processo; indicadores de desempenho para medir o processo como: nível de qualidade das atividades, quantidade, desempenho, custo, etc.; e

- Um fluxo de informação que conduz a cadeia de atividades utilizada pelo processo.

- Serviço: um meio de fornecer algo que um cliente perceba como certo (valor), facilitando a obtenção de resultados que os clientes desejam do 
negócio, sem que eles arquem com custos e riscos. Para fornecer esse diferencial estratégico a área de TI deve envolver o capital intelectual (pessoas), tecnológico (tecnologias), industrial ou outros necessários (processos), que torna a empresa diferente de seus concorrentes.

Segundo o ITIL $®$, o valor de um serviço pode ser medido a partir de quatro parâmetros:

- Alinhamento estratégico com o negócio da empresa - grau em que o serviço de TI está alinhado com as atuais e futuras necessidades do negócio;

- Custo - valor monetário desembolsado para disponibilização do serviço de TI em cada interação;

- Qualidade - nível de atendimento do serviço de TI em relação aos Acordos de Nível de Serviços (ANS) e Acordos de Nível Operacional (ANO), estabelecidos externa e internamente à área de $\mathrm{TI}$, respectivamente; e

- Independência em relação ao tempo - capacidade da área de TI em reagir às demandas de suporte e em atender às mudanças planejadas em relação aos serviços de TI disponibilizados.

A necessidade de assegurar aos clientes um nível de serviço adequado está associada à expressão Quality of Service QoS ${ }^{5}$ cuja definição é: "Efeito coletivo do comportamento do serviço, o qual determina o grau de satisfação do usuário". Neste caso a qualidade de serviço se traduz como uma combinação de comportamento (desempenho) que resultam na satisfação dos clientes e usuários.

Para medir o nível de satisfação do cliente com a qualidade do serviço é necessário avaliar cinco fatores segundo o autor Freitas (2010):

- Serviço esperado - aquele que o cliente espera receber em troca do valor pago;

\footnotetext{
${ }^{5}$ Instituída pelo ITU-T ( International Telecommunication Union). Acessado em 29/03/2011 através da URL: http://www.itu.int/itu-t
} 
- Serviço adequado - aquele que atende às necessidades do cliente;

- Serviço desejado - aquele que o cliente deseja receber a mais do que ele expressou necessitar;

- Serviço previsto - aquele que o cliente recebe em termos de serviço, ou seja, o acordado com o fornecedor;

- Serviço percebido - aquele que o cliente percebe o serviço prestado, considerando suas expectativas em relação ao que entende ser serviço adequado e serviço desejado.

A Versão 1 do ITIL $\circledast$ foi lançada na década de 80 contendo 31 livros que abordavam aspectos fundamentais ; para a ; provisão dos serviços de TI e foi utilizado principalmente no Reino Unido, seu local de origem. Sua abrangência alcançava o planejamento de contingência de sistemas de TI.

A Versão 2 do ITIL $®$ contou com uma revisão da versão inicial e foi publicada no ano 2000. Consistia em 7 livros que cobriam os aspectos relativos aos processos de gerenciamento de serviços de TI com uma forte orientação em processos e melhoria contínua (ciclo do PDCA).

A Versão 3 do ITIL® é composta de 5 livros onde a visão de processos da Versão 2 foi organizada em ciclos de vida contendo 5 fases, conforme Figura 8:

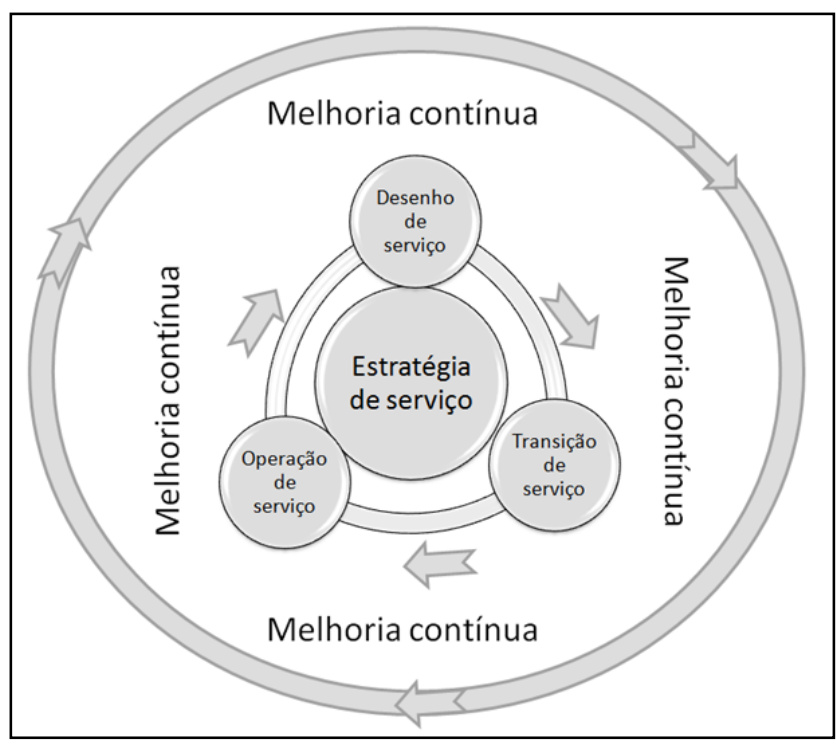

Figura 8: Ciclo de Vida do ITIL® V3. Fonte: ITIL® V3. 
Estratégia de serviço apresenta a concepção das idéias, com integração entre a área de $\mathrm{TI}$ e a área de negócios da organização. É responsável pela gestão dos ativos da organização, catalogando os recursos, as habilidades e os provedores necessários ao atendimento dos clientes.

Desenho de serviço cria um padrão de documentação e descrição dos requisitos de negócio, incluindo suas arquiteturas tecnológicas de construção, seus processos de apoio, suas políticas de segurança, de acesso, de disponibilidade e de confiabilidade.

Transição do serviço prepara o serviço e coloca-os em operação de forma que cause o menor impacto possível controlando os riscos de falha e interrupções.

Operação de serviço controla das atividades realizadas no dia a dia, quando o serviço já está em produção. É a parte mais perceptível ao cliente.

Melhoria Contínua analisa e monitora as atividades realizadas durante o ciclo de vida por meio do PDCA.

As fases do ciclo de vida do ITIL $®$ V3 possuem processos definidos, representados na Figura 9:

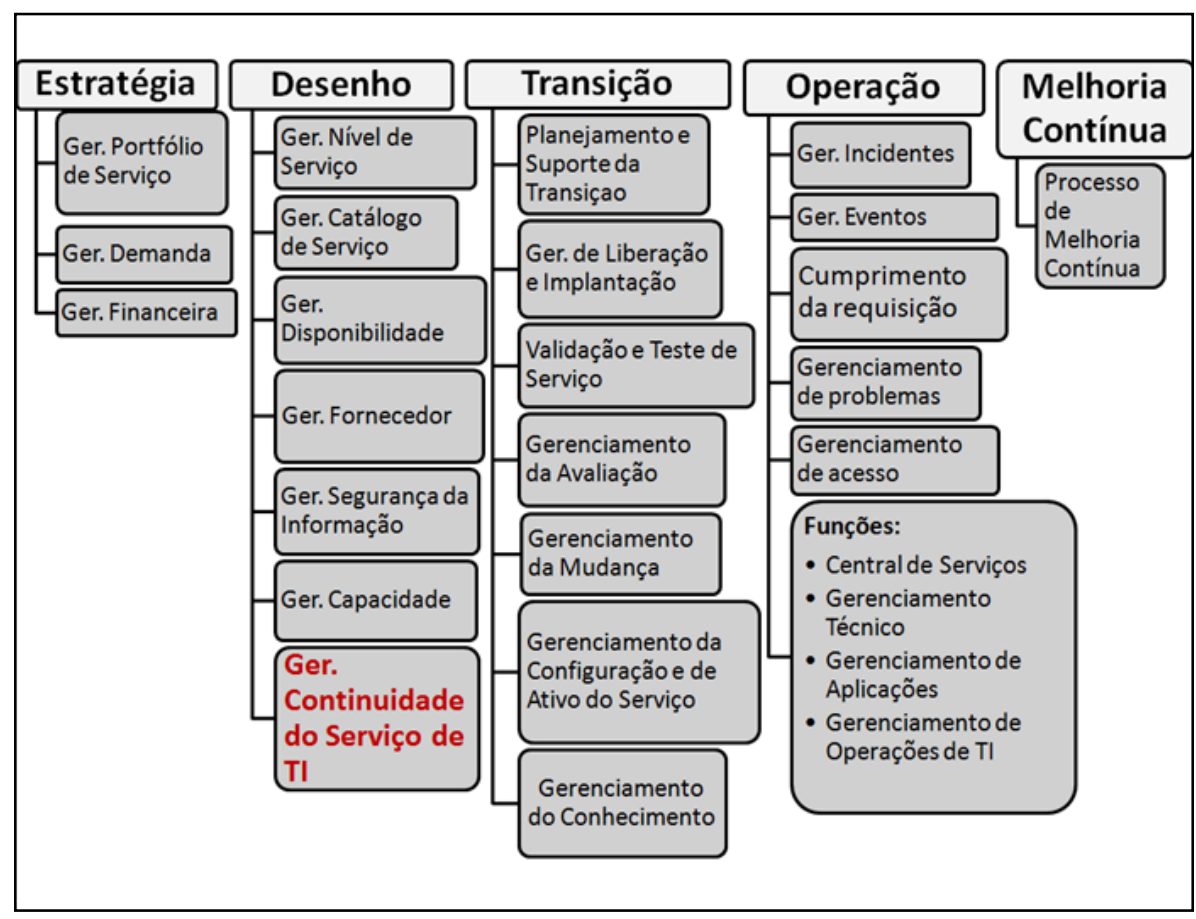

Figura 9: Ciclos e processos do ITIL $®$ V3. 
Os processos do ITIL ${ }^{\circledR}$ V3 são descritos a seguir, obedecendo as fases do ciclo de vida:

\section{Estratégia de Serviço:}

- Processo Gerenciamento Financeiro: seu objetivo é controlar os recursos da $\mathrm{TI}$ e garantir os recursos financeiros necessários para a entrega de serviços de acordo com os requisitos de valor estabelecidos pelo cliente.

- Processo Gerenciamento de Portfólio de Serviço: seu objetivo é gerenciar, a entrada dos serviços em produção (inclusão no catálogo de serviços) e quando estes serviços devem ser retirados. Esse processo analisa o valor do serviço e prioriza as ofertas de acordo com os ativos da área de TI disponíveis.

- Processo Gerenciamento da Demanda tem o objetivo de entender e influenciar a demanda dos clientes para os serviços e a provisão de capacidade para atender a essa demanda. Esse processo será responsável por analisar a necessidade de recursos de TI para acompanhar o negócio.

\section{Desenho de Serviço:}

- Gerenciamento do Nível de Serviço: o objetivo é negociar e documentar as metas de utilidade e garantia dos serviços de $\mathrm{TI}$ com os respectivos clientes, monitorando a entrega dos serviços de acordo com os ANS, Gaiarsa, (2007);

- Gerenciamento do Catálogo de Serviços: demonstra todos os serviços que a área de TI oferece efetivamente aos seus clientes ou que serão desenhados e planejados para entrar em produção durante o ciclo de vida Transição. O catálogo poderá ser fornecido sob duas linguagens, uma focada no cliente: catálogo de serviços do negócio, e outra em linguagem mais técnica para a área de TI: catálogo técnico de serviços.

- Gerenciamento da Capacidade: segundo o autor Gaiarsa (2007) este processo tem como objetivo garantir uma capacidade adequada de recursos e de infra-estrutura para a entrega do serviço a um custo 
justificado, e que esta capacidade esteja alinhada com as necessidades atuais e futuras da empresa.

- Gerenciamento da Disponibilidade: mantém os serviços disponíveis o maior tempo possível, evitando transtornos aos usuários e aos clientes de acordo com a classificação abaixo:

- Alta disponibilidade: característica de um serviço ou componente de TI que minimiza ou mascara os efeitos de uma falha para seus usuários.

- Tolerância a falhas; habilidade de um serviço ou componente de $\mathrm{TI}$ em continuar a operar mesmo depois de uma falha.

- Operação contínua: abordagem de identificar e eliminar falhas em um ambiente de $\mathrm{Tl}$; mesmo que alguns componentes falhem, o serviço continua disponível.

- Disponibilidade contínua: característica de planejar um serviço de forma a torná-lo disponível $100 \%$ do tempo acordado.

As principais técnicas de análise de falha e risco do Gerenciamento da Disponibilidade podem ser utilizadas para aplicação de padrões de qualidade como a GCN, e são, segundo os autores Gaspar; Gomez e Miranda (2010):

- Análise de Falha de Serviço (AFS);

- Análise de Impacto em Falhas de Componentes ou CFIA - Component Failure Impact Analysis;

- Análise de Ponto Único de Falha ou SPOF - Single Point of Failure Analysis; 
- Análise da Árvore de Falhas ou FTA - Fault Tree Analysis; e

- Análise e gestão do risco.

- Gerenciamento de Fornecedor: controla os serviços pelos fornecedores que devem estar alinhados ao negócio, ou seja, de acordo com os níveis de serviço (ANS), avalia novos fornecedores, realiza novos contratos, entre outras tarefas. Estes fornecedores podem ser classificados como:

- Fornecedor interno: a empresa possui recursos para a entrega de serviços aos clientes e realiza o desenho, a transição, a operação a análise de melhoria contínua internamente.

- Terceiros: a empresa transfere o fornecimento dos serviços de TI para um provedor de Serviço Externo. Pode ser através de um modelo de terceirização completo (full outsourcing) ou pode mesclar atividades de desenho, operação, entre outras.

- Parceiros: relacionamento entre duas organizações o qual envolve o trabalho em conjunto para alcançar os objetivos comuns e partilhar os benefícios mútuos, as oportunidades de mercado, os riscos associados aos serviços, etc.

- Terceiros de processos de negócio: conhecido no mercado como BPO (Business Process Outsourcing), envolve a entrega de uma cadeia de processos, como por exemplo: seleção, contratação e pagamento da folha de funcionários; Call Center, Telemarketing;

- Terceiros de processos de conhecimento: conhecido no mercado como KPO (Knowledge Process Outsourcing). Neste caso, o conhecimento e informações relacionadas aos processos e atividades 
(ativos de serviços) são geradas e realizadas por fornecedores visando a redução de custo.

- Provedor de serviço aplicativo: serviços de TI de software acessado e executado dentro de um provedor de serviço externo através de rede ou internet pública. Exemplos desta modalidade seriam: sites de serviços de correio eletrônico hospedados em datacenters; Software as a Service (SaaS) acesso a sistemas sob demanda.

- Gerenciamento da Continuidade do Serviço de TI: especificado para atuar na área de Tecnologia da Informação. Possui todas as etapas do ciclo de vida da GCN.

- Gerenciamento de Segurança da Informação: o objetivo é planejar e implementar políticas de segurança da informação que definirão regras a ser seguidas para evitar qualquer tipo de furto, invasão, vírus, ataques ou acesso indevido aos serviços oferecidos.

\section{Transição do Serviço}

- O Gerenciamento de Mudanças: garante os processos de mudança minimizando os impactos no negócio causados por mudanças nos Serviços de TI sem o devido planejamento.

- Gerenciamento da Configuração de Ativo de Serviço tem o objetivo de definir e controlar os serviços e componentes de $\mathrm{TI}$ e manter informações de configuração precisas e confiáveis.

- Gerenciamento da Liberação e Implantação: esse processo está estruturado na seguinte forma:

[...] na construção, teste e no fornecimento dos serviços especificados no desenho de serviço que atendam aos objetivos e aos requisitos das partes envolvidas e cujos principais itens são: registro de liberação, unidade de liberação, gerenciamento da liberação e liberação em si (identificação) [...] o procedimento mais importante dessa fase é a realização de testes através do modelo ' $\mathrm{V}$ ', utilizado por mapear os diferentes níveis de configuração que precisam ser construídos e testados [...]. 
A Figura 10 apresenta o modelo 'V' para teste e validação do serviço de TI:

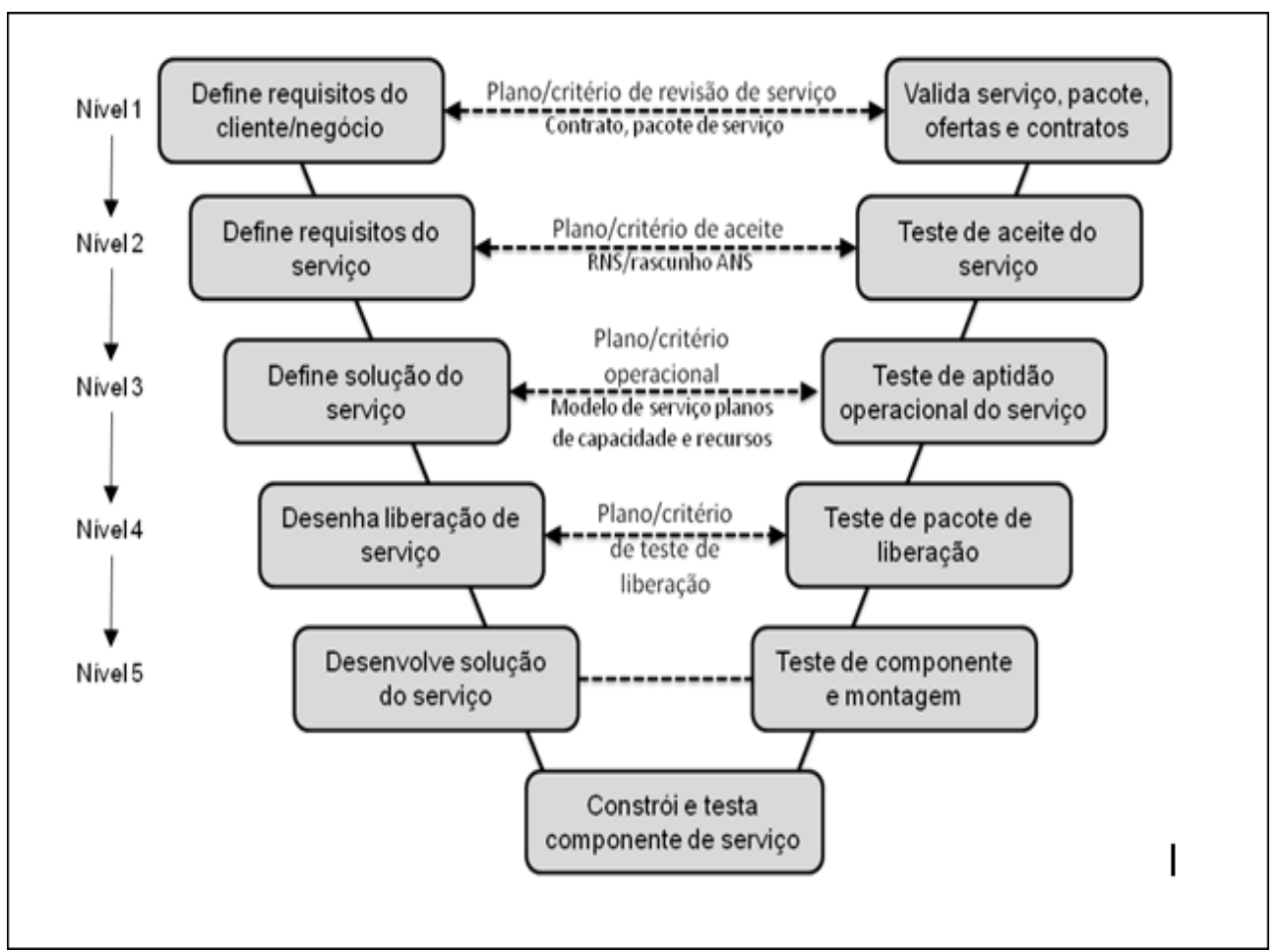

Figura 10: Modelo 'V' para validação e teste de serviço. Fonte: Arnold et al(1998) apud Holwell (2009).

- Gerenciamento da Avaliação: oferece elementos para validar a mudança de serviço, como por exemplo, o desempenho e o risco. Este processo verifica se o desempenho é aceitável, se o preço está correto, se está dentro da qualidade, se está sendo ou não usado, entre outros itens de conformidade com o Desenho do Serviço. Os elementos mais relevantes para validar uma mudança são:

- Gerenciamento do Conhecimento: o objetivo é assegurar que a informação certa seja entregue até o local adequado ou pessoa competente, no momento certro para permitir que a decisão certa seja realizada, Magalhães e Pinheiro, (2007), isto é, permitir que a informação confiável e segura esteja disponível através do Ciclo de Vida do Serviço. Esse gerenciamento é visualizado através da estrutura DIKW (Data, Information, Knowledge, Wisdom). Cada um desses 
elementos da estrutura DIKW, segundo os autores Gaspar; Gomez e Miranda (2010) significa:

- Data: dados - um conjunto de fatos sobre eventos;

- Information: Informação - o fornecimento do contexto para os dados. a informação é armazenada em conteúdos semi-estruturados, como documentos, email e multimídia, (quem, o quê, quando, onde?);

- Knowledge: Conhecimento - o composto de experiências subentendidas, idéias, valores e julgamentos dos indivíduos, (como?)

- Wisdom: Sabedoria - a intuição do material e da aplicação e a conscientização conceitual para fornecer um forte julgamento, (por que?)

A pessoa responsável pela disseminação do conhecimento durante o Ciclo de Vida do Serviço chama-se CKO (Chief Knowledge Officer).

\section{Operação do Serviço}

- Gerenciamento de Incidentes: tem como objetivo resolver incidentes da maneira mais rápida possível, diminuindo assim o impacto nos negócios e o tempo de parada para os usuários. A sua função é reparar a falha, erro ou defeito do componente ou serviço, Gaiarsa (2007).

- Gerenciamento de Eventos: possui o objetivo de monitorar todos os eventos que incidem no dia a dia da infra-estrutura de TI para garantir sua excelência e detectar e escalar as condições de exceção.

- Gerenciamento de Acesso: esse processo está intimamente relacionado com o Gerenciamento da Disponibilidade e o Gerenciamento da Segurança da Informação, pois vai executar suas tarefas de acordo com as políticas de segurança estabelecidas nestes dois processos relacionados. O Gerenciamento de Acesso faz o controle de uso dos serviços estendendo a permissão de acesso a quem precisa usar o serviço. 
- Gerenciamento de Problemas: esse processo busca as raízes dos incidentes, propondo soluções de contorno e identificando a causa de forma que o problema seja resolvido definitivamente, isto é, a restauração dos serviços para os clientes, Gaiarsa (2007),

\section{Melhoria Contínua}

Possui um único processo de Melhoria Contínua do Serviço e busca melhorar sempre os serviços disponíveis aos clientes. Neste processo os sete passos para Melhoria Contínua, segundo o autor Freitas (2010) são:

- Definir o que será medido;

- Definir o que pode ser medido;

- Coletar os dados;

- Processar os dados;

- Analisar os dados;

- Apresentar e utilizar a informação; e

- Implementar as ações corretivas.

\subsection{Dependabilidade}

Sistemas computacionais são caracterizados, segundo os autores Avizienis, Laprie e Randell (2001), por quatro elementos fundamentais: funcionalidade, desempenho, custo e dependabilidade.

Dependabilidade é a capacidade de um sistema entregar serviços que podem ser considerados, justificadamente, confiáveis, envolvendo elementos automatizados de informação como hardware, software, redes de computadores, etc..

Segundo o autor Laprie (1995), o conceito de Dependabilidade evoluiu desde 1830 com a construção da máquina de cálculo de Babbage e a utilização de código de controle de erros até a integração com outras técnicas e elementos, apresentados abaixo, e que, ao longo do tempo revolucionaram o termo Dependabilidade. São eles: 
- Técnicas de diagnóstico de falhas em componentes;

- Tolerância a falha com a redundância de componentes mascarando falhas de componentes menos confiáveis;

- Sistemas tolerantes a falha por detecção de erros, diagnóstico de falha e recuperação de sistemas;

- Software tolerante a falha (programação realizada através de escopo definido e construção de software com n-versões);

- Ameaça à segurança de sistemas através de sistemas tolerantes a falha e defesa contra falhas intencionais; e

- Computação confiável através da integração da Dependabilidade com segurança da informação (confidencialidade, integridade e disponibilidade).

Assim, a Dependabilidade consiste em três partes fundamentais: atributos, classificação e ameaças.

Os atributos representam as diferentes, mas complementares faces da Dependabilidade. A prontidão para o uso leva à disponibilidade; a continuidade do serviço leva à confiabilidade; a não-ocorrência de conseqüências sérias para o ambiente e para o usuário leva à segurança; a não-ocorrência de divulgação não autorizada de informação leva à confidencialidade; a não-ocorrência de alterações indevidas de informação leva à integridade; e a capacidade de sofrer reparos e evoluções leva à manutenibilidade.

A disponibilidade (Availability) é a "habilidade de um serviço ou um componente de $\mathrm{TI}$ para desempenhar a sua função acordada quando necessário", Freitas (2010). O cálculo da disponibilidade é uma taxa percentual de disponibilidade em relação ao tempo total de disponibilidade de um período e o tempo total de indisponibilidade no mesmo período de acordo com a fórmula apresentada na Figura 11: 
Disponibilidade $(\%)=\frac{[\text { Tempo Total de Disponibilidade }- \text { Tempo Total de Indisponibilidade] } \times 100}{\text { Tempo Total de Disponibilidade }}$

Figura 11: Fórmula do Cálculo da Disponibilidade.

Supondo, por exemplo, que um serviço opere 160 horas durante um determinado período do mês. Esse mesmo serviço ficou indisponível 40 horas nesse mês. A taxa de disponibilidade no mês, aplicando a fórmula é:

- Tempo Total de Disponibilidade $=160$ horas

- Tempo Total de Indisponibilidade $=40$ horas

- $\quad$ Disponibilidade $=75 \%$ de disponibilidade no mês.

A confiabilidade (Reliability) é uma medida que demonstra a capacidade de trabalhar sem interrupções, de acordo com o ANS (onde se define a meta de confiabilidade do serviço). É calculada através do Mean Time Between Failures (MTBF) ou Tempo Médio entre Falhas, ou seja, quanto tempo levou entre uma falha e a próxima, bem como por meio do Mean Time Between Service Incidents (MTBSI) ou Tempo Médio entre Incidentes. Os cálculos do MTBF e do MTBSI são respectivamente realizados através das fórmulas apresentadas nas Figuras 12 e 13:

$\operatorname{MTBF}($ em horas $)=\frac{\left\{\left[\begin{array}{c}\text { Tempo em que o serviço deve ficar } \\ \text { disponível em horas }\end{array}\right]-\left[\begin{array}{c}\text { Tempo total em que o serviço ficou } \\ \text { indisponível em horas }\end{array}\right]\right\}}{\text { Número de interrupções }}$

Figura 12: Fórmula do cálculo para do Tempo Médio entre Falhas.

Supondo novamente que um serviço deva operar, segundo o ANS, em 24 (vinte e quatro) horas por 7 (sete) dias, totalizando, por mês, 720 (setecentos e vinte) horas. Entretanto, durante o mês, este serviço apresentou problemas e ficou indisponível 5 (cinco) vezes durante 4 (quatro) horas em cada parada. O MTBF seria calculado, segundo a fórmula da Figura 12:

- $\operatorname{MTBF}=\{[720]-[(5 \times 4)]\} / 5=140$ horas. 
Utilizando o mesmo exemplo, o cálculo do MTBSI, em horas, segundo a Figura 13 seria:

$$
\text { MTBSI (em horas) }=\frac{\left(\begin{array}{c}
\text { Tempo em que o serviço deve ficar } \\
\text { disponível em horas }
\end{array}\right)}{\text { Número de interrupções }}
$$

Figura 13: Fórmula para o cálculo do Tempo Médio entre Incidentes.

- $\mathrm{MTBSI}=(720) / 5=144$ horas.

A manutenibilidade (Maintainability) em TI é a capacidade de resiliência, ou seja, quanto tempo leva para um serviço ou componente de TI ser restaurado ao seu estado original, caso haja uma indisponibilidade. $O$ indicador de manutenibilidade ou da resiliência é o Mean Time to Restore Service (MTRS) ou Tempo Médio para Restaurar o Serviço, que é calculado através da fórmula apresentada na Figura 14:

$$
\text { MTRS (em horas) }=\frac{\left(\begin{array}{c}
\text { Tempo Total em que o serviço ficou } \\
\text { indisponível em horas }
\end{array}\right)}{\text { Número de interrupções }}
$$

Figura 14: Fórmula para o cálculo do Tempo Médio para Restaurar o Serviço.

Utilizando o exemplo anterior, a resiliência ou manutenibilidade (MTRS) seria:

- $\mathrm{MTRS}=(5 \times 4) / 5=4$ horas.

Existe outra métrica para calcular a manutenibilidade, denominada de Tempo Médio para Reparo (TMPR). Segundo o autor Freitas (2010) a diferença entre o TMPR e o TMRS é a visão de confiabilidade. Para a área de TI quando se resolve uma falha no serviço fala-se de "serviço reparado", porém, por algum motivo técnico ele poderá ainda se encontrar indisponível ao usuário, ou seja, o serviço ainda não foi "restaurado". Por exemplo, no caso de uma fórmula automática para calcular um desconto fixo de tabela em aplicativos de gestão de compra/venda, para alterar o valor percentual 
do desconto no código, o desenvolvedor poderá levar apenas 5 minutos. Entretanto, para fazer um teste simples e a seguir um deploy do código fonte para o ambiente de produção do aplicativo, o desenvolvedor levará mais 30 minutos. Neste caso, o tempo de reparo foi de 5 minutos, mas o tempo para restaurar o serviço no caixa da empresa foi no total 35 minutos

$\mathrm{Na}$ classificação o desenvolvimento de um sistema confiável demanda a utilização de combinada de um conjunto de técnicas e métodos classificados como:

- Prevenção de falhas: como prevenir falhas

- Tolerância a falhas: como assegurar que um serviço irá cumprir a função do sistema na presença de falhas;

- Remoção da falha: como reduzir a presença de falhas; e

- Previsão da falha: como estimar o número atual de falhas, a incidência e conseqüências futuras das falhas.

Estes métodos podem ser relacionados com os meios de entrega de serviços mantidos pelo Gerenciamento da Disponibilidade do ITIL®.

As ameaças, segundo a Dependabilidade são o erro, a falha e o defeito.

- Um erro é a manifestação do defeito, comprometimento das informações internas do sistema.

- Um defeito é a causa ou a hipótese provável da existência do erro. O serviço entregue por um sistema computacional é o comportamento perceptível pelo usuário desse sistema; o usuário é qualquer elemento (humano ou físico) que interage com esse sistema através de uma interface apropriada. Um serviço correto é aquele que implementa de forma adequada uma função do sistema e o entrega em igual estado; a função do sistema é o que o sistema se destina a fazer e está descrita em seus requisitos. A recuperação de um sistema é a transição entre a entrega de serviços incorretos para a entrega de serviços corretos; e a interrupção dos serviços é o intervalo de tempo no qual está sendo entregue um serviço incorreto. 
- Uma falha ocorre quando um erro atinge a interface do sistema e fica sensível ao usuário alterando a entrega correta do serviço O modo de falha de um sistema pode ser avaliado a partir de três pontos de vista:

- Domínio;

- Percepção em números dos usuários; e

- Conseqüências no ambiente.

A origem da falha está classificada em seis categorias:

- Fenômeno que a causou: falha humana ou falha física;

- Natureza da falha: acidental; intencional, mas não maliciosa; e ato malicioso;

- Ocorrência da falha: fase de concepção do sistema; fase de desenvolvimento do sistema; e fase de produção do sistema;

- Domínio da falha: física ou de informação;

- Limites da falha: interna ou externa ao sistema; e

- Persistência da falha: permanente ou temporária.

O primeiro passo para desenvolver sistemas confiáveis é estabelecer as necessidades do cliente e uma análise funcional para implementação do produto.

O segundo passo para atingir a Dependabilidade é estabelecer os requisitos da Dependabilidade (taxa de falha, entrega de serviços, condições de entrega, período de entrega, tempo médio entre falhas, tempo de vida útil dos componentes, tempo médio para reparo, etc.). Segundo o autor Laprie (1995) desde que esses requisitos estejam definidos o próximo passo é determinar e avaliar os riscos do sistema. Essa tarefa pode ser feita através de técnicas de análise de risco (Failure Mode and Effect Analysis (FEMEA) ou Análise do modo e efeito da falha, árvore de falha, etc.).

A última tarefa compreende a definição de meios para conter os riscos identificados sintetizando o conhecimento através do modelo de Dependabilidade do sistema. 


\section{SISTEMAS DE ENSINO}

Este capítulo foi elaborado para apresentar conceitos sobre tecnologias educacionais, como funcionam, onde são aplicadas, quais são suas características técnicas e componentes tecnológicos utilizados no ensino e na aprendizagem. Estes elementos são utilizados em conjunto no modelo denominado Ensino Presencial Mediado por Recursos Tecnológicos. O objetivo é compreender o ambiente tecnológico onde são desenvolvidas as atividades reconhecendo a essencialidade da sua disponibilidade, da segurança, da confiabilidade e da continuidade dos serviços.

O sistema de ensino consiste em uma gestão tecnológica que relaciona os elementos da ciência, da organização (governamental, institucional, escolar, etc.) e do ambiente social (como as comunidades, e as famílias). A tecnologia por sua vez pode ser definida por um conjunto de conhecimentos e princípios científicos que se aplicam ao planejamento, à construção, e à utilização de equipamentos, elementos lógicos, aplicativos, entre outros produtos para uma determinada finalidade ou tipo de atividade. A informação e o conhecimento são as bases de sustentação desses elementos que apresentam como resultados a aplicação e a entrega do conhecimento científico para melhoria da sociedade, Sage, (2000).

O dicionário do Aurélio (apud Kenski, 2007) define educação como um processo de desenvolvimento da capacidade física, intelectual e moral do ser humano em geral, visando à sua melhor integração individual e social.

Educar para a inovação e para a mudança é propor dinâmicas de aprendizagem, onde são desenvolvidas concepções sócio-históricas da educação, nos aspectos cognitivo, ético, político, científico, cultural, lúdico e estético; em toda a sua plenitude e, assim, através da integração, garantir a formação de pessoas para o exercício da cidadania e do trabalho com liberdade e criatividade, (João Pedro da Ponte, 2004 apud Kenski, 2007).

Para uma verdadeira integração, proposta no papel da escola, é preciso novos: conhecimento, valores, hábitos, atitudes e comportamentos que 
valorizem o ensinar e o aprender em grupo e que convivam em uma sociedade em permanente processo de transformação.

A evolução tecnológica não se restringe apenas ao uso de novos equipamentos e produtos, ela altera comportamentos e impõe-se à cultura existente. Cabe à escola um papel fundamental na utilização dos meios de comunicação, transformando-os em meios para elaborar e apresentar mensagens qualificadoras, isto é, pedagogicamente corretas, com conteúdo adequado a ser entregue ao seu público.

No entanto, mais importante que as tecnologias disponíveis nas escolas, é a capacidade de adequação do processo educacional aos objetivos do aprendizado. A escolha correta dos procedimentos pedagógicos mais modernos, dos equipamentos e produtos tecnológicos que levem motivação para aprender, permitindo a valorização dos alunos e a formação de pessoas conscientes da importância dos meios de comunicação, de como usá-los em benefício delas.

Para isso, o essencial é que todo o corpo escolar (professores, pais e alunos) se prepare para o uso de tecnologias e mídias, tratando-as não mais como adversárias e sim como parceiras no processo de aprendizagem, aprendendo a utilizá-las para interagir e participar socialmente e, desse modo, integrar-se em novas comunidades e criar novos significados para a educação num espaço muito mais amplo.

As tecnologias da informação e comunicação (TIC) utilizadas na educação garantem a produção e propagação de informações, interação e comunicação em tempo real, ou seja, no momento em que o fato acontece. Nessa categoria pode-se considerar desde os produtos mais simples como o rádio, a televisão, os computadores, e mais recentemente os celulares, as redes de computadores, a Internet, as redes sociais, a TV Digital, os Ambientes Virtuais de Aprendizagem (AVA), programas educativos, jogos eletrônicos, sites e software educacionais de realidade virtual, de inteligência artificial, de simulações, de tele-presença e vídeo-conferência, etc.. Todos esses produtos de tecnologia da informação e comunicação convivem atualmente com a lousa, o giz, o livro impresso, a voz do professor em sala de aula, e tantos outros elementos qualificadores do ensino presencial. 
A escola deve assumir um papel de formar cidadãos para a complexidade do mundo e dos desafios que ele propõe. Isso somente será possível se a escola romper paradigmas que a fundamentam sobre ações mecânicas, reducionistas e lineares, Freire, (2008).

Escolas são institutos de ensino, mas que precisam estar com o foco comprometido com a aprendizagem dos alunos. A escola de aprendizagem é diferente dos institutos de ensino, pois apresenta um novo e amplo espaço para grupo de alunos e professores, através de novas propostas pedagógicas e tecnologias educacionais, onde estas pessoas possam estar reunidas com o objetivo maior de aprender juntas, ponto de partida para um modelo educacional diferenciado, que é a formação de comunidades de aprendizagem, Kenski, (2010).

O foco da aprendizagem resume-se em quatro elementos:

- Aprender a conhecer, isto é, adquirir os instrumentos da compreensão;

- Aprender a fazer, isto é, saber agir sobre o meio envolvente;

- Aprender a viver junto, isto é, aprender a participar e cooperar com os outros em todas as atividades humanas; e

- Aprender a ser, isto é, a integração dos três precedentes.

A seguir, serão apresentados modelos de sistemas de ensino que utilizam recursos tecnológicos para a aprendizagem; desde os mais conservadores, como o ensino presencial, até os mais evoluídos como a Educação à Distância.

\subsection{Sistema de Ensino Presencial}

O sistema de ensino presencial é caracterizado, segundo o autor Kenski (2007) pelo modelo seriado de aulas, finitas no tempo, definidas no espaço restrito das salas de aula, ligadas a uma única disciplina e graduadas em níveis hierárquicos e lineares de aprofundamento dos conhecimentos em áreas específicas do saber. 
Além dessas características, o ensino presencial possui 0 fator preponderante do contato entre professor e alunos para o a transmissão do conhecimento fragmentado em disciplinas, baseado na voz do professor (no falar - ditar - repetir) e no desenvolvimento das atividades educativas.

Marco Silva (apud Freire, 2008) apresenta o ensino presencial como um modelo baseado na explicação do professor, nas lições-padrão, na lógica da distribuição de pacotes de informação, própria de um modelo unidirecional.

As evoluções tecnológicas estão influenciando as atividades pedagógicas das escolas tradicionais. Este processo se iniciou com:

- O uso da tecnologia para apostar na memorização, através da repetição e continuidade (programas de televisão, vídeos e outros tipos de equipamentos narrativos);

- A tecnologia utilizada em mídias e em conteúdos digitais introduz um conhecimento aberto, particionado, mas dinâmico e veloz, interdisciplinar, articulando relações entre conteúdos, espaços e pessoas diferentes.;

- Adequação da tecnologia ao conteúdo que vai ser ensinado e aos propósitos do ensino;

- Os recursos didáticos são utilizados como apoio ao professor e alunos como data show, software educativo e aplicativo, jogos eletrônicos, pesquisas na Internet, CDs e DVDs com gravações de áudio e vídeo para utilização em sala de aula, com conteúdos alternativos.

- Utilização de tecnologias digitais que integram a equipe de: professores, gestores e organizadores, responsáveis pelo plano de ensino de acordo com a previsão curricular, e que democratizam o processo de formação, com a mobilização da comunidade, participação dos cidadãos e transparência política 


\subsection{Sistema de Ensino à Distância (EaD)}

O termo Educação à Distância (EAD) abrange as diversas formas de estudo, em todos os níveis que não dispõem da supervisão contínua e imediata de tutores ou professores presentes com seus alunos em salas de aula ou nos mesmos locais, mas que ainda se beneficiam do planejamento, orientação e ensino oferecidos por uma organização tutorial. Belloni (2003) apud (PEREIRA, 2010).

"[...] educar para a inovação e mudança significa, planejar e implantar propostas dinâmicas de aprendizagem, que possam exercer e desenvolver os aspectos éticos, políticos, científicos, culturais, lúdicos e estéticos, e acima de tudo, garantir a formação de pessoas para o exercício da cidadania. (KENSKI, 2007, p.75).

Desse modo, integrar-se em novas comunidades e criar novos significados para a educação num espaço muito mais amplo que a escola tradicional, pautada pela intensificação das oportunidades de aprendizagem e autonomia dos alunos em relação à busca do conhecimento, da definição de seus caminhos, para que possam criar oportunidades e serem os sujeitos de seus projetos.

Segundo o autor Pereira (2010) o conceito de Ensino a Distância envolve várias formas de estudo: e-learning, m-learning, educação on-line, entre outros. Esta forma de educação encontra-se em todos os níveis e não dispõem da supervisão contínua e imediata de tutores ou professores presenciais, em sala de aula, fisicamente com os alunos ou nos mesmos locais. Mesmo assim, essa tecnologia educacional (EaD) necessita da gestão pedagógica do ensino tradicional, que depende do planejamento, orientação e ensino oferecidos por uma organização tutorial. Belloni (2003) (apud PEREIRA, 2010).

O Ensino à Distância libera os envolvidos na ação educativa das rígidas determinações dos espaços e tempos da educação presencial (tradicional). Professores e alunos não precisam estar presentes nas mesmas salas de aula, nem nas mesmas cidades; podem participar do processo de 
aprendizagem em momentos diferentes, conforme sua disponibilidade e necessidade. Isso é possível pelo uso mais intensivo das novas tecnologias digitais (televisão, computadores, satélites artificiais e Internet, por exdemplo).

Kenski, (2007) destaca cinco aspectos diferentes no significado de distância para esse sistema de ensino: distância geográfica, distância temporal, distância tecnológica e distância social, econômica, psicológica e cultural.

A distância geográfica se caracteriza pela separação entre a instância de onde emana a iniciativa e a formação e o local efetivo onde se realiza a aprendizagem envolvendo instituição de ensino, professores, tutores e alunos. A distância geográfica inverte o processo educacional e leva a aula até o espaço onde o aluno está favorecendo pessoas em estados permanentes ou temporários de isolamento.

No aspecto temporal Litto e Formiga, (2009) definem como interações realizadas sem atraso entre ação e reação, são denominadas síncronas $p$. ex: chat, enquanto aquelas que apresentam defasagem são ditas assíncronas, por exemplo: e-mail. $\mathrm{O}$ balanceamento entre as atividades síncronas e assíncronas permite a liberdade para o aluno estudar, gerenciar seu tempo de acordo com suas próprias obrigações e disponibilidade.

No aspecto tecnológico a velocidade da evolução tecnológica pode criar distâncias, que segundo o autor Jacquinot (2003) apud Kenski (2007), devem ser consideradas em duplo sentido. $\mathrm{O}$ primeiro diz respeito à própria formulação de projetos em EaD, que podem se tornar defasados e obsoletos diante das necessidades. O segundo sentido diz respeito aos problemas de acesso às tecnologias e do domínio de conhecimentos básicos para uso das tecnologias avançadas em projetos educacionais de EaD. Incluindo aí a dificuldade e o problema de acesso a Internet, a democratização do acesso à tecnologia e na inclusão digital de pessoas com problemas de audição, visão, comunicação oral, professores, tutores, e profissionais para a viabilização de projetos educacionais significativos para a sociedade.

No aspecto social, econômico, psicológico e cultural a distância se materializa pela inexistência de oportunidade no ensino presencial, deixando 
grande quantidade de alunos excluídos dessa oferta e em busca deste direito.

Nesse caso, a falta de oportunidade repercute diretamente nas posições econômicas, sociais e culturais que esses contingentes irão ocupar na sociedade. Essa defasagem pode ser suprida pela oferta de projetos educacionais de qualidade através da educação à distância, democratizando a realização da aprendizagem. Entretanto, essa alternativa possui o obstáculo a ser ultrapassado que é o acesso contínuo à tecnologia de suporte à EAD, pois, segundo o autor Amora et. al, (2008), o Ensino à Distância não é só uma forma massiva de oferecer educação. Ela é uma modalidade de ensino cara e trabalhosa, que envolve equipe de profissionais e tecnologias específicas e que garante a interlocução, o trabalho em grupo, a pesquisa, a avaliação, dentro dos limites de cada um dos alunos.

As experiências com EaD começaram com processos ensino-aprendizagem através de:

- Correspondência;

- Rádio;

- Televisão;

- Cursos via computadores off-line com CD-Rom e DVDs;

- Inclusão da Internet e da interatividade.

Esse meio educacional é possível através do uso intensivo das ferramentas digitais de comunicação, síncronas e assíncronas como: e-mails, fóruns, chats, tele e vídeo-conferência e demais componentes das mídias digitais.

A lei que impulsionou as atividades de EaD no Brasil foi a Lei 9.394 (Lei de diretrizes e Bases da Educação), de 20 de dezembro de 1996 - Lei de Diretrizes e Bases da Educação, Artigo 80, que determinou que: "O Poder Público incentivará o desenvolvimento e a veiculação de programas de ensino a distância, em todos os níveis e modalidades de ensino, e de educação continuada". No ano de 2005, o Decreto no 5622, de 19 de dezembro de 2005, regulamentou o Art. 80 da Lei $n^{\circ}$ 9.394/96 definindo as características da EaD como "modalidade educacional na qual a mediação 
didático-pedagógica nos processos de ensino e aprendizagem ocorre com a utilização de meios e tecnologias de informação e comunicação, com estudantes e professores desenvolvendo atividades educativas em lugares ou tempos diversos".

Algumas terminologias expressam uma tendência atual de adaptar os elementos da EAD em outras modalidades de ensino com a mesma estrutura, mas que se realizam de diferentes formas, como por exemplo:

- Educação on-line;

- e-learning;

- m-learning;

A educação on-line é uma modalidade de ensino à distância realizada via Internet, cuja comunicação ocorre de forma síncrona, ou assíncrona. Nesse tipo de ensino, usa-se a Internet para distribuir rapidamente as informações e para concretizar a interação entre as pessoas.

A interação pode ser através de formas diferenciadas de comunicação como, por exemplo: e-mail, fóruns de discussão, sites colaborativos, wikis, comunidades virtuais de aprendizagem, etc. Esta última destaca-se por ser uma ferramenta acadêmica que permite aos alunos e aos professores compartilharem informações, de conteúdo aberto - open content - que pode conter qualquer trabalho criativo incluindo artigos, imagens, vídeos, áudio, etc., tudo compartilhado para ser livremente reutilizado.

Outro modelo tecnológico utilizado nesta modalidade de ensino são os AMBIENTES VIRTUAIS DE APRENDIZAGEM (AVA) que simulam os ambientes presenciais de aprendizagem com o uso da TIC e enfatizam a produção coletiva do conhecimento, a experiência de autoria coletiva na Web. Neste contexto o aluno passa a ter uma maior autonomia para aprender e o professor assume o papel de facilitador no processo de aprendizagem, produzindo conteúdos ou atividades que levem à aprendizagem significativa nesses ambientes. Barreto et al., (2009, p. 358, apud LITTO; FORMIGA, 2009). 
Os recursos tecnológicos necessários como software, hardware permitem realizar tarefas de receber, processar, distribuir e armazenar os dados e as informações, permitindo a interação (relação de um usuário com o equipamento ou de um grupo social com outro) e a interatividade (capacidade que um sistema possui em permitir a interação) sem restrições de tempo e espaço.

O AVA permite novas experiências de aprendizado através da criação dos objetos de aprendizagem, definidos na Norma IEEE 1484 (2002) (apud ARAÚJO JR; MARQUESI, 2010) como qualquer entidade, digital ou não, que possa ser usada para aprendizagem, educação ou treinamento. São exemplos os: vídeos, fotos ou imagens digitais, animações, softwares educacionais, páginas Web que combinam texto, imagem, formulários e outros elementos da mídia. A principal vantagem de utilização de objetos de aprendizagem é a reutilização em aulas virtuais e a possibilidade de personalização de um objeto, a ilustração de conceitos abstratos, o aspecto interativo e utilização de aspectos de virtualização desses objetos. Os objetos de aprendizagem permitem ao professor modelar a aula/ conteúdo por meio de diversas formas de visualização e de uso de mídias diferentes, abrangendo diversos estilos de seus alunos e possibilitando a melhora no processo ensino-aprendizagem.

Os objetos de aprendizagem podem ser encontrados em repositórios próprios, locais em que ficam armazenados os objetos de aprendizagem produzidos para ambientes virtuais. Como exemplo o repositório mantido no pelo MEC ${ }^{6}$ unicamente ou em parcerias com os Estados Unidos ${ }^{7}$ ou com a Organização das Nações Líberoamericanas ${ }^{8}$

O AVA também permite a troca de mensagem entre pessoas e comunidades, implementado através de seus inúmeros recursos. São possíveis, por exemplo, atividades como:

- O feedback dos professores e alunos;

\footnotetext{
${ }^{6}$ Banco Internacional de Objetos Educacionais. Acessado em 05/04/2011. Disponível em: <http://objetoseducacionais2.mec.org.br>

${ }^{7}$ RIVED. Acessado em 05/04/2011. Disponível em: <http://rived.mec.gov.br/site_objeto_lis.php>

${ }^{8}$ CAEU/OEI - Centro de Altos Estudios Universitários da Organização dos Estados Lïberoamericanos. Acessado em 05/04/2011. Disponível em <http://www.oei.es/caeu.php>
} 
- A colaboração e orientação do professor;

- A troca de informações dos recursos digitais através de links, vídeos, objetos virtuais de aprendizagem; e

- A socialização de experiências através de homepage, fóruns e mensagens.

O conceito de atividade, no entanto, para o AVA pode alcançar muitos outros recursos a partir de três elementos: a estratégia didática, o domínio e o recurso.

A estratégia didática refere-se aos procedimentos e às técnicas específicas para que os objetivos de ensino e de aprendizagem sejam atingidos.

Os recursos virtuais ou físicos constituem as possibilidades específicas de uso que cada ambiente virtual oferece (funcionalidades e materiais utilizados na aprendizagem).

O domínio da disciplina diz respeito à área de conhecimento de aplicação da estratégia didática.

As atividades realizadas no AVA, segundo os autores Araújo Jr. e Marquesi (2010, p. 365) estão sujeitas a determinados fatores críticos e recomendações:

- Potencial motivador, o significado e a pertinência: escolher o objeto ou recurso motivador e significativo para o resultado da aprendizagem. A pertinência está relacionada com conteúdo da disciplina e habilidade do professor em utilizar a atividade;

- Potencial do AVA: primeiramente, se o software está funcional para atividade escolhida, e em segundo lugar, se professores e alunos estão treinados para esta oportunidade de interação;

- Recursos digitais: esses podem ser exteriores ao AVA (pesquisas em bibliotecas digitais, sites educacionais, científicos) ou interiores (através de conteúdos incluídos no mural da disciplina (diretório ou ambiente onde está incluída a disciplina no AVA);

- Recursos físicos: utilização de laboratórios, bibliotecas locais, etc.; 
- Dimensionamento da atividade: essa atividade deve ser elaborada considerando o tempo disponível para sua realização. Muitos ambientes virtuais de aprendizagem possuem um mecanismo para abrir e fechar o acesso as atividades postadas pelos professores;

- Flexibilidade: para atividades síncronas o tempo deve ser considerado como um fator estimulador da pesquisa, análise e resultado;

- Colaboração: o uso de recursos colaborativos não deve repercutir negativamente no resultado da atividade. Marcar uma discussão entre alunos com média de 100 pessoas pode não ser produtivo para a aprendizagem;

- Linguagem e comunicação: a linguagem deve ser direta, simulando um ambiente presencial, procurando dialogar e interagir naturalmente.

Os autores destacam ainda as ferramentas complementares do AVA como: espaço para avisos, documentos da disciplina, glossário, calendários, informações da disciplina e das equipes, relatórios de desempenho e acompanhamento de acesso, avaliações e espaço para divulgação de notas.

O e-learning surgiu como opção das organizações para o aprimoramento e para o treinamento de seus empregados funcionários; também destina-se à formação continuada à distância com o uso de Internet. Em geral são cursos de auto-aprendizagem que se desenvolvem em ambientes colaborativos online (portais, sites colaborativos, etc.), Litto e Formiga, (2009).

O aluno interage com um conteúdo seqüenciado disponível no ambiente digital e, em alguns casos, encaminha respostas através de ferramentas assíncronas de comunicação. O gerenciamento do professor incorpora atividades com maior grau de cooperação entre os alunos, segundo o autor Almeida (2003, p.81) apud Kenski (2010) para existir uma participação ativa dos estudantes.

O meio digital do e-learning enfoca:

- O material instrucional disponível, com informação fornecida por um tutorial ou livro eletrônico; 
- A utilização de outros recursos educacionais como CDs e DVDs, material impresso - entregues pelo correio - , videoconferências e até mesmo aulas presenciais são articulações possíveis para o e-learning.

- O aluno recebe as informações e realiza as atividades dentro do seu tempo e espaço;

- As relações que se formam entre alunos são colaborativas e podem produzir conhecimento de alto nível;

- As dúvidas, colaborações, validações de experiências e conhecimentos são encaminhados ao professor através de e-mail.

O m-learning (mobile-learning) segundo Litto e Formiga (2009, p. 81) foram dois fatores que originaram o termo mobile-learning ou aprendizagem móvel ou aprendizagem em movimento: primeiro a necessidade de constante deslocamento dos alunos para aprendizagem e treinamento; segundo o deslocamento de professores e tutores.

Outras influências contribuíram para divulgação dessa modalidade de ensino e marcam um paradigma do futuro da aprendizagem: primeiro a aprendizagem por toda a vida, e o segundo a aprendizagem não-formal (lifelong learning e non-formal learning). O primeiro diz respeito às atividades e informações que contribuem para o aumento do conhecimento e habilidades ao longo da vida. O segundo abrange todo conhecimento adquirido por meio de atividades informais tanto no local de trabalho quando na vida em sociedade.

O desenvolvimento do mobile-learning foi possível por meiodo uso de telefones celulares, que passou a utilizar os PDAs e Laptops. Como possui a forte característica de ter aluno e/ou professor móveis essa modalidade de ensino permeia todas as formas de aprendizagem utilizando comunicação sem fio e em redes.

Por fim, as regulamentações em vigor da EAD exigem que, independe das modalidades de ensino propostas atualmente, independente dos diferentes desenhos e múltiplas combinações de recursos didáticos e tecnológicos, um ponto deve ser comum a todas as modalidades: a compreensão da 
educação como 'o aprender' e como fundamento, antes de se pensar no modo de organizar a distância. Quanto à avaliação dos cursos oferecidos, o Ministério da Educação, segundo Brasil (2007, p.7) apud Kenski (2010) define como critério de avaliação a verificação "in loco" das condições institucionais necessárias para o julgamento dessa modalidade de ensino. As condições principais são: integração da educação superior à distância no plano de desenvolvimento institucional; organização curricular definida; equipe multidisciplinar para a definição, construção e liberação dos recursos utilizados, objetos educacionais e tecnologia empregada; materiais educacionais de apoio; avaliação institucional; infra-estrutura de apoio; gestão acad6emico-administrativa; sustentabilidade financeira e convênios e parcerias para e desenvolvimento do programa.

\subsection{Sistema de Ensino Presencial Mediado por Recursos Tecnológicos}

A Universidade do Estado do Amazonas (UEA) foi criada através da Lei $n^{\circ}$. 2.637 de 12 de janeiro de 2001 e regulamentada através do Decreto n. ${ }^{\circ}$ 21.666, de $1^{\circ}$. de fevereiro de 2001.

Iniciou seus trabalhos, efetivamente, em $1^{\circ}$. de agosto de 2001 com o objetivo de levar a oportunidade de educação, pelo ensino superior, para a população do interior do Estado do Amazonas, principalmente àqueles estudantes que não tinham condições de se locomover até uma unidade na Capital do Estado, Manaus.

Com 10 anos de trabalho, a Universidade apresenta dezesseis unidades com sede própria, espalhadas pelos municípios e Capital do Estado e com resultados significativos de trabalho representados principalmente pelo histórico de ter entregado uma parcela do seu trabalho já desenvolvido, aos sessenta e dois municípios do Estado. "O resultado desse esforço demonstra uma disposição da UEA em trabalhar no interior do Estado, com aproximadamente 21.000 (vinte e um mil) alunos graduados no Estado do 
Amazonas, oitenta por cento deles residentes nos municípios do interior (informação verbal) ${ }^{9 "}$.

O estado do Amazonas, o maior em territorialidade do Brasil, apresenta algumas diferenças de outros estados brasileiros.

As mais significativas estão justamente relacionadas com as distâncias entre seus 62 municípios, que em geral, e para grande parte da população amazonense, é superada pelas estradas fluviais, com rios abundantes, mas de natureza sinuosa, o que torna o deslocamento mais lento, superando dentre esse e outros obstáculos, o volume das águas, a força da correnteza, pedras nos leitos dos rios, períodos de seca, a pouca infra-estrutura durante o caminho e nos barcos utilizados para navegação, denominados de 'recreios'. As poucas estradas interligando municípios do Estado do Amazonas, não superam as distâncias entre os municípios pois não ultrapassam os limites impostos pelos numerosos rios e igarapés.

Outro ponto importante de diferença é a baixa densidade demográfica em quase a totalidade dos municípios do estado. Dos 62 municípios destacamse como os de maior número de habitantes, aproximadamente10: Manaus (1.700.000); Itacoatiara (85.000); Coari (73.000); Manacapuru (83.000); e Parintins (96.000). Perto de 10 municípios somente alcançam a população em números, de 30.000 a 50.000 habitantes; os demais municípios estão na faixa de menos de 20.000 habitantes.

Outros fatores diferenciais são o clima e a vegetação, cujo conjunto faz do Amazonas responsável por promover práticas sustentáveis dos seus recursos naturais na busca da preservação do rico meio ambiente.

Todos esses elementos tornam árdua a tarefa de desenvolver os municípios do interior, pois, a pouca infra-estrutura dessas cidades não favorece a manutenção de centros de ensino para oferta de cursos de graduação, negligenciando a população o direito de capacitar-se e buscar a melhoria das condições de vida.

\footnotetext{
${ }^{9}$ Informações extraídas da palestra do vice-reitor da UEA, professor Carlos Eduardo de Souza Gonçalves, na abertura da Semana Nacional de Ciência e Tecnologia, em Manaus, em 19 de outubro de 2009.

${ }^{10}$ Censo, 2010, publicado no Diário Oficial da União em 04/11/2010. Acessado em 05/04/2011.

Disponível em <http://www.censo2010.ibge.gov.br>
} 
Através da Lei de Diretrizes e Bases da Educação, em 2000, esta realidade começou um longo processo de transformação com a oferta de cursos de graduação e, posteriormente, a oferta de cursos lineares para o ensino médio, através da tecnologia de Ensino Presencial Mediado por Recursos Tecnológicos (EPMRT).

Essa modalidade de ensino superou as expectativas traçadas pelas políticas governamentais para educação no Estado ao promover o ensino com qualidade e recebendo dos alunos nos municípios, a credibilidade pela efetiva aprendizagem através do modelo tecnológico adotado, bem como através da própria Universidade que evolui durante uma década de educação.

O professor José Ademir Ramos, colaborador do modelo através do Programa de Formação e Valorização dos Profissionais da Educação (PROFORMAR) define a tecnologia de ensino 'Educação Presencial Mediada pela TV' como uma:

\footnotetext{
"[...] modalidade tecnológica, que se apropria de variados elementos da EAD (Educação a Distância), enriquecidos pelas possibilidades que as novas ferramentas de comunicação e de informação agregam no processo ensino-aprendizagem, fundamentado nos princípios, diretrizes e procedimentos que regulamentam esta nova prática de ensino. (BARBOSA; RAMOS, 2008, p. 72).
}

Várias ações, que envolvem pessoas e tecnologias, foram empregadas na realização desse sistema educacional que revolucionou a política de educação no Estado e superou adversidades da região amazônica exigindo uma nova estratégia de logística além da logística tradicional, propondo novas metodologias de ensino, superando preconceitos e adversidades e apostou na capacidade de utilização das novas tecnologias utilizadas de alunos e professores.

A concepção do modelo de Ensino Presencial Mediado por Recursos Tecnológicos (EPMRT) originou-se da necessidade da UEA em formar professores de Ensino Fundamental da Capital e do interior, segundo os professores Barbosa e Ramos (2008, p. 23) esta tarefa foi solicitada pela Secretaria de Educação do Estado do Amazonas em atendimento aos dispositivos legais da Lei de Diretrizes e Bases da Educação Nacional, Lei $n^{\circ}$ 
$9.394^{11}$ de 20 de dezembro de 1996, que define e regulariza o sistema de educação brasileiro com base nos princípios presentes na Constituição de 05 de outubro de 1988.

O Art. 87 \& 4º da Lei no 9.394 instituía a Década da Educação e dava as diretrizes para formação em ensino superior de professores "[...] até o fim da Década da Educação somente serão admitidos professores habilitados em nível superior ou formados por treinamento em serviço" (grifo nosso).

A mesma Lei determinou, em seu Art. 62, a qualificação obrigatória de professores, feita em cursos superior, independente do nível de ensino:

\begin{abstract}
"A formação de docentes para atuar na educação básica far-se-á em nível superior, em curso de licenciatura, de graduação plena, em universidades e institutos superiores de educação, admitida, como formação mínima para o exercício do magistério na educação infantil e nas quatro primeiras séries do ensino fundamental, a oferecida em nível médio, na modalidade Normal."
\end{abstract}

A solução encontrada pela UEA envolveu processos, tecnologias e recursos humanos e possibilitou a mudança no papel da escola e um conceito de aprendizagem novo.

[...] se definiu o instrumento do Sistema de Ensino Presencial Mediado, fundamentado no tripé - recursos tecnológicos, pessoal devidamente qualificado e procedimentos didáticos específicos criando, dessa feita, a ambiência comparável as salas de aula do curso presencial. (BARBOSA; RAMOS, 2008, p. 36).

O Ensino Presencial Mediado por Recursos Tecnológicos envolve as práticas pedagógicas do ensino presencial bem como a inovação tecnológica e a superação física do ensino a distância, utilizando ferramentas interativas para agregar valor atemporal às atividades, envolvendo grupos de alunos e professores em comunidades de aprendizagem.

O aprendizado no EPMRT é realizado através de uma seqüência de atividades descritas a seguir no modelo de ensino-aprendizagem, Figura 15:

\footnotetext{
${ }^{11}$ Sobre a Lei ${ }^{\circ}{ }^{\circ} 9.394$, de 1996, disponível: http://www.portal.mec.gov.br/sesu/arquivos/pdf/lei9394.pdf.
} 


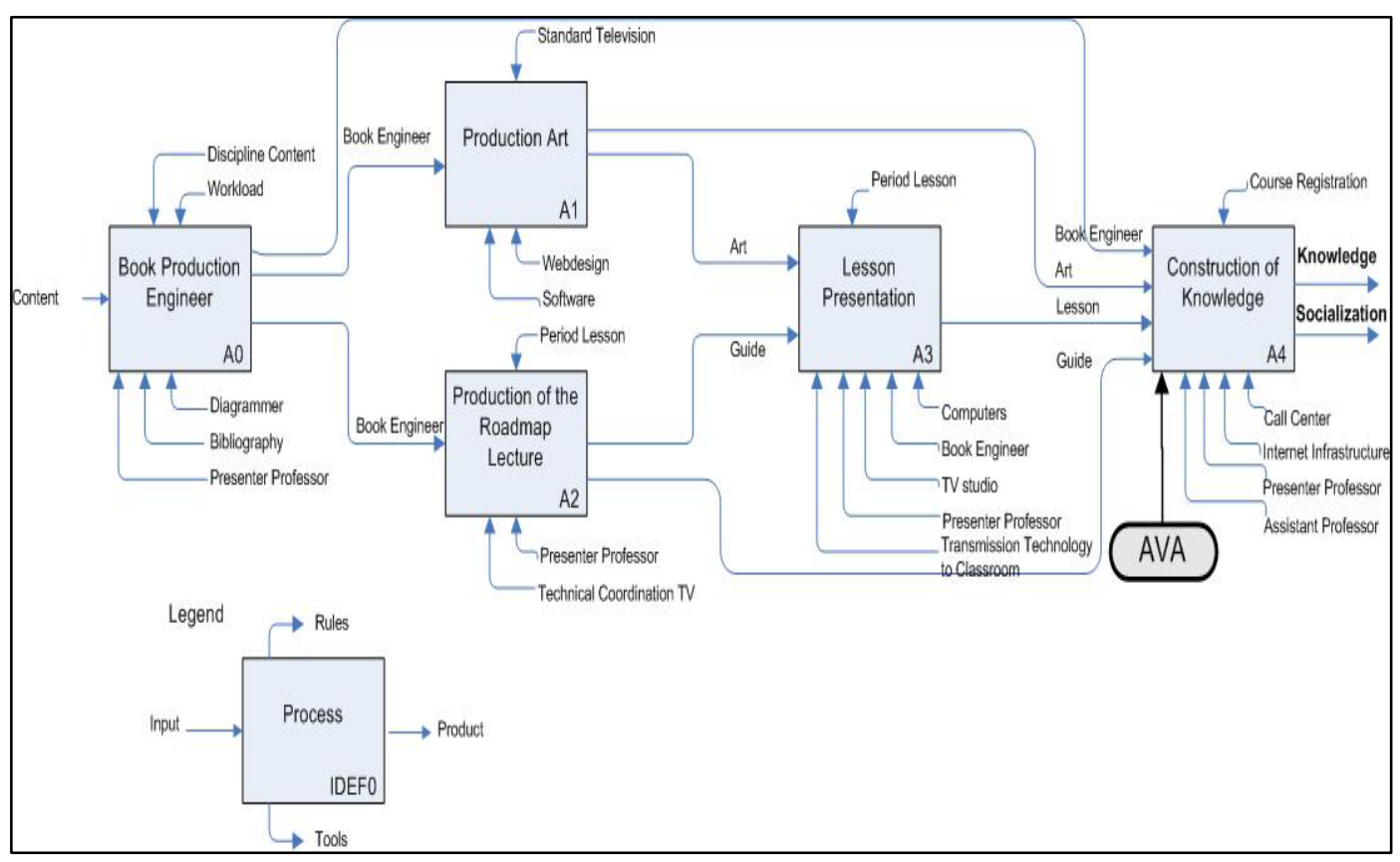

Figura 15: Modelo ensino-aprendizagem do EPMRT.

- O primeiro processo é a produção do livro técnico. Esse processo inicia com a seleção do professor titular por disciplina, mediante a sua titulação acadêmica e pela avaliação de sua prática pedagógica. Feito isso ele passa a compor um grupo de trabalho de 3 integrantes.

- Nos primeiros cursos na modalidade EPMRT o grupo de professores contava com 5 integrantes, Barbosa e Ramos, (2008, p. 44), a partir da utilização da tecnologia para outros cursos oferecidos pela UEA, em 2006, o número de professores titulares foi reduzido para 3. A criação de grupo de professores titulares (atuando pela Televisão e call center) serviu para minimizar os problemas de deslocamento dos professores aos municípios do Estado, reduzindo os custos do projeto.

- Esses professores, sob a coordenação de um deles, definem o escopo do livro técnico, de acordo com a ementa da disciplina, pesquisam, elaboram, escrevem e acompanham a edição dos textos junto à UEA com o auxílio de um diagramador. As obras são editadas na forma de livros com registros de ISBN da Biblioteca Nacional. 
- O diagramador, as diversas bibliografias, o conteúdo programático, a carga horária e a ementa da disciplina (oriunda do plano pedagógico) são insumos do processo.

- O segundo processo é a produção da arte. Esse processo consiste na produção e elaboração das aulas, com escolha de software apropriado, vídeos e outros recursos de apoio didático.

- O web design, a escolha de softwares para elaboração das aulas, o padrão de arte televisivo e o livro técnico são insumos e regras para este processo.

- O terceiro processo é a produção do roteiro. Esse processo utiliza o trabalho especializado do professor apresentador em conjunto com a coordenação técnica de televisão (responsável pela produção da arte) e de estúdio que definem a correta utilização do tempo em relação ao conteúdo a ser apresentado durante as aulas, bem como a seleção dos recursos audiovisuais apropriados.

- O livro técnico e o período diário reservado para as aulas (04 horas divididas em 03 tempos de 70' cada, intervalados por 15' cada tempo) são respectivamente o insumo e a regra do processo, Barbosa e Ramos (2008, p. 27).

- O quarto processo é a apresentação de aulas. Esse processo consiste com a utilização de um estúdio de televisão, que permite a transmissão das aulas para todos os municípios participantes do curso, de forma simultânea e ao vivo, através de uma rede privada de Internet, conectada via satélite, fazendo uso das mídias de áudio, vídeo e voz. Esse estúdio cria condições para apresentação das aulas pelos professores titulares, através de câmeras-robôs, intercaladas pela utilização dos múltiplos recursos didáticos preparados como: filmes, documentários, animações, ilustrações, quadro branco inteligente e interativo, (alguns desses recursos são produzidos exclusivamente para as aulas do curso).

- Como insumo o processo conta com a arte e roteiros produzidos e como regra a correta utilização dos tempos de aula pré-definidos. 
"[...] se definiu o instrumento do Sistema de Ensino Presencial Mediado, fundamentado no tripé - recursos tecnológicos, pessoal devidamente qualificado e procedimentos didáticos específicos criando, dessa feita, a ambiência comparável as salas de aula do curso presencial [...]", Barbosa e Ramos, (2008).

- O quinto e último processo é a construção do conhecimento. Ele conta com a infra-estrutura de Internet, o professor apresentador, o professor assistente e a central de atendimento ao aluno.

- O professor assistente fica em cada de sala de aula geograficamente distante do estúdio de televisão, interage com os professores titulares e tem a função de acompanhar aulas, organizar e monitorar a dinâmica local, orientar pedagogicamente os alunos nos procedimentos de pesquisa, ensino e extensão.

- Os insumos compreendem o livro técnico, as artes e os roteiros de aulas, a regra existente é a exigência de aluno regularmente matriculado no curso.

- Uma ferramenta especial foi incluída no processo de produção do conhecimento: o Ambiente Virtual de Aprendizagem, implementado através do software livre Moodle ${ }^{12}{ }^{12}$, versão 1.9 , e que possibilita aos alunos e professores um espaço alternativo para troca de informação, organização de comunidades de aprendizagem.

A seguir, a descrição dos recursos tecnológicos utilizados pelo EPMRT para promover a aprendizagem. A Figura 16 apresenta uma visão geral dos recursos tecnológicos empregados no modelo.

O estúdio de televisão em Manaus conta com estrutura apropriada de software e hardware, central de atendimento assíncrono e síncrono para atendimento ao aluno e equipamentos necessários para produção como: sala acusticamente tratada, luminárias artísticas, 03 câmeras para estúdio multi-formato, robotizadas, monitores, controladores de câmera, switcher de vídeo e tecnologia de transmissão de aula com canal de satélite dedicado.

\footnotetext{
${ }^{12}$ Moodle $^{\circledR}$ é um software livre que disponibiliza o ambiente virtual de aprendizagem. Acessado em 05/04/2011. Disponível em: <http://www.moodle.org>.
} 


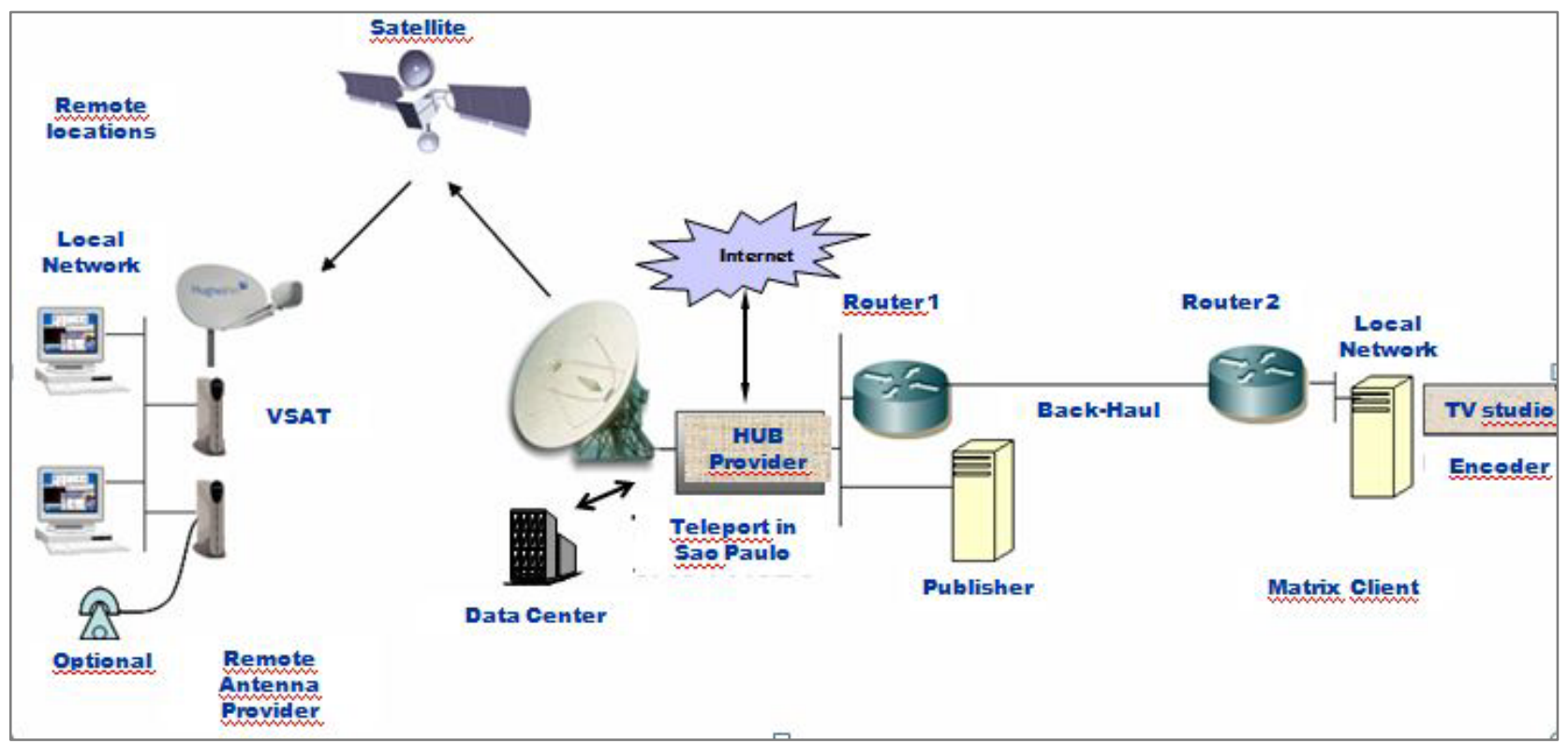

Figura 16: Modelo tecnológico utilizado no EPMRT. Fonte: Pereira, (2010).

A plataforma de ensino a distância segundo o Relatório técnico da Universidade do Estado do Amazonas (2008) é composta dos seguintes elementos:

- Rede de comunicação via satélite baseado em protocolo IP, interligando 67 pontos de presença distribuídos um em cada sala de aula e os demais entre a sede da UEA e estúdio de televisão para tráfego das sessões de videoconferência, acesso a Internet e banda larga e VoIP; e

- Software de vídeo conferência multiponto e de colaboração;

A estação central da rede, dispositivo HUB, está localizada em São Paulo e o satélite utilizado provê cobertura para todo Brasil.

Esta rede opera ou em banda $\mathrm{C}$ ou em banda $K u$ e todas as estações (VSATs) fornecidas são bi-direcionais, ou seja, com capacidade para receber e transmitir dados IP.

O estúdio de televisão (estúdio de geração de vídeo) está localizado em Manaus e utiliza a estação VSAT para transmitir o vídeo para a estação central da rede (HUB), em são Paulo. O vídeo é então retransmitido da estação central (HUB) para todos os pontos de presença via multicast, simultaneamente. 
A rede via satélite tem capacidade de prover QoS (Quality of Service) tanto para upload, carga quanto para download, descarga, para todos os pontos da rede com 4 níveis diferentes para prioridade de tráfego: dados, vídeo, áudio e multicast. Os recursos contemplados na rede de satélite são:

- Canal para download com taxa nominal de serviço de transmissão de 1.024 Kbps - multicast de vídeo;

- Canal para download com taxa nominal de serviço de transmissão de $2.048 \mathrm{Kbps}$ - unicast de Internet e VolP;

- Canal para upload com taxa nominal de serviço de transmissão de 1.024 Kbps - upload de vídeo do estúdio;

- Canal para upload com taxa nominal de serviço de transmissão de 1.024 Kbps - colaboração dos pontos remotos, Internet e tráfego de VoIP;

- Conexão de saída com backbone Internet pública de $2.048 \mathrm{Kbps}$, no ponto central da rede (HUB) compartilhada por todos os pontos da rede.

O equipamento utilizado no estúdio é um terminal:

- VSAT com 1 porta de LAN 10/100baseT (conexão com cabo de par trançado e conectores RJ45) e 2 portas VolP com interface FXS integradas no mesmo equipamento.

- Dynamic Host ConFiguration Protocol (DHCP) ${ }^{13}$. Para endereçamento estático e dinâmico.

- Domain Nome System (DNS) Caching ${ }^{14}$. Para armazenar endereços de DNS em área de memória.

- Aceleração http integrada no equipamento. Mecanismo de caching para páginas Web.

- Network Address Translater (NAT)/Port Address Translater (PAT). NAT é um mecanismo que mapeia os endereços IPS de uma rede para outra;

\footnotetext{
${ }^{13}$ RFC 2131 de Março/97. Acessado em: 05/04/2011. Disponível em: < http://www.rfc-editor.org/>.

${ }^{14}$ RFC 1034/1035 de Novembro/87. Acessado em: 05/04/2011. Disponível em: < http://www.rfceditor.org/>.
} 
PAT é um mecanismo para mapear as portas TCP/IP de uma área para outra, são utilizados em conjunto. ${ }^{15}$

- Codec de voz G.729AB e G.723. Coder /Decoder ${ }^{16}$ (codificador/decodificador) software utilizado para comprimir ou descomprimir um arquivo de multimídia digital.

- Capacidade de transmissão expansível de, no mínimo, 1.6 Mbps (upload)

- Capacidade de recepção de até 12 Mbps (download).

- VLAN ${ }^{17}$ Tagging.

A solução VolP ${ }^{18}$ permite a conversação do sentido ponto de presença para UEA e vice-versa. Os telefones, nos pontos de presença remotos, são tratados como um ramal de PABX da sede da UEA.

A rede de telecomunicações disponibiliza transmissão máxima para até 8 conversações, simultâneas entre os pontos de presença e a sede da UEA. Essa banda compartilha todo tráfego da Internet gerado pela rede e cada canal de voz ocupa no máximo 16 Kbps full-duplex (caminho nos 2 sentidos da rede).

A solução Internet ${ }^{19}$ é disponibilizada em todos os pontos de presença na rede satélite, com banda total de 2.048/512 Kbps (256 Kbps para download/128 Kbps para upload).

A solução de vídeo conferência ${ }^{20}$ realiza sessões multipontos (pelo menos 62 pontos) interagindo na sessão de vídeo conferência e/ou sessões pontoa-ponto, onde somente dois pontos interagem.

\footnotetext{
${ }^{15}$ RFC 2663 de Agosto/99. Acessado em 05/04/2011. Disponível em: <http://www.rfc-editor.org/info >.

${ }^{16}$ Acessado em 05/04/2011. Disponível em: <http://windows.microsoft.com/>.

${ }^{17}$ IEEE 802.1Q de Novembro/2006. Acessado em 05/04/2011. Disponível em<http://www.ieee802.org/1/pages/802.1Q.html>.

${ }^{18}$ Fonte: Relatório técnico da Plataforma de Ensino à Distância, Universidade do Estado do Amazonas, (2008).

${ }^{19}$ Fonte: Relatório técnico da Plataforma de Ensino à Distância, Universidade do Estado do Amazonas, (2008).

${ }^{20}$ Fonte: Relatório técnico da Plataforma de Ensino à Distância, Universidade do Estado do Amazonas, (2008).
} 
O uso de quadro branco inteligente e interativo é permitido e seu conteúdo é gerado e compartilhado simultaneamente pelos participantes da sessão com a transmissão do streaming de vídeo pré-gravado.

Existe funcionalidade para troca de mensagens instantâneas públicas ou privadas entre os pontos de presença de uma sessão.

O acesso as sessões é condicionado ao nome do usuário e senha de acesso, e existe conFiguração para permissão de interação dos pontos de presença por dia e hora.

Permite o controle de usuário cadastrado, usuário conectado, usuário com sessão ativa, exibição de informações de mídia transmitida (pacote perdido, tamanho do pacote), verificação do uso da estação do usuário.

Em cada ponto de presença (pelo menos nos 62 municípios) há:

- Equipamento microcomputador VSAT com sistema operacional MSWindows XP;

- Software client da solução de TV digital interativa e vídeo conferência multiponto;

- PLUGINS do Direct X e Windows Media para áudio e vídeo;

- Adaptador de rede com conFiguração do endereço IP do roteador;

- Antivírus AVG Freeware;

- Software OpenOffice versão 2.0;

- Antena parabólica orientada ao satélite.

O acordo de nível de serviço (ANS) define:

- Disponibilidade da solução de 99,5\% (média anual);

- Taxa máxima de erro admitida para cada circuito é de 10/7;

- Rede de telecomunicações e solução de vídeo conferência monitorada em regime 24 (vinte e quatro) horas por 7 (sete) dias;

- Help Desk em regime 24 (vinte e quatro) horas porx 7 (sete) dias acessível através de número 0800 com: registro da ocorrência; classificação do tipo do problema (em até 3 horas após a abertura do 
chamado); classificação de sua severidade; tempo de reparo com prazo máximo de 72 horas (para pontos de presença localizados até $300 \mathrm{Km}$ da Capital) e de até 120 horas (para pontos de presença localizados com distância superior a $300 \mathrm{Km}$ da Capital). 


\section{PROPOSTA DAS DIRETRIZES DE CONSTRUÇÃO DO PLANO DE CONTINUIDADE DE NEGÓCIOS}

O programa de GCN é aplicado em processos definidos, sem os quais, não há possibilidade de existir padrões para a entrega dos serviços de TI.

A Figura 17 apresenta o pacote de componentes da GCN utilizando as ferramentas escolhidas para a geração e suporte das diretrizes do Plano de Continuidade de Negócios: o ITIL ${ }^{\circledR}$ V3 e a Dependabilidade; e utiliza o diagrama de componentes da $\mathrm{UML}^{21}$ para sua representação:

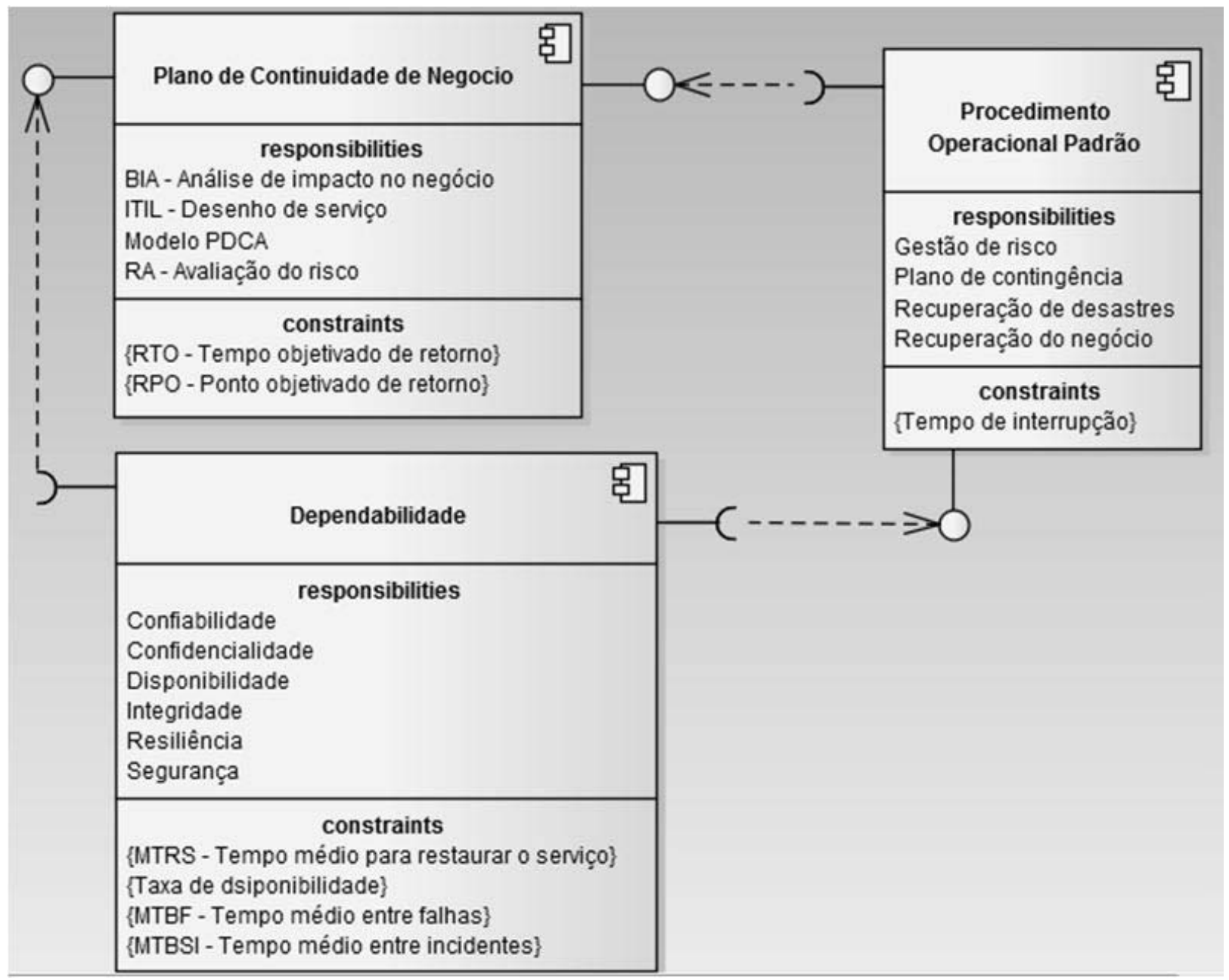

Figura 17: Diagrama de componentes da GCN.

\footnotetext{
${ }^{21}$ UML (Unified Modeling Language ou Linguagem de Modelagem Unificada) é uma linguagem visual utilizada para modelar sistemas computacionais por meio do paradigma de Orientação a Objetos, (GUEDES, 2007).
} 
Pelo diagrama acima, o PCN é uma composição de 1 ou muitos procedimentos operacionais padrão - SOP e possui como requisitos de construção os resultados das análises do BIA, ITIL $®$, RA e PDCA. Como restrições, o PCN possui o tempo de recuperação e o ponto de recuperação dos serviços quando uma vez interrompidos. O ponto de recuperação será classificado como;

- Forward error recovery: que conduz a um novo estado ainda não ocorrido desde a última falha detectada; ou

- Backward error recovery: que conduz ao estado anterior a manifestação do erro.

O componente Procedimento Operacional Padrão possui como requisito de construção pelo menos um tipo de plano de controle: a gestão de risco ou/e a gestão emergencial da crise, ou/e os procedimentos para recuperação de desastres ou/e a recuperação do negócio. A restrição do SOP resume-se ao tempo de interrupção de uma atividade ou serviço. A partir da variação do tempo que o serviço estiver indisponível o gestor do PCN pode demandar diferentes esforços do plano (medidas de controle) para atender a gravidade da situação.

Cada medida de controle poderá restabelecer um ou mais atributos da Dependabilidade. Essa relação está definida pelo relacionamento entre os componentes Dependabilidade e Procedimento Operacional Padrão.

A Dependabilidade apresenta ainda classes distintas que servem a cada atributo e seus indicadores (medidas do impacto). Está associada ao PCN para fornecer restrições de tempos de manutenção e de recuperação dos serviços.

\subsection{Diretrizes para a construção do Plano de Continuidade de Negócios}

As diretrizes para a construção do PCN estão a seguir detalhadas e ilustradas na lista abaixo:

$1^{\text {a }}$. Etapa: iniciar o PCN: 
- Direcionar, por meio do ITIL $®$, a avaliação dos serviços de TI, permitindo a análise das necessidades dos recursos e serviços de tecnologia da informação, objetivando como resultado a disponibilidade e segurança da informação;

- Entender a necessidade da organização, organizar suas expectativas, organizar o valor dos investimentos no PCN e estabelecer os recursos, as habilidades e os provedores de cada serviço. A descrição deverá contemplar: pessoas, processo, parceiro e produto (4P's);

O quadro 10 apresenta o template para atender à $1^{\text {a }}$. Etapa, descrevendo os recursos que fazem parte do escopo do plano (processo de negócio); as pessoas relacionadas ao recurso (responsáveis); as habilidades necessárias para a entrega do serviço (premissas); e ainda a abrangência e escala de interrupção:

\begin{tabular}{|l|l|l|}
\hline \multicolumn{3}{|c|}{ ABERTURA DO PLANO DE CONTINUIDADE DE NEGÓCIO } \\
\hline Processo de negócio & Descrição \\
\hline Responsáveis & Lista de responsáveis \\
\hline Objetivo & Descrição \\
\hline Premissas & Descrição & \\
\hline \multirow{4}{*}{$\begin{array}{l}\text { Abrangência / } \\
\text { Tipo de interrupção (P, } \\
\text { E; D)* }\end{array}$} & $\begin{array}{l}\text { Plano para gestão do risco } \\
\text { (emergencial de crise) }\end{array}$ & \\
\cline { 2 - 4 } & $\begin{array}{l}\text { Plano de recuperação de } \\
\text { desastres (disaster recovery) }\end{array}$ & \\
\cline { 2 - 4 } & $\begin{array}{l}\text { Plano de recuperação do de } \\
\text { negócio }\end{array}$ & \\
\hline \multirow{2}{*}{ *P: Problema; E: Emergência; D: Desastre } \\
\hline
\end{tabular}

Quadro 10: Template para primeira etapa do PCN.

$2^{\mathrm{a}}$. Etapa: entender a organização:

- Permitir a identificação de todas as atividades de um serviço, produzindo um catálogo que deve ser analisado e mantido pela organização. Identificar as atividades críticas da infra-estrutura de TI através da descrição dos bens e componentes de bens. Nesta metodologia, bem é 
todo serviço ou produto que dispõe recursos para atender as atividades críticas da área de TI. Faz parte da identificação todos os requisitos de hardware, softwares básicos e aplicativos, rede de comunicação, rede elétrica, controles de segurança e acordos de níveis de serviços existentes dependências do conhecimento, pessoas, etc.;

- Avaliar se a organização possui procedimentos adequados à segurança da informação;

- Relacionar as vulnerabilidades sobre os componentes de TI e classificar a probabilidade de ocorrência das ameaças; identificar para cada vulnerabilidade, o grau de impacto sobre cada um dos atributos da Dependabilidade: disponibilidade, confiabilidade, confidencialidade, integridade, manutenibilidade (definida nesta metodologia como a resiliência do sistema, ou recuperabilidade do sistema) e segurança.

- Calcular a média aritmética entre os valores obtidos nos atributos da Dependabilidade;

- Identificar o nível de risco através da relação 'impacto e probabilidade'. O nível do risco deve atender a seguinte classificação:

- BAIXO para valores de nível do risco entre 1 e 25;

- MÉDIO para valores de nível do risco maiores que 25 e até 50 ;

- ALTO para valores de nível do risco maiores que 50 e até 80; e

- DANO para os valores do nível do risco maiores que 80.

O quadro de classificação do bem/ serviço/ atividade, quadro 11, relaciona as informações necessárias de descrição, incluindo os relacionamentos com outros recursos: 


\begin{tabular}{|c|c|c|c|c|c|c|c|}
\hline \multicolumn{8}{|c|}{ CLASSIFICAÇÃO DO BEM/ SERVIÇO/ ATIVIDADE } \\
\hline \multicolumn{8}{|c|}{ Descrição do serviço ou bem } \\
\hline \multicolumn{8}{|l|}{ Componente } \\
\hline \multicolumn{8}{|l|}{ Hardware } \\
\hline \multicolumn{8}{|l|}{ Software } \\
\hline \multicolumn{8}{|c|}{ DEPENDÊNCIAS } \\
\hline \multicolumn{8}{|c|}{ Rede de comunicação } \\
\hline \multicolumn{8}{|l|}{ Rede elétrica } \\
\hline \multicolumn{8}{|l|}{ Periféricos } \\
\hline \multicolumn{8}{|l|}{ SGBD } \\
\hline \multicolumn{8}{|l|}{ Servidores WEB } \\
\hline \multicolumn{8}{|c|}{ Servidores de aplicação } \\
\hline \multicolumn{8}{|c|}{ Sistemas legados } \\
\hline \multicolumn{8}{|c|}{ Sistemas externos } \\
\hline \multicolumn{8}{|c|}{ Outras funções do sistema } \\
\hline \multicolumn{8}{|c|}{ Interfaces } \\
\hline \multicolumn{8}{|c|}{ Dados e informações } \\
\hline \multicolumn{8}{|l|}{ Pessoas } \\
\hline \multicolumn{8}{|c|}{ Missão do sistema } \\
\hline Ameaça & Vulnerabilidade & \multicolumn{4}{|c|}{ Impacto (Nível) (Baixo (10) / Médio (50) / Alto (100)) } & $\begin{array}{c}\text { Probabilidade } \\
\text { (Alto/Médio/Baixo) }\end{array}$ & Risco \\
\hline & & & \begin{tabular}{|l} 
Indicadores \\
\end{tabular} & & & & \\
\hline & & & Pública (10) & \begin{tabular}{|l} 
Interna (50) \\
\end{tabular} & Confidencial (100) & & \\
\hline & & Confidencialidade & & & & & \\
\hline & & & Baixo (10) & \begin{tabular}{|l} 
Médio (50) \\
\end{tabular} & Alto (100) & & \\
\hline & & Confiabilidade & & & & & \\
\hline & & Segurança & & & & & \\
\hline & & Integridade & & & & & \\
\hline & & Resiliência & & & & & \\
\hline & & & Básica (10) & Alta (50) & Contínua (100) & & \\
\hline & & Disponibilidade & & & & & \\
\hline
\end{tabular}

Quadro 11: Descrição Template para descrever as funções críticas da empresa. 
3a. Etapa: definir estratégia de continuidade de negócio:

- Definir a medida de controle orientada ao maior nível de risco sobre os atributos da Dependabilidade:

- Prevenção da falha;

- Previsão da falha;

- Remoção da falha; e

- Tolerância a falha;

- Definição das medidas de recuperação para os níveis de risco e controle estabelecidos: RTO; RPO; MTRS, utilizando as medidas estabelecidas no ANS; ou dos procedimentos de serviços, ou das informações e dos históricos de falhas e incidentes (MTBF e MTBSI);

4⿳. Etapa: escrever e implantar o PCN:

- Definir as funções ou serviços que serão atendidos pelo PCN;

- Definir os atores e suas responsabilidades no PCN;

- Escrever os procedimentos operacionais padrão (SOP's) a partir dos diagramas de componentes e de caso de uso, Figura 18:

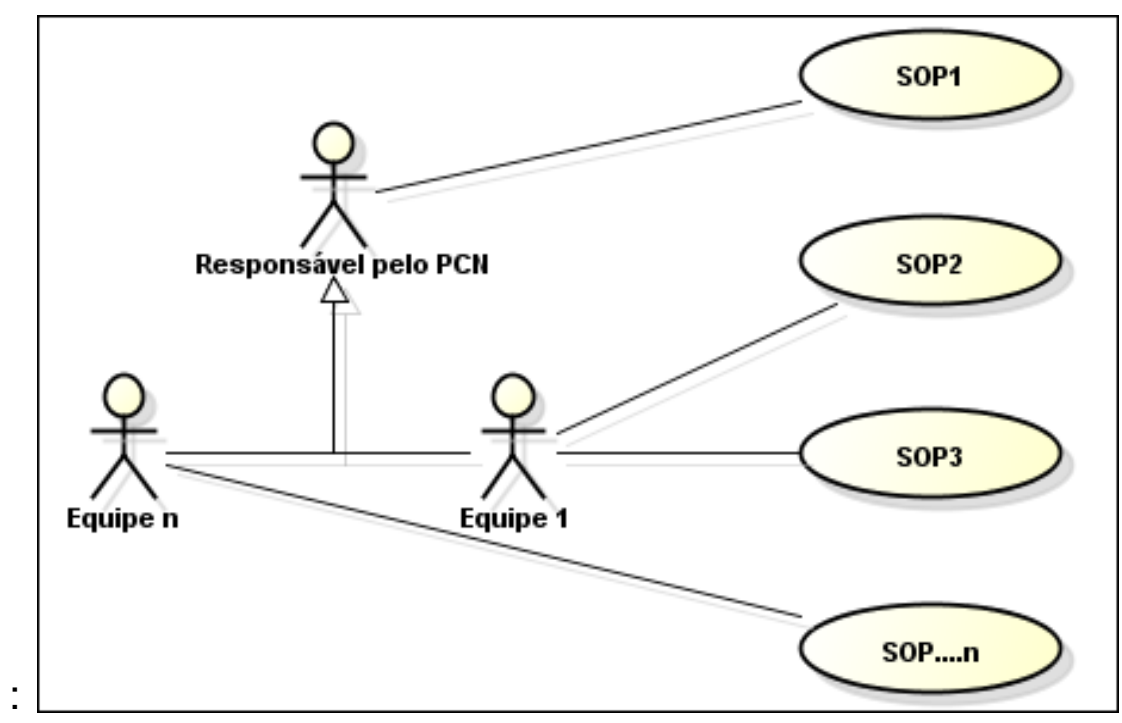

Figura 18: Representação do PCN composto de1 ou vários SOP através do diagrama de casos de uso da UML. 
O registro do SOP é feito através da descrição de um caso de uso demonstrando o comportamento de prevenção de falhas, de detecção de falhas, de remoção de falhas ou de tolerância a falhas.

O SOP será executado quando solicitado, isto é, quando houver um incidente envolvendo a atividade crítica relacionada com o serviço/ bem/ função do SOP.

O template de caso de uso está na Figura 19. Ele apresenta:

- Descrição sucinta do objetivo do caso de uso (SOP);

- Atores envolvidos nos procedimentos;

- Pré-condição de execução; e

- Pós-condição (resultado que deve ser apresentado após a execução do SOP).

O procedimento é descrito através de passos seqüenciados, chamando, quando necessário, regras de negócio, observações e mensagens que devem ser administradas durante a execução do procedimento.

As medidas identificadas na fase 3 tempo objetivado de retorno (RTO), ponto objetivado de retorno (RPO) e tempo médio de retorno do serviço (MTRS), devem estar incorporadas ao SOP para validação do procedimento Os fluxos alternativos e de exceção devem estar previstos para cenários não favoráveis.

Os fluxos alternativos representam situações que fogem das situações normais e regulares do caso de uso, ou opções de procedimentos que podem ser executados ou não, dependendo das condições que se apresentam no momento da chamada do SOP.

Os fluxos de exceção determinam os procedimentos que devem ser administrados quando o fluxo do SOP não pode ser concluído.

As regras de recuperação têm o objetivo de tornar o procedimento mais consistente, descrevendo as validações necessárias ao SOP. 


\begin{tabular}{|l|l|}
\hline Cliente: & $\begin{array}{l}\text { Página: } 1 \\
\text { Preencher com o nome do cliente do PCN) }\end{array}$ \\
\hline Projeto: & $\begin{array}{l}\text { (Página: 1 } \\
\text { Preencher com o nome do projeto) }\end{array}$ \\
\hline Objetivo: & $\begin{array}{l}\text { (Preencher com o propósito do SOP. Se à gestão de risco, } \\
\text { plano de emergência de crise, plano de recuperação de } \\
\text { desastre ou plano de recuperação de negócio) }\end{array}$ \\
\hline $\begin{array}{l}\text { Serviço/Bem/Função } \\
\text { crítica: }\end{array}$ & (Preencher com o nome do serviço) \\
\hline Atividade crítica: & (Preencher com o nome da atividade crítica do serviço) \\
\hline
\end{tabular}

\section{[ NOME DO SOP ]}

\section{DESCRIÇÃO SUCINTA}

(Breve descrição do propósito do SOP)

\section{ATORES}

- Ator 1 (Listar de responsáveis pelo serviço, e pela atividade crítica).

- Etc.

\section{PRÉ-CONDIÇÕES}

- Descrição da pré-condição 1 (Preencher com uma lista de condições que devem ser atendidas antes da execução do SOP, como por exemplo, quantas horas de serviço interrompido).

- Descrição da pré-condição 2.

- Etc.

\section{PÓS-CONDIÇÕES}

- Descrição da pós-condição 1 (Página: 1

Preencher com uma lista de condições que devem estar atendidas ao final da execução do SOP, não importando qual cenário foi executado. Informar se há intenção de atingir prevenção de falha; remoção da falha, previsão da falha ou a tolerância a falha).

- Descrição da pós-condição 2.

- Etc.

\section{FLUXO PRINCIPAL}

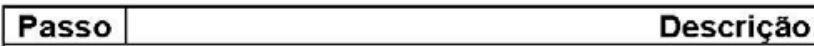

(Preencher com uma lista contendo os passos principais do caso de uso. O fluxo básico de eventos deve abranger o que "normalmente" acontece quando o caso de uso é executado)

\begin{tabular}{|l|l|}
\hline & O responsável informa... (Estilo Fluxo Básico - Tópico) \\
\hline & Descrição deste passo do fluxo. (Estilo: Fluxo Básico - Descrição) \\
\hline & O procedimento apresenta... \\
\hline & Descrição deste passo do fluxo. \\
& O responsável escolhe: \\
& (A 01) - Fluxo Alternativo 1. \\
& (A 03) - Fluxo Alternativo 2 (O 01). \\
Etc.
\end{tabular}

Figura 19: SOP documentado através de caso de uso (1 de 3). 


\section{FLUXOS ALTERNATIVOS}

(A 01) Fluxo Alternativo 1 (Estilo: Fluxo Alternativo - Tópico)

\begin{tabular}{|c|c|}
\hline Passo & \multicolumn{1}{|c|}{ Descrição } \\
\hline $\begin{array}{l}\text { (Preencher com uma lista contendo os fluxos alternativos dentro do procedimento. Um fluxo } \\
\text { alternativo de eventos abrange comportamentos opcionais em relação ao comportamento } \\
\text { normal) }\end{array}$ \\
\hline $\mathbf{1 .}$ & Fluxo Alternativo 1. \\
\hline
\end{tabular}

(A 02) Fluxo Alternativo 2

\begin{tabular}{|c|l|}
\hline Passo & \multicolumn{1}{c|}{ Descrição } \\
\hline $\mathbf{1 .}$ & Fluxo Alternativo 2. \\
\hline 2. & Etc. \\
\hline
\end{tabular}

(A 03) Etc.

\begin{tabular}{|c|lc|}
\hline Passo & \multicolumn{1}{c|}{ Descriçăo } \\
\hline 1. & Etc. & \\
\hline
\end{tabular}

\section{FLUXOS DE EXCEÇÕES}

(E 01) Fluxo de Exceçåo 1

\begin{tabular}{|l|l|}
\hline Passo & Descrição \\
\hline (Preencher com uma lista contendo os fluxos de exceção do procedimento. Um fluxo de \\
exceção abrange comportamentos de exceção (tratamento de erro, tratamento de entrada \\
incorreta dos usuários, tratamento de casos especiais tais como queda de performance, etc.) \\
em relaçăo ao comportamento normal) \\
\hline $\mathbf{1 .}$ & Fluxo de Exceçäo 1 \\
\hline
\end{tabular}

(E 02) Fluxo de Exceção 2

\begin{tabular}{|c|l|}
\hline Passo & \multicolumn{1}{|c|}{ Descriçäo } \\
\hline $\mathbf{1 .}$ & Fluxo de Exceção 2 \\
\hline $\mathbf{2 .}$ & Etc. \\
\hline
\end{tabular}

(E 03) Etc.

\begin{tabular}{|c|c|c|}
\hline Passo & Descrição
\end{tabular}

1. Etc.

\section{ENTRADAS EXTERNAS}

(Inserir arquivos, relatórios, ou qualquer outro trabalho a ser submetido no procedimento)

\section{ATRIBUTOS DA DEPENDABILIDADE}

(Estilo: Normal)

(Inserir informaçóes a respeito de segurança, disponibilidade, confidencialidade, confiabilidade, integridade, resiliéncia ou qualquer outro trabalho a serem avaliados no procedimento)

\section{CENÁRIOS}

(Indicar os cenários dos procedimentos. Em quais casos de risco devem ser executados)

\section{OBSERVAÇÕES}

(0 01) Observação 1 (Relate qualquer observação complementar relevante. Em geral são

\begin{tabular}{|l|l|}
\hline SOP & Página 2 de 3 \\
\hline
\end{tabular}

Figura 19: SOP documentado através de caso de uso (2 de 3). 
criadas novas seções a partir deste ponto para cada um dos assuntos que se deseja aborda)

Descriçăo da Observaçăo 1. (Estilo: Observaçăo - Descriçăo)

(O 02) Observação 2.

Descrição da Observação 2.

\section{REGRAS DE RECUPERAÇÃO}

(RR 01)Regra de Negócio 1. (Indicar o tempo de recuperação do negócio; o ponto de recuperação do negócio (se backward error recovery ou forward error recovery); o tempo de execução do procedimento; o tempo de recuperação do serviço, etc.)

Descrição da Regra de Negócio 1.

(RR 02)Regra de Negócio 2.

Descrição da Regra de Negócio 2.

\section{MENSAGENS}

(M 01) Mensagem 1. (Preencher com todos os informes e mensagens que devem ser preparadas, para quem devem ser enviadas, em quanto tempo devem ser enviadas, etc.)

Descrição da Mensagem 1.

(M 02) Mensagem 2.

Descriçāo da Mensagem 2.

\section{CONTROLE DE VERSÃO}

\begin{tabular}{|c|c|c|c|}
\hline Versão & Data & Descrição da Alteração & Autor \\
\hline & & & \\
\hline & & & \\
\hline & & & \\
\hline
\end{tabular}

Figura 19: SOP documentado através de caso de uso (3 de 3). 
5a. Etapa: testar e avaliar o PCN:

- Apresentar um plano de teste deve ser apresentado aos gestores do PCN e quando permitido, conduzir simulações para avaliar os procedimentos propostos;

- Associar o plano de teste deve a 1 caso de uso ou SOP:

- Descrever no caso de teste tarefas com data de início e término dos procedimentos, e controlar se ocorreram ou não erros durante a recuperação do atributo de Dependabilidade.

A Figura 20 apresenta o template do caso de teste para o PCN incluindo as seguintes especificações:

- Identificação do caso de teste;

- Ambiente do caso de teste, por exemplo, ambiente de produção, ambiente secundário, os hardwares, os softwares e outros elementos que estarão envolvidos;

- Estratégia a ser adotada, se o ambiente de produção vai ser impactado pelo teste ou se somente o ambiente secundário ficará indisponível;

- Equipes envolvidas;

- Tarefas que serão executadas e por quem serão executadas;

- Resultados esperados;

- Tempos das tarefas que devem ser anotados;

- Resultados documentados;

- Atributos da dependabilidade que serão testados;

- Evento não previsto deve ser registrado para futura melhoria nos processos de teste.

A seguir o template do caso de teste: 
CASO DE TESTE DA GCN

\begin{tabular}{|l|l|}
\hline Identificação: & Colocar o nome e número do SOP \\
\hline
\end{tabular}

\begin{tabular}{|l|l|}
\hline $\begin{array}{l}\text { Ambiente de } \\
\text { Teste: }\end{array}$ & $\begin{array}{l}\text { Definir, caso necessário, as configuraçöes de hardware e software necessárias aos } \\
\text { testes }\end{array}$ \\
\hline
\end{tabular}

\begin{tabular}{|l|l|l|}
\hline \multicolumn{2}{|c|}{ Equipe de Testes } \\
\hline Nome & Responsabilidades & Área / Empresa \\
\hline Definir a equipe de teste e suas responsabilidades & & \\
\hline
\end{tabular}

\section{Estratégia de Testes:}

Informar, caso definida, a estratégia de testes a ser seguida - testes caixa branca, testes caixa preta, teste de carga, teste de integraçăo, teste de segurança, teste de validaçăo do sistema, etc.

\section{Plano de Testes}

Escrever as tarefas a serem efetuadas. Ex.: Montar ambiente de testes, executar testes módulo A, testar integraçäo $X \mathrm{c} / \mathrm{Y}$, etc.

\begin{tabular}{|c|c|c|c|c|c|}
\hline \multirow[b]{2}{*}{ Tarefa } & \multirow[b]{2}{*}{ Responsável } & \multicolumn{2}{|c|}{ Previsto } & \multicolumn{2}{|c|}{ Realizado } \\
\hline & & Início & Término & Início & Término \\
\hline & & & & & \\
\hline & & & & & \\
\hline & & & & & \\
\hline 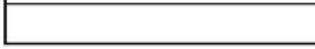 & & & & & \\
\hline
\end{tabular}

\begin{tabular}{|c|c|c|c|}
\hline \multicolumn{3}{|c|}{ Atributo da Dependabilidade } & Identificaçăo do atributo (o mesmo utilizado no SOP) \\
\hline \multirow[t]{3}{*}{ Caso de Teste } & \multirow{2}{*}{\multicolumn{2}{|c|}{$\begin{array}{r}\text { Status: } \\
\text { Descrição: }\end{array}$}} & Ok / Pendente de Teste / Pendente de Correção \\
\hline & & & \begin{tabular}{|l|} 
Página: 1 \\
Descriçăo e/ou objetivo do caso de teste \\
\end{tabular} \\
\hline & \multicolumn{2}{|c|}{ Resposta Esperada: } & $\begin{array}{l}\text { Página: } 1 \\
\text { Resultado esperado com a execução deste caso de teste }\end{array}$ \\
\hline & \multicolumn{3}{|c|}{ Eventos: } \\
\hline & \multirow[t]{3}{*}{$\varnothing$} & Data: & \\
\hline & & Erro: & \\
\hline & & Identificado por: & \\
\hline & \multirow[t]{3}{*}{$\sqrt{ }$} & Data: & \\
\hline & & Correção: & \\
\hline & & Corrigido por: & \\
\hline
\end{tabular}


6a. Etapa: incluir a GCN na cultura da organização:

- Promover a manutenção constante do plano de continuidade de negócios, algumas alterações podem ser incorporadas aos SOP's. Essas alterações podem se originar através das análises dos casos de testes e das evoluções do negócio em si.

A Figura 21 detalha os componentes da diretriz do PCN: o plano de continuidade de negócios possui 2 pacotes bem definidos com um número de objetos que representam os elementos distintos do PCN: BEM e RISCO.

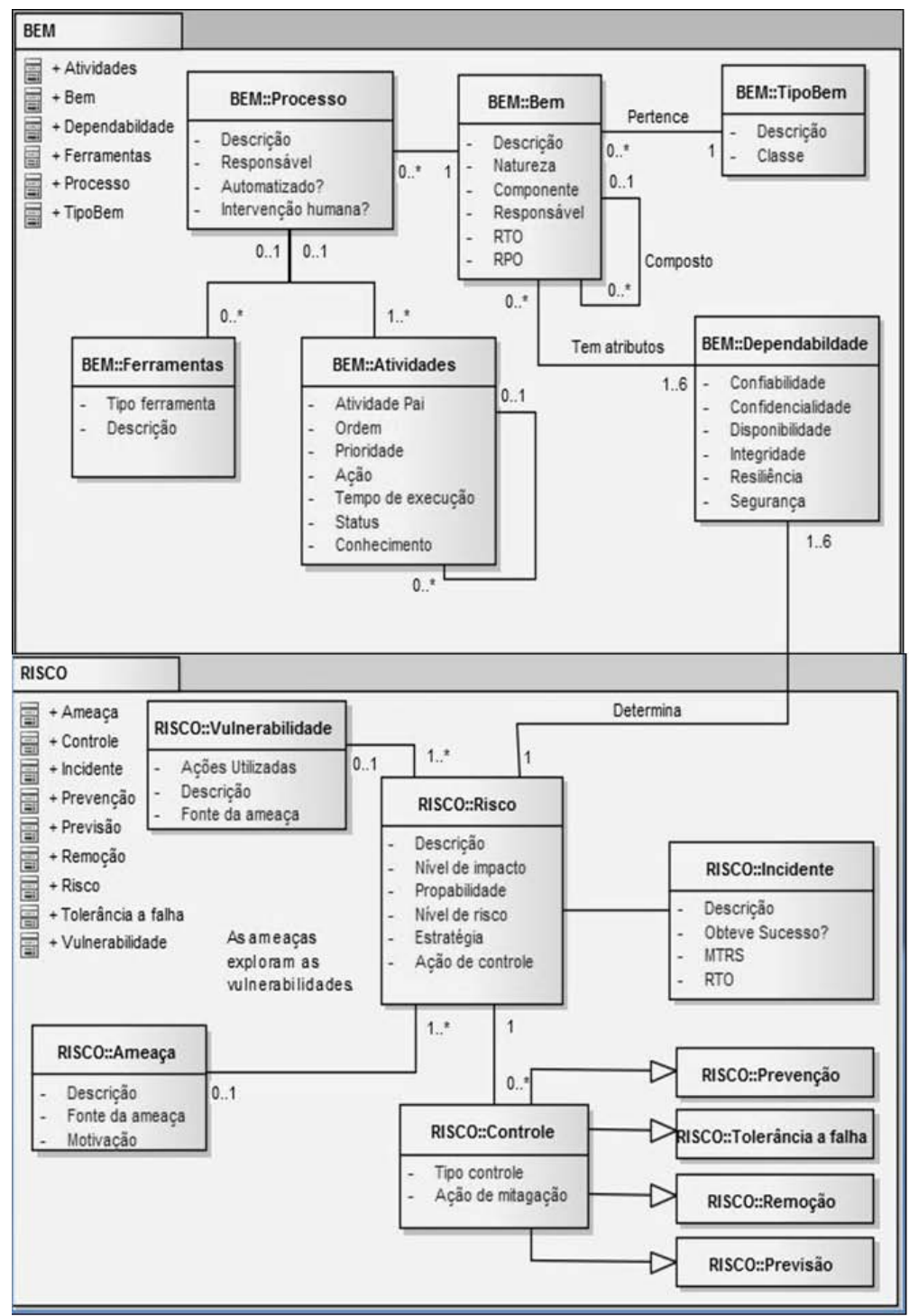

Figura 21: Diagrama de classes da diretriz do PCN.

O primeiro pacote, do BEM, apresenta a classe Bem (ou serviço ou produto) a partir dos atributos de definição tipo do bem, natureza do bem, componentes do bem, pessoas responsáveis, etc.. Um bem poderá ser 
constituído a partir de outros bens (representado pela associação reflexiva ou unária da classe Bem, que ocorre quando há relacionamento entre objeto de uma classe com outros objetos da mesma classe).

O bem ou serviço é entregue a partir da execução de 1 ou $\mathrm{m}$ (muitos) processos. O processo pode ou não possuir ferramentas ou máquinas. $O$ processo possui 1 ou $\mathrm{m}$ (muitos) atividades e tarefas dependentes para sua execução. A dependência (ou seqüência) de tarefas estão representadas pela associação reflexiva (ou unária) da classe Bem:Atividades.

O bem está obrigatoriamente associado a 1 ou m (muitos) atributos da Dependabilidade (confiabilidade, confidencialidade, disponibilidade, integridade, resiliência e segurança).

O segundo pacote, do RISCO, apresenta a classe Risco como uma associação de 1 ou $\mathrm{m}$ (muitos) elementos das classes: Vulnerabilidade, Ameaça e Bem. A ação de controle (atributo do risco) está associada à classe Controle $\mathrm{e}$ as suas classes dependentes que são: Controle:Prevencão; Controle:Tolerância a falha; Controle:Remoção; e Controle:Previsão.

O ciclo de melhoria contínua promove a atualização constante do diagrama de classe através da elaboração de instâncias ou do diagrama de objetos, específicos para cada bem ou serviço da organização. O PDCA é o meio para o controle e avaliação dos objetos e manutenção do PCN.

A seguir, o Capítulo 5 apresenta uma aplicação da metodologia proposta com a utilização dos templates para representar o cenário tecnológico do EPMRT através do serviço de transmissão de aula; um procedimento operacional padrão com abrangência de solução de Disaster Recovery e tipo de controle: remoção de falhas. 


\section{APLICAÇÃO DAS DIRETRIZES DO PROGRAMA DE CONTINUIDADE DE NEGÓCIO AO EPMRT}

A diretriz para construção do Plano de Continuidade de Negócios será aplicada para os processos de negócio de TI do modelo de ensino denominado Sistema Presencial Mediado por Recursos Tecnológicos.

As principais áreas de atividades do EPMRT são: área pedagógica; área de gerência de fornecedores e de contratos; área de infra-estrutura e área de logística.

Os processos da área pedagógica possuem pouca dependência com a área de TI. Utilizam em geral, software aplicativos para manutenção dos alunos na base cadastral da Universidade do Estado do Amazonas ou outros softwares que auxiliam na produção e arte das aulas.

Os processos da área de logística compreendem basicamente a distribuição de material para as salas de aula; a movimentação de pessoal, incluindo professores e coordenadores e a movimentação de equipamentos.

Os processos da área de Fornecedores e Contratos também não dependem exclusivamente da área de $\mathrm{TI}$, pois tratam da aquisição e pagamentos de fornecedores, pessoal interno, etc.. Por outro lado, definem ANS para produtos e serviços o que impacta profundamente na medida da continuidade de negócios.

Os processos da área de Infra-estrutura necessitam exclusivamente da tecnologia para promover suas atividades. Eles incluem desde a produção de aulas e vídeos, até a transmissão de dados, vídeo e áudio, help desk, call center, vídeo conferência, procedimentos de backup das mídias, qualidade de sinal, tempo de retorno, etc..

A Figura 22 apresenta uma visão das áreas do Sistema Presencial Mediado por Recursos Tecnológicos, que inclui: área pedagógica, fornecedores e contratos, infra-estrutura e logística. 


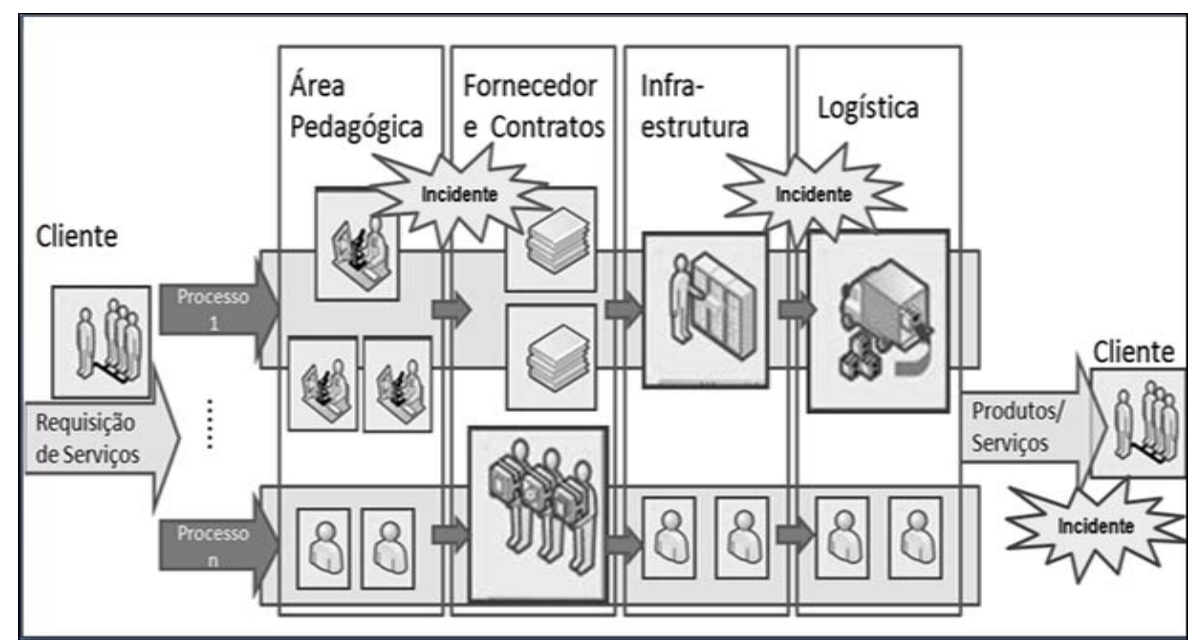

Figura 22: Representação das áreas envolvidas no EPMRT.

\section{A abertura do Plano de Continuidade de Negócios da UEA para o EPMRT} está definida no quadro 12 abaixo:

\begin{tabular}{|c|c|c|c|}
\hline \multicolumn{4}{|c|}{$\begin{array}{l}\text { ABERTURA DO PLANO DE CONTINUIDADE DE NEGÓCIO DA UNIVERSIDADE DO ESTADO DO } \\
\text { AMAZONAS - UEA. }\end{array}$} \\
\hline Processo de negócio & \multicolumn{3}{|c|}{$\begin{array}{l}\text { Apresentação de aulas através do Sistema Presencial Mediado por } \\
\text { Recursos Tecnológicos. }\end{array}$} \\
\hline Responsáveis & \multicolumn{3}{|c|}{$\begin{array}{l}\text { Pró-reitor de graduação; } \\
\text { Pró-reitor de administração; } \\
\text { Coordenador geral de projetos (responsável pela definição de abrangência) } \\
\text { Coordenador de Tecnologia; } \\
\text { Coordenador Pedagógico. }\end{array}$} \\
\hline Objetivo & \multicolumn{3}{|c|}{$\begin{array}{l}\text { Prover em nome da Universidade do Estado do Amazonas - UEA um plano } \\
\text { eficiente que quando executado permita a recuperação das operações } \\
\text { interrompidas de apresentação de aulas através do EPMRT; } \\
\text { Assegurar a continuidade de negócios caso exista uma situação de } \\
\text { desastre; } \\
\text { Minimizar os inconvenientes e as potenciais interrupções das aulas para os } \\
\text { alunos; } \\
\text { Prevenir que a UEA tenha impactos operacionais que prejudique sua } \\
\text { imagem diante da sociedade. }\end{array}$} \\
\hline Premissas & \multicolumn{3}{|c|}{$\begin{array}{l}\text { Conscientização da equipe técnica e pedagógica do método da GCN; } \\
\text { Disponibilização de pessoal qualificado envolvido na execução do plano } \\
\text { para a recuperação da infra-estrutura tecnológica. }\end{array}$} \\
\hline \multirow{4}{*}{ Abrangência } & Plano para gestão do risco & & $\begin{array}{l}\text { Problemas até } 30 \text { minutos de } \\
\text { interrupção; }\end{array}$ \\
\hline & Plano emergencial de crise & $E$ & $\begin{array}{l}\text { A partir de } 30 \text { minutos de serviços } \\
\text { interrompidos. }\end{array}$ \\
\hline & Plano de disaster recovery & $E / D$ & $\begin{array}{l}\text { A partir de } 60 \text { minutos de serviços } \\
\text { interrompidos e até uma hora } \\
\text { depois. (três horas de serviços } \\
\text { interrompidos). }\end{array}$ \\
\hline & $\begin{array}{l}\text { Plano de recuperação do } \\
\text { negócio }\end{array}$ & $\mathrm{D}$ & $\begin{array}{l}\text { Até cinco horas da interrupção dos } \\
\text { serviços. }\end{array}$ \\
\hline
\end{tabular}

Quadro 12: Abertura do PCN para o EPMRT. 
O quadro 13 apresenta um exemplo da aplicação do questionário para o serviço de negócio: transmissão da aula para o EPMRT, que envolve a geração da aula no estúdio de TV em Manaus e a transmissão até a central na cidade de São Paulo.

\begin{tabular}{|c|c|}
\hline $\begin{array}{l}\text { Descrição do serviço ou } \\
\text { bem }\end{array}$ & Sessão de vídeo conferência para plataforma de ensino a distância. \\
\hline Componente & Transmissão de aulas pelo IP.TV para o EPMRT. \\
\hline Hardware & $\begin{array}{l}\text { Estação VSat local Manaus; } \\
\text { Estação central de rede satelital (em São Paulo); } \\
\text { HUB Central distribui para VSATs em cada município. }\end{array}$ \\
\hline Software & Ferramenta de vídeo conferência multiponto IP.TV. \\
\hline \multicolumn{2}{|l|}{ DEPENDÊNCIAS } \\
\hline Rede de comunicação. & Rede satelital, \\
\hline Rede elétrica & Gerador de energia \\
\hline Periféricos & Microcomputadores, Impressora laser, gravador de DVD \\
\hline SGBD & Banco de dados MySQL \\
\hline Servidores WEB & Apache TomCat \\
\hline Servidores de aplicação & Servidor de TV Digital / JBoss \\
\hline Sistemas legados & Não possui \\
\hline Sistemas externos & Não possui \\
\hline $\begin{array}{lll}\begin{array}{l}\text { Outras } \\
\text { sistema }\end{array} & \text { funções } & \text { do } \\
\end{array}$ & Não possui \\
\hline Interfaces & VOIP como plataforma de comunicação com os municípios rede VSAT \\
\hline Dados e informações & Dados, voz e vídeo. Utilizados para ministrar as aulas através do IP.TV. \\
\hline Pessoas & $\begin{array}{l}\text { Equipe de edição e finalização; } \\
\text { Equipe de coordenação do curso; } \\
\text { Equipe de produção. }\end{array}$ \\
\hline Missão do sistema & Transmissão de aula via internet banda larga, VoIP, para vários municípios. \\
\hline
\end{tabular}

Quadro 13: Descrição das atividades críticas (1 de 3). 


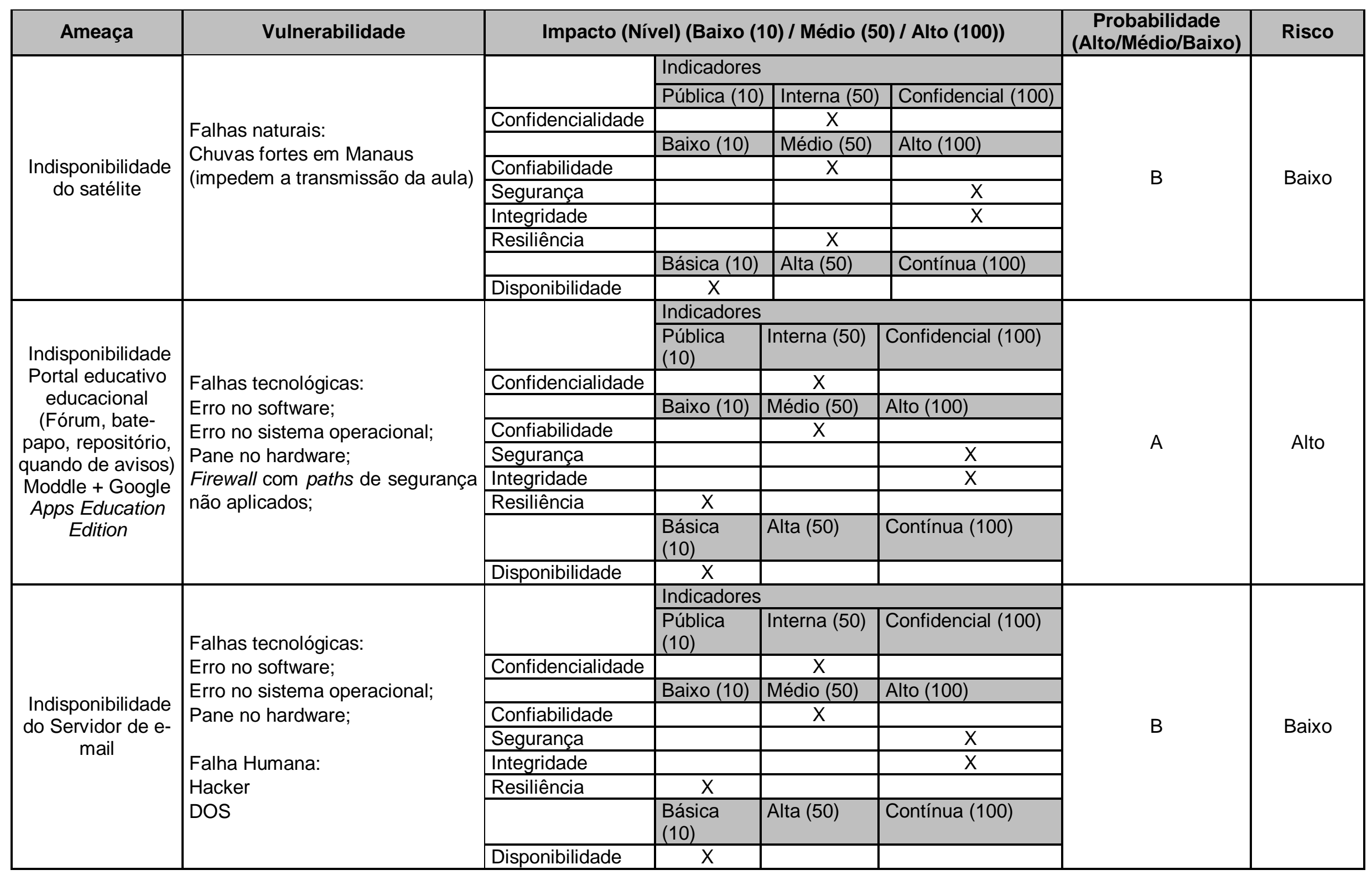

Quadro 13: Descrição das atividades críticas (2 de 3). 


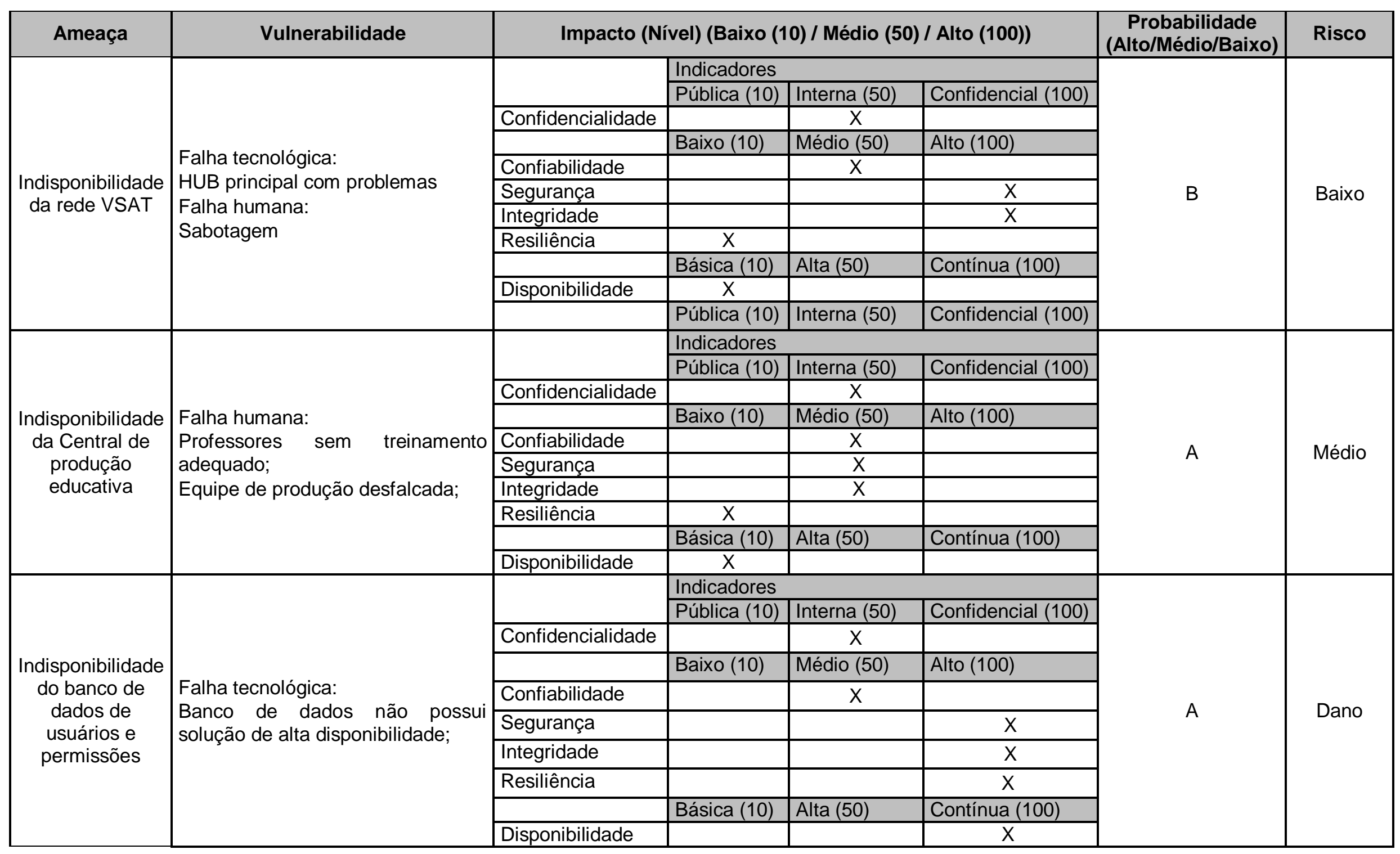

Quadro 13: Descrição das atividades críticas (3 de 3). 
O quadro acima apresenta, entre outras informações, o detalhamento das vulnerabilidades que podem provocar a indisponibilidade da atividade de transmissão da aula pelo IP.TV para o EPMRT.

Uma das vulnerabilidades, por exemplo, é de natureza tecnológica: 'banco de dados não possui solução de alta disponibilidade' e sua análise de impacto, segundo os atributos da Dependabilidade, possui indicador ALTO para 4 dos 6 possíveis. Isso porque, o banco de dados atual, que é utilizado para armazenar os usuários e os privilégios de acesso para técnicos, professores e alunos, não dispõe de mecanismos de alta disponibilidade como, por exemplo, solução do software e/ou hardware que assegure a continuidade dos serviços em outro equipamento, sem a perda do serviço e ou informações.

O cálculo dos pontos atribuídos para o impacto sobre a Dependabilidade foi realizado segundo a fórmula abaixo:

Pontos do impacto = média aritmética (atributos da
Dependabilidade) * probabilidade do evento.

Segundo os indicadores apresentados no quadro 13, para a indisponibilidade de banco de dados o impacto totaliza 83,333 pontos. O calculo dos valores são apresentados abaixo:

Pontos $=(50+50+100+100+100+100) / 6 * 1=$
Pontos $=83,33333$

O nível do risco corresponde ao critério DANO para valores maiores que 80.

A partir das análises semelhantes para obtenção do nível do risco para o serviço: Sessão de vídeo conferência para plataforma de ensino a distância, outras medidas de controle são escolhidas, de acordo com as categorias: prevenção, previsão, remoção ou tolerância à falha.

A Figura 23 apresenta uma visão segmentada do diagrama de casos de uso, contendo tão somente a função crítica que deverá ser desenvolvida para atender ao plano de recuperação do banco de dados corporativo. O SOP e os atores envolvidos na estratégia de solução estão representados pelos elementos da UML: 


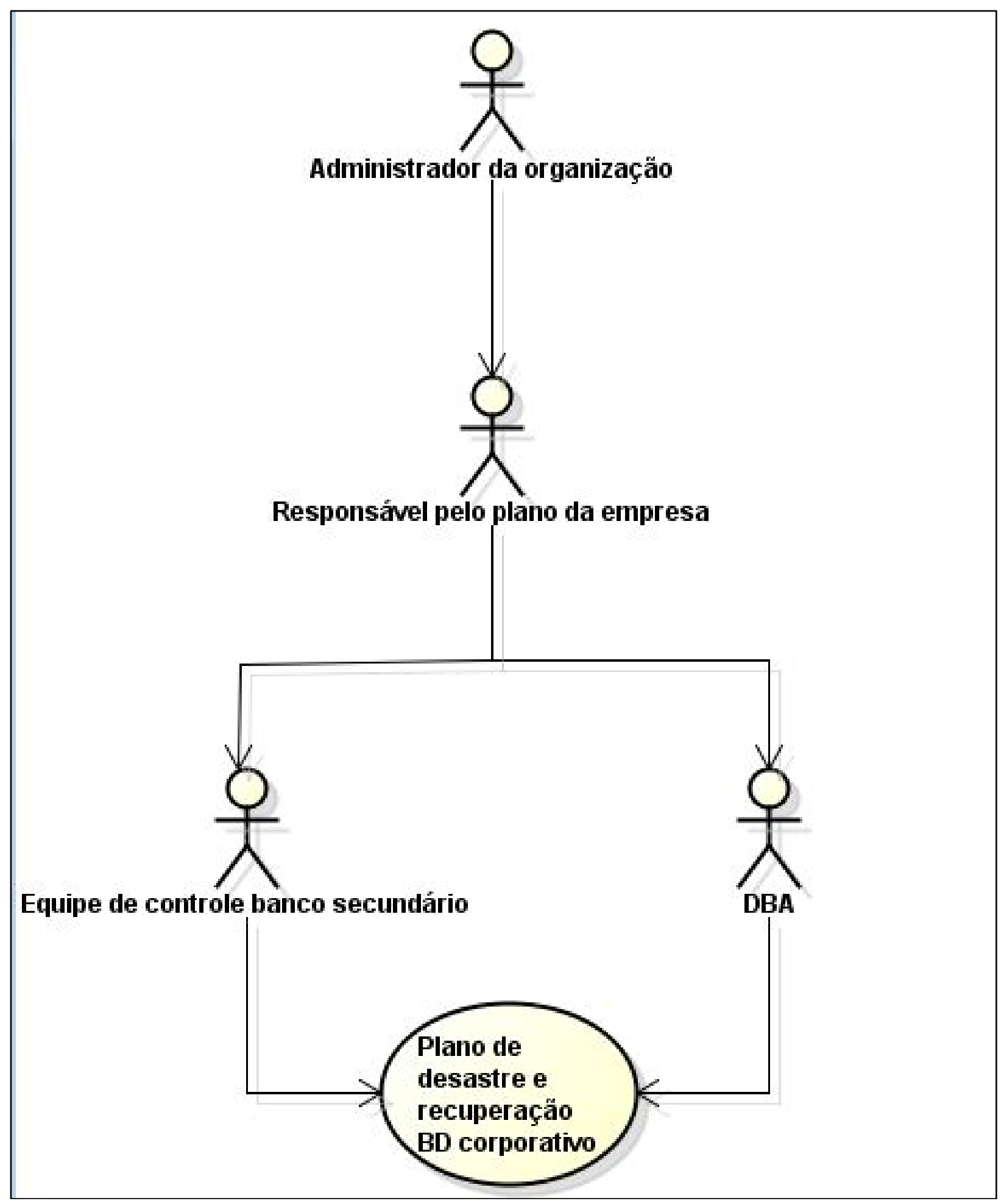

Figura 23: Diagrama de caso de uso da atividade crítica - Executar failover para o banco de dados secundário.

A seguir, a Figura 24 apresenta a relação entre os componentes da GCN por meio de uma instância do diagrama de componentes, específica do caso de uso Plano de desastre e recuperação BD corporativo. 


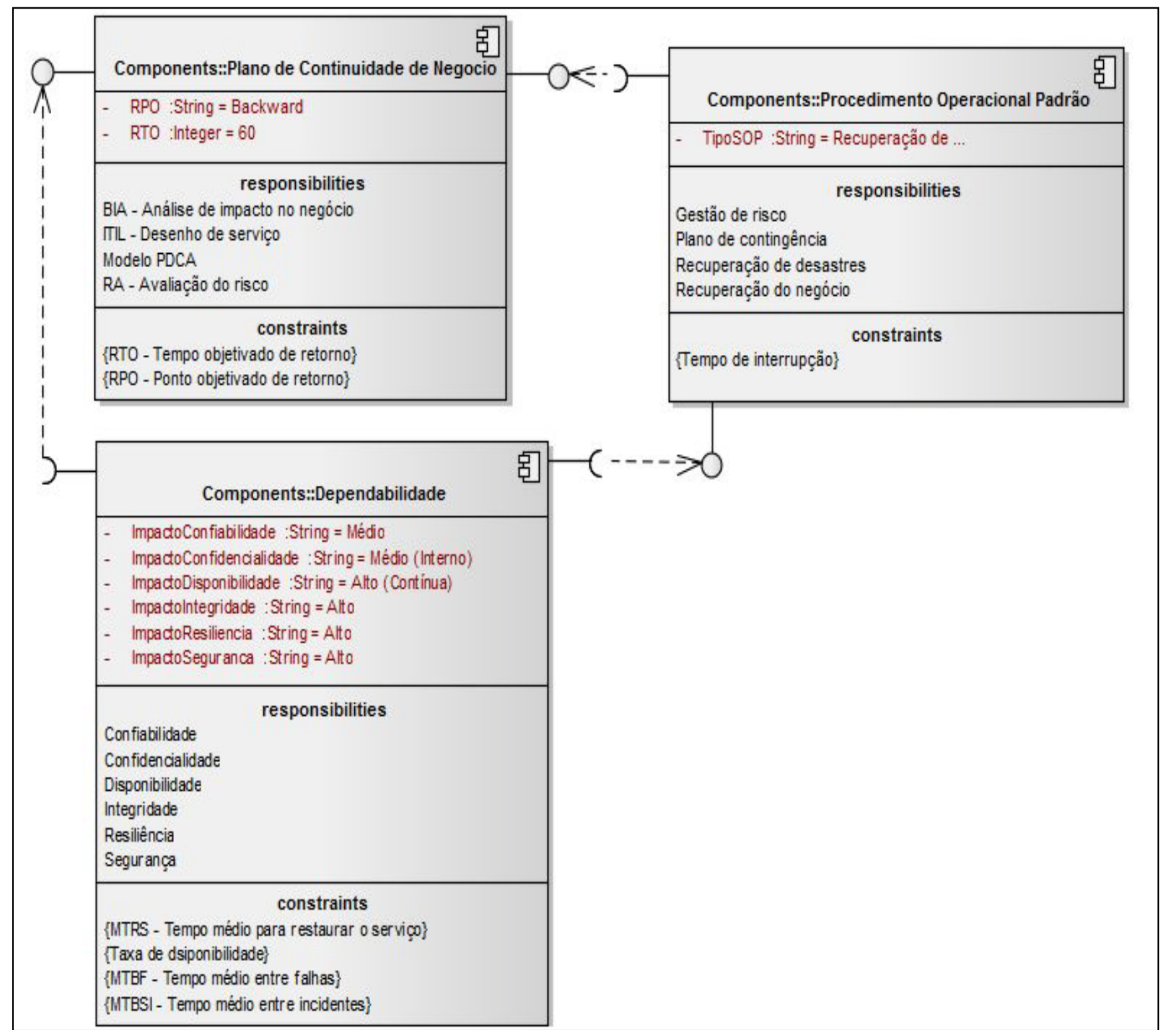

Figura 24: Instância do diagrama de componentes para o caso de uso Plano de desastre e recuperação BD corporativo.

A descrição do procedimento operacional padrão (SOP) com abrangência para solução de Disaster Recovery é apresentada por meio do caso de uso abaixo, na Figura 25

Este SOP, chamado PLANO DE DESASTRE E RECUPERAÇAO BD CORPORATIVO, tem o objetivo de ativar o banco de dados secundário que está geograficamente distante do estúdio de transmissão de aula, no caso de incidentes no banco de dados principal. 


\begin{tabular}{|l|l|}
\hline Cliente: & Universidade do Estado do Amazonas - UEA \\
\hline Projeto: & Sistema presencial mediado por recursos tecnológicos - AVA \\
\hline Objetivo: & Plano de Desastre e Recuperação (Disaster Recovery) \\
\hline $\begin{array}{l}\text { Serviço/Bem/Funçäo } \\
\text { crítica: }\end{array}$ & Banco de dados corporativo \\
\hline Atividade crítica: & Executar Failover para o Banco de Dados Secundário \\
\hline
\end{tabular}

\section{PLANO DE DESASTRE E RECUPERAÇÃO BD CORPORATIVO}

\section{DESCRIÇÃO SUCINTA}

Ativar o banco de dados secundário, que está instalado em local geograficamente distante do banco de dados principal. Esta ativaçăo permitirá que as atividades da organizaçăo e a entrega de serviços voltem a normalidade após desastre, seja natural, falha tecnológica, ou sabotagem do nó principal.

\section{ATORES}

- Responsável do Plano de Emerge̊ncia

- Suporte de Banco de Dados (DBA)

- Administrador da organizaçăo, Diretor, Vice-Presidente, Presidente

- Equipe que controla o banco de dados secundária na localização do mesmo.

\section{PRÉ-CONDIÇÕES}

- Plano de emergência ativo e em execução

- Equipamento secundário ativo e operante.

- Banco de dados secundário deve estar sincronizado com o principal.

\section{PÓS-CONDIÇÕES}

- Executar SOP de serviços de diretório nó secundário.

- Executar SOP de servidores de aplicaçăo no nó secundário

- Executar SOP de servidores web no nó secundário

- Executar SOP de emergência de movimentaçăo da lista de pessoas em emergência para o no secundário para operacionalização dos serviços.

Este SOP removeu a falha e irá operar no modo secundário até o site primário voltar a sua operação normal, momento que devera ser realizado um switch over para o nó principal.

- Executar SOP de recuperação do negócio

Este SOP removeu a falha e irá operar no modo secundário até o site primário voltar a sua operaçăo normal, momento que devera ser realizado um switch over para o nó principal.

\section{FLUXO PRINCIPAL}

\begin{tabular}{|c|l|}
\hline Passo & \multicolumn{1}{|c|}{ Descrição } \\
\hline Passos para execução do FAIL OVER \\
\hline 1 & $\begin{array}{l}\text { Após a ocorrência do desastre a equipe de emergência entra em ação e ativa o DBA para realizar } \\
\text { o procedimento de FAILOVER }\end{array}$ \\
\hline 2 & O DBA é deslocado para o local onde está instalado o Banco de Dados secundário \\
\hline 3 & O DBA verifica o estado do Banco Secundário. \\
\hline 4 & $\begin{array}{l}\text { O responsável escolhe: } \\
\text { (A 01) - Fluxo Alternativo 1 - Banco sincronizado } \\
\text { (A 02) - Fluxo Alternativo 2 - Banco não sincronizado }\end{array}$ \\
\hline 5 & Liberação do Banco e finalização do SOP \\
\hline
\end{tabular}

Figura 25: SOP - Plano de desastre e recuperação do banco de dados corporativo. (1 de 2). 


\section{FLUXOS ALTERNATIVOS}

(A 01) Fluxo Alternativo 1 (Estilo: Fluxo Alternativo - Tópico)

\begin{tabular}{|c|l|}
\hline Passo & \multicolumn{1}{|c|}{ Descriçäo } \\
\hline Banco esta sincronizado ativar o FAILOVER \\
\hline $\mathbf{1 .}$ & Conectar-se diretamente no equipamento secundário localizado na sala de continge̊ncia. \\
\hline $\mathbf{2 .}$ & Utilizar o usuário oracle e senha \\
\hline $\mathbf{3 .}$ & conectar-se ao Data Guard Broker utilizado o comando dgmgrl. \\
\hline $\mathbf{4}$. & $\begin{array}{l}\text { Execute o FAILOVER } \\
\text { Sintaxe: } \\
\text { FAILOVER TO <standby database name> [IMMEDIATE]; }\end{array}$ \\
\hline $\mathbf{5 .}$ & Exibir (M01) \\
\hline
\end{tabular}

(A 02) Fluxo Alternativo 2

\begin{tabular}{|c|l|}
\hline Passo & \multicolumn{1}{|c|}{ Descrição } \\
\hline 1. & Näo há possibilidade de executar FAlLOVER banco não sincronizado \\
\hline 2. & Ativar o Plano de Recuperaçăo a partir de Backup em Fita em novo servidor. \\
\hline 3. & Exibir (MO2) \\
\hline
\end{tabular}

\section{ENTRADAS EXTERNAS}

Năo há

\section{ATRIBUTOS DA DEPENDABILIDADE}

Ocorreu um desastre no site primário a Disponibilidade, Integridade, Resiliência, e Segurança dos dados foram severamente impactadas, a confidencialidade e a confiabilidade tiveram um impacto menor.

\section{CENÁRIOS}

Deverá ser ativado o Plano de Desastre e Recuperação.

\section{REGRAS DE RECUPERAÇÃo}

(RR 01) O tempo objetivado de recuperação (RTO) é de 60 minutos.

(RR 02) O ponto objetivado de recuperaçăo (RPO), do tipo backward, é o da última transaçăo realizada com sucesso no banco principal.

(RR 03)Caso não seja possível ativar o banco secundário ativar o SOP de Recuperação de backup em novo equipamento imediatamente. Comunicar equipe de emergência desta mudança pois o RTO não será atingido. O ponto de recuperaçăo será o do ultimo backup.

\section{MENSAGENS}

(M 01) Mensagem 1. Banco secundário ativado com sucesso dentro do RTO..

(M 02) Mensagem 2. anco secundário não sincronizado O RTO não será atingido ativar SOP de recuperação em novo equipamento

CONTROLE DE VERSÃO

\begin{tabular}{|l|c|c|c|}
\hline Versăo & Data & Descrição da Alteraçáo & Autor \\
\hline 1.0 & $01 / 06 / 2011$ & Criação do Documento & DBA \\
\hline & & & \\
\hline & & & \\
\hline
\end{tabular}

Figura 25: SOP - Plano de desastre e recuperação do banco de dados corporativo. (2 de 2). 
O caso de uso apresenta o passo a passo para um procedimento de REMOÇÃO DA FALHA. Isto porque o usuário do sistema percebe a indisponibilidade do serviço no período de tempo em que o banco de dados secundário é inicializado para trabalhar como banco de dados primário.

Neste período de mudança do banco de dados corporativo o processo tecnológico de transmissão de aula pelo IP.TV fica indisponível, bem como o serviço de sessão de vídeo conferência para o EPMRT.

Para este SOP 'Plano de desastre e recuperação de BD corporativo' foi elaborado um plano de teste correspondente para avaliar a solução.

Este plano de teste, descrito na Figura 26, denominado CST_SOP_PLANO_DE_DESASTRE_E_RECUPERAÇÃO_BD_CORPORATIVO, apresenta o ambiente de testes como sendo o próprio ambiente de produção e também o ambiente secundário. Como se trata de um teste real o ambiente de produção estará indisponível, portanto, foi determinando uma data estratégica para sua realização de forma a não impactar a organização.

Todas as pessoas envolvidas no teste estão definidas bem como suas responsabilidades.

As tarefas estão claramente definidas com os tempos previstos de inicio e fim de maneira a documentar a realização do teste com os tempos reais.

O caso de testes alcança todos os atributos da Dependabilidade envolvidos na atividade crítica do SOP, descrevendo o comportamento da solução para restabelecer os serviços no nível indicado de cada operação.

O teste será considerado com sucesso se apresentar o resultado esperado definido no caso de teste.

Quaisquer acontecimentos ou eventos não previstos devem ser documentados e encaminhados para e equipe de melhoria continua.

Este caso de teste preenchido e assinado é prova documental para processos de auditoria, comuns e rotineiros nas grandes organizações. 
CASO DE TESTE DA GCN

Identificação: $\quad$ CST_SOP_PLANO_DE_DESASTRE_E_RECUPERAÇÃO_BD_CORPORATIVO

\begin{tabular}{|l|l|}
\hline $\begin{array}{l}\text { Ambiente de } \\
\text { Teste: }\end{array}$ & $\begin{array}{l}\text { Este tipo de teste deverá ser realizado periodicamente nos ambientes reais de } \\
\text { produção e ambiente secundário, para garantir que o mesmo esteja de acordo com } \\
\text { O ANS. }\end{array}$ \\
& $\begin{array}{l}\text { O ambiente de produçăo esta no data center do estúdio de televisăo, sito à Rua } \\
\text { Acre, 234, Manaus, AM. } \\
\text { O ambiente de produção esta localizado no data center da UEA, sito à Leonardo } \\
\text { Malcher, prédio Samuel Benchimol, Manaus, AM. }\end{array}$ \\
\hline
\end{tabular}

\begin{tabular}{|l|l|l|}
\hline \multicolumn{3}{|c|}{ Equipe de Testes } \\
\hline Nome & \multicolumn{1}{|c|}{ Responsabilidades } & Área / Empresa \\
\hline Coordenador do serviço & Registrar o teste e validar o ambiente. & TI \\
\hline Diretor de TI & $\begin{array}{l}\text { Facilitar o teste, disponibilizando todos os meios } \\
\text { necessários (recursos humanos e técnicos) }\end{array}$ & TI \\
\hline Gerente de Suporte & $\begin{array}{l}\text { Coordenar a execuçăo dos procedimentos } \\
\text { operacionais padrăo do teste. }\end{array}$ & SUPORTE \\
\hline Administrador de banco de dados & $\begin{array}{l}\text { Executar o SOP } \\
\text { PLANO_DE_DESASTRE_E_RECUPERAÇÃO__ } \\
\text { BD_CORPORATIVO }\end{array}$ & BD \\
\hline
\end{tabular}

\section{Estratégia de Testes:}

1. Definir junto aos usuários do sistema uma data para ser executado o failover entre os sites primário e secundário.

2. Executar o passo a passo das tarefas e verificar o atendimento do SOP de Desastre e Recuperação

\begin{tabular}{|c|c|c|c|c|c|}
\hline \multicolumn{6}{|c|}{ Plano de Testes } \\
\hline \multirow[b]{2}{*}{ Tarefa } & \multirow[b]{2}{*}{ Responsável } & \multicolumn{2}{|c|}{ Previsto } & \multicolumn{2}{|c|}{ Realizado } \\
\hline & & Início & Término & Início & Término \\
\hline $\begin{array}{l}\text { 1. Realizar verificaçăo dos bancos de dados, } \\
\text { primário e secundário para constatar se os } \\
\text { mesmos encontram-se sincronizados. }\end{array}$ & DBA & \begin{tabular}{|l|} 
Domingo \\
05/06/2011 \\
$07: 00 \mathrm{~h}$ \\
\end{tabular} & \begin{tabular}{|l|} 
Domingo \\
$05 / 06 / 2011$ \\
$07: 15 \mathrm{~h}$ \\
\end{tabular} & & \\
\hline $\begin{array}{l}\text { 2. Desligar os cabos de comunicação entre os } \\
\text { servidores primário e secundário. }\end{array}$ & DBA & \begin{tabular}{|l|} 
Domingo \\
05/06/2011 \\
$07: 15 \mathrm{~h}$ \\
\end{tabular} & \begin{tabular}{|l|} 
Domingo \\
05/06/2011 \\
$07: 30 \mathrm{~h}$ \\
\end{tabular} & & \\
\hline $\begin{array}{l}\text { 3. Identificar a ocorrência do incidente e seu } \\
\text { devido registro }\end{array}$ & $\begin{array}{l}\text { Coordenador } \\
\text { do serviço }\end{array}$ & \begin{tabular}{|l|} 
Domingo \\
05/06/2011 \\
$07: 30 \mathrm{~h}$ \\
\end{tabular} & \begin{tabular}{|l|} 
Domingo \\
05/06/2011 \\
07:40h \\
\end{tabular} & & \\
\hline $\begin{array}{l}\text { 4. Constatado o incidente executar os } \\
\text { procedimentos conforme SOP de Desastre e } \\
\text { Recuperaçăo. Registrar todos os passos. }\end{array}$ & DBA & \begin{tabular}{|l|} 
Domingo \\
05/06/2011 \\
$07: 40 \mathrm{~h}$ \\
\end{tabular} & \begin{tabular}{|l|} 
Domingo \\
05/06/2011 \\
$08: 40 \mathrm{~h}$ \\
\end{tabular} & & \\
\hline $\begin{array}{l}\text { 5. Registrar o retorno do serviço no banco de } \\
\text { dados secundário (agora primário). }\end{array}$ & $\begin{array}{l}\text { Coordenador } \\
\text { do serviço }\end{array}$ & \begin{tabular}{|l|} 
Domingo \\
05/06/2011 \\
08:40h
\end{tabular} & \begin{tabular}{|l|} 
Domingo \\
05/06/2011 \\
09:00h
\end{tabular} & & \\
\hline
\end{tabular}

Controle de Teste de GCN Página 1 de 2

Figura 26: Caso de teste do SOP - Plano de desastre e recuperação do banco de dados corporativo. (1 de 2). 


\begin{tabular}{|c|c|c|c|}
\hline $\begin{array}{l}\text { 6. Executar o retorno para o banco de dados } \\
\text { original. Ou seja executar o SOP novamente, } \\
\text { agora em sentido contrário de forma e } \\
\text { restaurar a produção no localização original. }\end{array}$ & DBA & $\begin{array}{l}\text { Domingo } \\
\text { 05/06/2011 } \\
09: 00 \mathrm{~h}\end{array}$ & $\begin{array}{l}\text { Domingo } \\
\text { 05/06/2011 } \\
10: 00 \mathrm{~h} \\
\end{array}$ \\
\hline
\end{tabular}

\begin{tabular}{|c|c|c|c|}
\hline \multicolumn{3}{|c|}{ Atributo da Dependabilidade } & Disponibilidade \\
\hline \multirow{3}{*}{ Caso de Teste } & \multirow{2}{*}{\multicolumn{2}{|c|}{$\begin{array}{r}\text { Status: } \\
\text { Descricáo: }\end{array}$}} & Ok \\
\hline & & & Execução do SOP de Desastre e Recuperação \\
\hline & \multicolumn{2}{|c|}{ Resposta Esperada: } & Após o FAILOVER o sistema estar disponivel \\
\hline & \multicolumn{3}{|c|}{ Eventos: } \\
\hline & \multirow[t]{3}{*}{$\varnothing$} & Data: & \\
\hline & & Erro: & \\
\hline & & Identificado por: & \\
\hline & \multirow[t]{3}{*}{$\sqrt{ }$} & Data: & \\
\hline & & Correção: & \\
\hline & & Corrigido por: & \\
\hline
\end{tabular}

\begin{tabular}{|c|c|c|c|}
\hline \multicolumn{3}{|c|}{ Atributo da Dependabilidade } & Confiabilidade \\
\hline \multirow[t]{3}{*}{ Caso de Teste } & \multirow{2}{*}{\multicolumn{2}{|c|}{$\begin{aligned} \text { Status: } \\
\text { Descriçäo: }\end{aligned}$}} & Ok \\
\hline & & & Execuçăo do SOP de Desastre e Recuperação \\
\hline & \multicolumn{2}{|r|}{ Resposta Esperada: } & $\begin{array}{l}\text { Após o FAILOVER o sistema estar disponivel para } \\
\text { autenticação dos usuários e seus privilégios. }\end{array}$ \\
\hline & \multicolumn{3}{|c|}{ Eventos: } \\
\hline & \multirow[t]{3}{*}{$\varnothing$} & Data: & \\
\hline & & Erro: & \\
\hline & & Identificado por: & \\
\hline & \multirow[t]{3}{*}{$\sqrt{ }$} & Data: & \\
\hline & & Correçäo: & \\
\hline & & Corrigido por: & \\
\hline
\end{tabular}

\begin{tabular}{|c|c|c|c|}
\hline \multicolumn{3}{|c|}{ Atributo da Dependabilidade } & Integridade \\
\hline \multirow[t]{3}{*}{ Caso de Teste } & \multirow{2}{*}{\multicolumn{2}{|c|}{$\begin{array}{r}\text { Status: } \\
\text { Descriçăo: }\end{array}$}} & Ok \\
\hline & & & Execução do SOP de Desastre e Recuperação \\
\hline & \multicolumn{2}{|c|}{ Resposta Esperada: } & Após o FAILOVER o sistema deverá ter os dados íntegros. \\
\hline & \multicolumn{3}{|c|}{ Eventos: } \\
\hline & \multirow[t]{3}{*}{$\varnothing$} & Data: & \\
\hline & & Erro: & \\
\hline & & Identificado por: & \\
\hline & \multirow[t]{3}{*}{$\sqrt{ }$} & Data: & \\
\hline & & Correção: & \\
\hline & & Corrigido por: & \\
\hline
\end{tabular}

Figura 26: Caso de teste do SOP - Plano de desastre e recuperação do banco de dados corporativo. (2 de 2). 
A Figura 27 estabelece o diagrama de objetos para o processo de TI: transmissão de aula pelo IP.TV para o EPMRT (primeira tarefa do ciclo de melhoria contínua do PDCA), disponibilizando através dessa instância todos os elementos necessários para o controle desse serviço (segunda tarefa do ciclo de melhoria contínua do PDCA).

Esta instância será monitorada e analisada pelo caso de uso e plano de teste correspondente e atualizada se necessário, pela avaliação do processo de negócio e pelos resultados apresentados ao usuário do serviço (terceira e quarta tarefas do ciclo de melhoria contínua do PDCA).

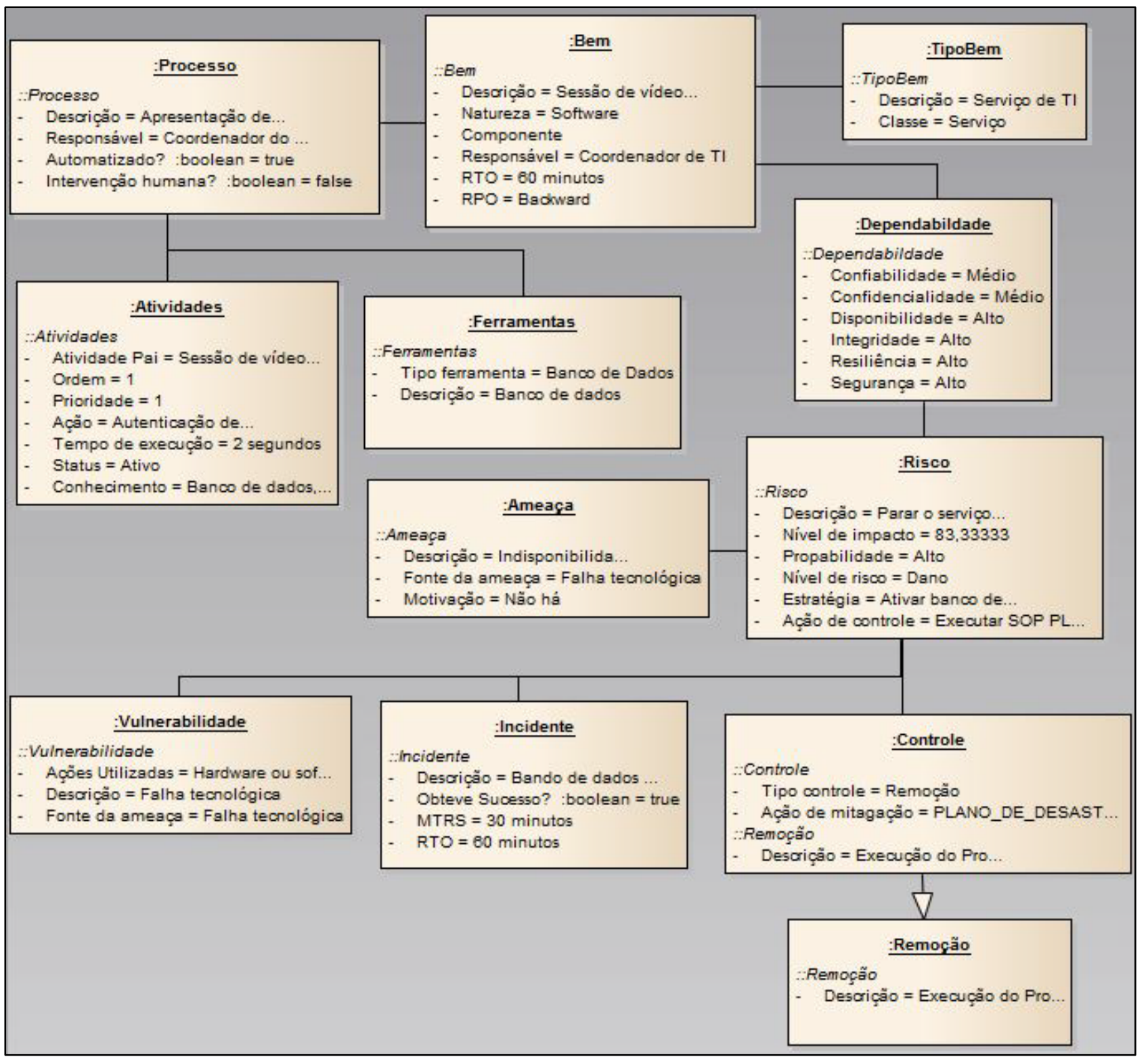

Figura 27 - Diagrama de objetos do serviço transmissão de aula pelo IP.TV para o EPMRT. 
A classe Bem apresenta o atributo 'Descrição' com o valor: sessão de vídeo conferência para plataforma de ensino a distância.

A classe Risco apresenta o atributo 'Descrição' com o valor: parar o serviço de transmissão de aula; o atributo 'Estratégia' possui valor: ativar banco de dados stand by.

O atributo 'Ação de controle' possui valor: executar SOP_Plano_Desastre_Recuperação_BD_Corporativo.

A classe Controle também apresenta os valores de atributos reduzidos pelo espaço. 'Ação de mitigação' e 'Descrição (Remoção)' são respectivamente: SOP_Plano_Desastre_Recuperação_BD_Corporativo e Execução do Procedimento SOP_Plano_Desastre_Recuperação_BD_Corporativo.

A classe Processo apresenta o atributo 'Descrição' com o valor: Apresentação de aulas através do EPMRT. O atributo 'Responsável' possui valor: Coordenador do serviço.

A classe Atividades apresenta o atributo 'Atividade Pai' com o valor: Sessão de vídeo conferência; os atributos 'Ação' e 'Conhecimento' possuem valores respectivamente: Autenticação dos usuários e privilégios de acesso; e BD, usuários, privilégios e Administração.

A classe Vulnerabilidade apresenta o atributo 'Ações utilizadas' com o valor: Hardware ou software falharam.

A classe Ameaça apresenta o atributo 'Descrição' com o valor: não disponibilidade do BD corporativo.

Os demais atributos são definidos através das análises das tabelas apresentadas anteriormente, ou através dos ANS previstos para o EPMRT. 


\section{CONTRIBUIÇÕES}

Este capítulo apresenta as contribuições deste trabalho a partir do modelo de aplicação da GCN que adapta técnicas de especificação formal das Normas ABNT NBR 15999-1 e 15999-2 com princípios de projeto, como a UML e ITIL $®$, de maneira a torná-la mais fácil de aplicar, implementar e adaptar, melhorando sua precisão e capacidade de utilização.

\subsection{Considerações finais}

A grande dificuldade na aplicação da Gestão de Continuidade de Negócios estava na forma de documentar os serviços e as atividades da empresa, bem como na forma de documentar o Plano de Continuidade de Negócio. Todos os autores estudados não apresentavam uma sequencia de informação completa e ampla o suficiente que permitisse visualizar todas as fases da GCN. Os documentos apresentados eram relatórios com campos de dados contendo informações e requisitos de alto nível, sem detalhar e demonstrar todas as interligações existentes, inerentes de um processo complexo como o da tecnologia da informação.

A adaptação de ferramentas já conhecidas pela comunidade de tecnologia da informação como: UML, casos de uso, casos de teste, ITIL $®$, Dependabilidade, PDCA, entre outros artefatos da engenharia de sistema, facilitou a aplicação da Gestão de Continuidade de Negócios, implementando um processo documentado, de acordo com as recomendações das Normas Técnicas 15999-1 e 15999-2.

Cada fase da GCN apresentou um conjunto de artefatos para expressar as informações resultantes e evoluiu o modelo de relatórios apresentado pelos autores estudados neste trabalho, o que foi determinante para o sucesso deste trabalho

O objetivo era fornecer múltiplas visões da aplicação da GCN na área de TI do Ensino Presencial Mediado por Recursos Tecnológicos (EPMRT), permitindo o levantamento da necessidade, o detalhamento do negócio, a análise das soluções de continuidade de negócio, a modelagem da solução escolhida, o teste da solução, o controle e a evolução do modelo. 
Entretanto, ao alcançar este objetivo, em um caso particular, observou-se que as informações oferecidas por meio dos artefatos gerados, permitem aplicar as diretrizes de construção do Plano de Continuidade de Negócio para a documentação da GCN na área de TI em outros casos, em outras empresas e organizações, não somente da área educacional, mas em qualquer área de negócio. Primeiro porque a equipe envolvida (atores do plano) poderá se utilizar desses artefatos para leitura e compreensão do plano, bem como para sua aplicação, de acordo com a função que cada ator possui. Um segundo aspecto refere-se ao tipo de informação constante no caso de uso adotado para a documentação do procedimento operacional padrão (SOP). O formato do caso de uso foi elaborado para permitir a descrição de todo o procedimento, objetivos e resultados esperados, incluindo se necessário, trechos de códigos ou pseudocódigos para os atores mais técnicos que atuam diretamente no suporte dos equipamentos e dos aplicativos da área de TI.

Para isto, o template de caso de uso foi adaptado com outros campos de dados para agregar informações da Dependabilidade. Além dos campos normalmente usados no caso de uso: descrição, atores, pré-condições pós-condições, fluxo principal e exceções, foram incrementados os dados de fluxo alternativo, entradas externas, atributos da Dependabilidade, cenário, observações, regras de negócio e mensagens.

O caso de teste também sofreu algumas adaptações daqueles utilizados para desenvolvimento de sistemas. Foi preciso acrescentar um campo específico para retratar o atributo da Dependabilidade e registrar os eventos de erro para durante a execução do SOP.

Outro aspecto relevante que favorece a utilização da diretriz proposta para área de TI em outros tipos de negócio foi a utilização de outros diagramas da UML para complementar a informação do SOP e representar o serviço, os relacionamentos e dependências, os riscos e as propriedades da informação. Estes diagramas, de natureza técnica, expressam o comportamento de cada serviço, agregando um forte valor ao detalhar o fluxo de controle das atividades críticas do serviço, demonstrando condições trabalho de sistemas e subsistemas, apresentando o estado e características físicas de hardware, de software e de midleware, informando as partes de componentes específicos de uma atividade incluindo até mesmo a mais granularizada das informações que é a representação de uma instância do sistema. 
Outro fator de sucesso da diretriz proposta foi a análise de risco por meio dos atributos da Dependabilidade. A Dependabilidade introduziu critérios (disponibilidade, confiabilidade, segurança, confidencialidade, integridade e manutenibilidade) para avaliar e descrever o comportamento das atividades críticas e quais eram os riscos da não operação dessas atividades segundo estes critérios. Foi determinado assim, um cenário comportamental para cada atividade crítica, e a partir deste cenário analisada e escolhida uma solução de continuidade de negócio.

Este cenário estabeleceu um padrão de análise para ser utilizado nos processos de identificação das funções críticas (BIA) e de avaliação dos riscos (RA) o que facilitou a obtenção de informações na etapa da GCN entender a organização.

A Figura 28 apresenta um resumo da utilização das ferramentas conhecidas da engenharia de sistemas de forma equivalente ao modelo cascata e seus artefatos:

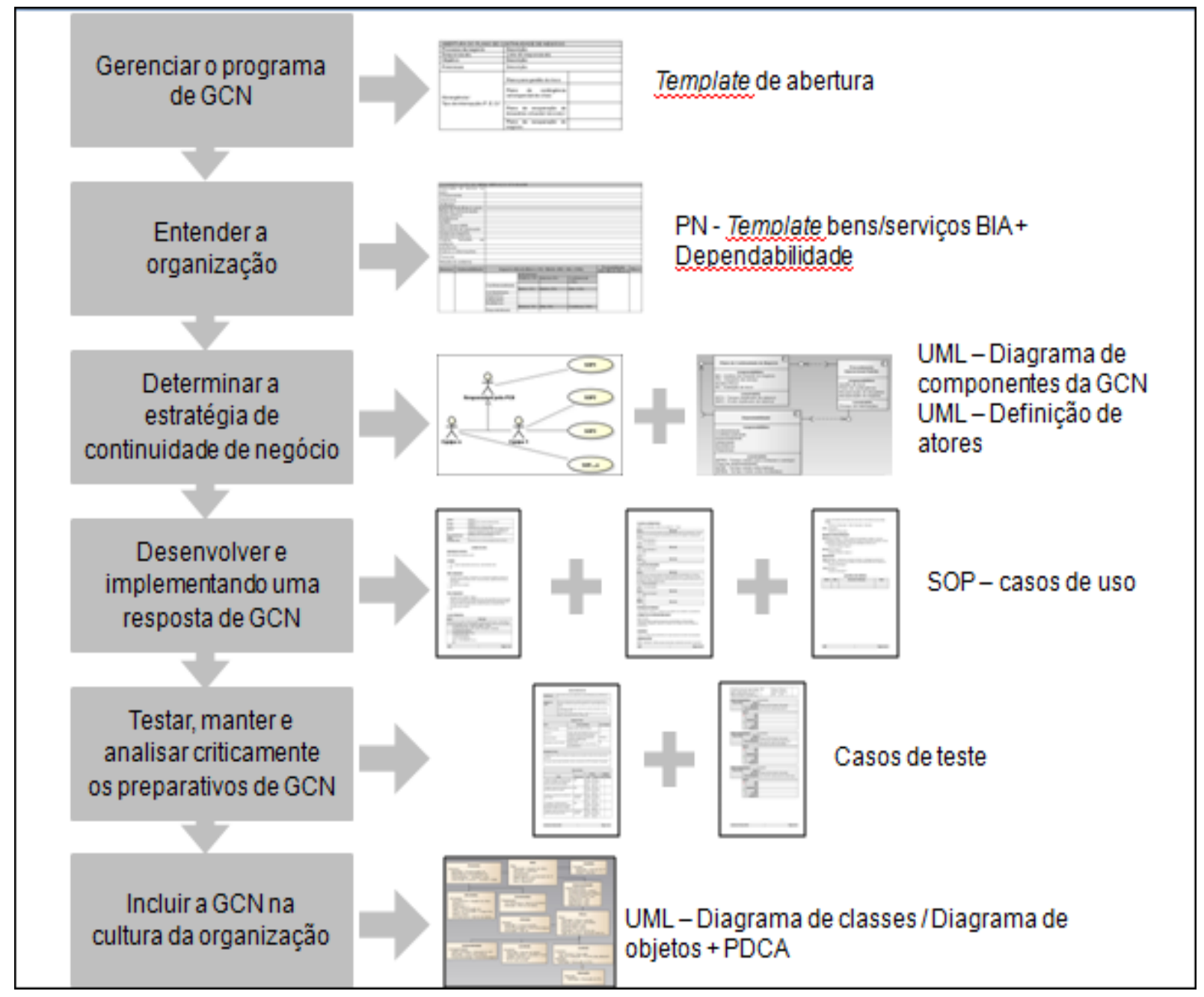

Figura 28: Ferramentas utilizadas para desenvolver a GCN. 
A operação contínua da GCN permitiu a utilização de técnicas do ITIL® e do PDCA. Estas ferramentas auxiliaram a elaboração das diretrizes de construção de PCN, pois permitiram estabelecer uma ordem temporal para as atividades executadas, desde as atividades estratégicas, de natureza gerencial, até as atividades de suporte de natureza técnica.

Inicialmente as atividades foram dividias entre planejamento, implementação, avaliação e planejamento da correção.

As atividades de planejamento foram: planejamento da capacidade, planejamento da disponibilidade e planejamento de recuperação de falhas, de continuidade e de segurança, o planejamento da implementação do PCN e o desenho para o suporte de operação do plano.

As atividades de implementação foram: negociação dos acordos de nível de serviço e a documentação do PCN.

As atividades de avaliação foram: avaliação e teste do plano.

$\mathrm{E}$ as atividades de planejamento da correção incluíam a melhoria do plano tanto corretiva quanto evolutiva.

Depois de identificadas de acordo com o PDCA, as atividades foram reagrupadas buscando uma aplicação dentro dos processos do ITIL ${ }$. Isto facilitou a definição de processos internos da área de $\mathrm{TI}$, associando-os aos atores envolvidos no plano.

O quadro 14 descreve quais os ciclos e processos contribuíram na construção do plano:

\begin{tabular}{|c|c|c|c|}
\hline \multirow{2}{*}{ Fases da GCN } & \multirow{2}{*}{ Ferramentas utilizadas } & \multicolumn{2}{|r|}{ Contribuição ITIL® } \\
\hline & & Ciclo & Processo \\
\hline \multirow{2}{*}{$\begin{array}{l}\text { Gerenciar o } \\
\text { programa de } \\
\text { GCN }\end{array}$} & \multirow{2}{*}{$\begin{array}{l}\text { Inicio do plano através do } \\
\text { template de Abertura de } \\
\text { Plano. }\end{array}$} & $\begin{array}{l}\text { Estratégia } \\
\text { do serviço }\end{array}$ & $\begin{array}{l}\text { - Gerenciamento da demanda } \\
\text { - Gerenciamento de portfólio de } \\
\text { serviços }\end{array}$ \\
\hline & & $\begin{array}{l}\text { Desenho } \\
\text { de serviço }\end{array}$ & $\begin{array}{l}\text { - Gerenciamento da continuidade } \\
\text { dos serviços de } \mathrm{TI}\end{array}$ \\
\hline $\begin{array}{l}\text { Entender a } \\
\text { organização }\end{array}$ & $\begin{array}{l}\text { Análise do impacto do negócio } \\
\text { (BIA) através do PN, plano de } \\
\text { negócio, composto do } \\
\text { template de análise de bens e } \\
\text { serviços através da } \\
\text { dependabilidade. }\end{array}$ & $\begin{array}{l}\text { Desenho } \\
\text { de serviço }\end{array}$ & $\begin{array}{l}\text { - Gerenciamento do catalogo de } \\
\text { serviços } \\
\text { - Gerenciamento do nível de } \\
\text { serviço } \\
\text { - Gerenciamento da segurança da } \\
\text { informação }\end{array}$ \\
\hline $\begin{array}{l}\text { Determinar a } \\
\text { estratégia de } \\
\text { continuidade de }\end{array}$ & $\begin{array}{l}\text { Definição dos atores } \\
\text { envolvidos no processo, } \\
\text { análise de risco, nível de risco }\end{array}$ & $\begin{array}{l}\text { Desenho } \\
\text { de serviço }\end{array}$ & $\begin{array}{l}\text { - Gerenciamento da capacidade } \\
\text { - Gerenciamento da } \\
\text { disponibilidade }\end{array}$ \\
\hline
\end{tabular}




\begin{tabular}{|l|l|l|l|}
\hline negócio & $\begin{array}{l}\text { através da criação de } \\
\text { diagramas de casos de uso } \\
\text { em UML. }\end{array}$ & $\begin{array}{l}\text { • Gerenciamento de fornecedor } \\
\text { - Gerenciamento da segurança da } \\
\text { informação }\end{array}$ \\
\hline $\begin{array}{l}\text { Desenvolver e } \\
\text { implementar } \\
\text { uma resposta } \\
\text { de GCN }\end{array}$ & $\begin{array}{l}\text { Criação dos SOP baseados } \\
\text { diagramas de caso de uso e } \\
\text { descrição de casos de uso. }\end{array}$ & $\begin{array}{l}\text { Desenho } \\
\text { de serviço }\end{array}$ & $\begin{array}{l}\text { • Gerenciamento da capacidade } \\
\text { Gerenciamento da } \\
\text { disponibilidade }\end{array}$ \\
\hline $\begin{array}{l}\text { Testar, manter e } \\
\text { analisar } \\
\text { criticamente os } \\
\text { preparativos de } \\
\text { GCN }\end{array}$ & $\begin{array}{l}\text { Implementação de casos de } \\
\text { testes. }\end{array}$ & $\begin{array}{l}\text { Desenho } \\
\text { de serviço }\end{array}$ & $\begin{array}{l}\text { Gerenciamento do catalogo de } \\
\text { serviços }\end{array}$ \\
\hline $\begin{array}{l}\text { Incluir a GCN na } \\
\text { cultura da } \\
\text { organização }\end{array}$ & $\begin{array}{l}\text { Criação de diagrama de } \\
\text { classes para monitorar, } \\
\text { garantindo a melhoria continua } \\
\text { através do PDCA. }\end{array}$ & $\begin{array}{l}\text { Melhoria } \\
\text { contínua de } \\
\text { serviço }\end{array}$ & Ciclo de controle monitorado \\
\hline
\end{tabular}

Quadro 14: Contribuição do ITIL® na aplicação da GCN.

\subsection{Trabalhos futuros}

A sequencia natural deste trabalho é ampliá-lo para tratar de todas as áreas da organização além da área de TI, ou seja, para todas as áreas do EPMRT, como por exemplo, as áreas de fornecimento de material, controle acadêmico, controle de pessoal, etc..

A partir da aplicação das diretrizes para todos os serviços e produtos (internos e externos, em todas as áreas) de uma empresa o estudo poderá evoluir para a validação dos documentos gerados, avaliando a eficiência da informação documentada nos templates e nos artefatos gerados, avaliando a eficiência do momento estratégico de preenchimento dos templates e artefatos.

Outro aspecto para evoluir as diretrizes de construção do PCN é classificar em níveis a execução dos SOPs. Estes níveis indicam a ordem em que os SOPs serão usados, sequencialmente. O primeiro nível engloba um conjunto de SOPs que devem ser executados logo na interrupção dos serviços, e, caso estes procedimentos operacionais padrão restabeleçam os serviços os demais níveis não serão necessários, caso contrário, se o primeiro nível não recuperar os serviços conforme esperado nos objetivos, o segundo nível de SOPs deve ser executado com este objetivo, e assim sucessivamente: o terceiro, quarto ou n-níveis até que a recuperação dos serviços seja concretizada. 
O prosseguimento da pesquisa poderá abranger a aplicação das diretrizes de construção do PCN com o desenvolvimento de métricas para avaliar o Plano de Continuidade de Negócios de uma organização, se ele já existe, em qual nível de maturidade, em qual nível de documentação, se em conformidade com as normas, se atualizado conforme o negócio da empresa, etc. Utilizar indicadores para avaliar cada solução existente, ou a não existência de solução de continuidade de negócios. Esta ferramenta deve classificar a GCN de uma organização, semelhante a um processo de auditoria, atribuindo níveis de conformidade de acordo com as métricas que a pesquisa irá desenvolver.

Estudos complementares a este podem alcançar uma análise para a utilização de uma ferramenta de Business Process Modeling Notation (BPMN) ou Notação para Modelagem de Processos de Negócios para documentar o PCN. A técnica de BPMN foi utilizada para representar a fase de apresentação do método de GCN para a empresa, Figura Diante das constantes mudanças nos negócios da empresa e consequentemente nos serviços entregues pela área de TI o BPMN é uma alternativa aos templates utilizados neste trabalho. O estudo poderá comparar as ferramentas de UML e BPMN apontando casos em que uma ferramenta poderá ser mais eficiente que a outra.

Por fim, outro trabalho importante é o de automatização da produção do Plano de Continuidade de Negócios. Esta etapa da pesquisa inicia com a atualização automatizada dos valores descritos nos templates e alcança a evolução adaptativa para os diagramas de classes, objetos, casos de uso, componentes e pacotes. 


\section{REFERÊNCIAS}

AVIZZIENIS. A.; LAPRIE, J. C.; RANDELL, B. Fundamental Concepts of Dependability. 1992. In: Workshop on Robot Dependability: Technological Challenge of Dependable Robots in Human Environments, Seoul, Korea, May 21-22, 2001.

ASSOCIAÇÃO BRASILEIRA DE NORMAS TECNICAS. NBR 15999-1: 2007. Gestão da continuidade de negócios, Rio de Janeiro, 2007.

ASSOCIAÇÃO BRASILEIRA DE NORMAS TECNICAS. NBR 15999-2: 2008. Gestão da continuidade de negócios Parte 2: Requisitos, Rio de Janeiro, 2008.

ASSOCIAÇÃO BRASILEIRA DE NORMAS TECNICAS. NBR 17799: 2005. Tecnologia da informação - Técnicas de segurança - Código de prática para a gestão da segurança da informação, Rio de Janeiro, 2005.

ASSOCIAÇÃO BRASILEIRA DE NORMAS TECNICAS. NBR 27001: 2006. Tecnologia da informação - Técnicas de segurança -Sistemas de gestão de segurança da informação - Requisitos, Rio de Janeiro, 2006.

BARBOSA, W. A.; RAMOS, J. A. G.; UEA Proformar e a Educação no Amazonas. Manaus: Ed. Valer, 2008. 140 p.

BARNES, P. Business Impact Analysis. In: HILES, A. (Editor) The definitive handbook of Business Continuity Management. 2. ed. Inglaterra, 2007, p.145-160.

BRASIL. Constituição da República Federativa do Brasil. Brasília: Senado Federal, 1988.

. Lei n. ${ }^{\circ}$ 9.394, de 20 de dezembro 1996. Estabelece as Diretrizes e Bases da Educação Nacional. Diário Oficial da União, Brasília, 1996.

BRYANS, J.W. et al. E-voting: Dependability Requirements and Design for Dependability. ARES 2006. First International Conference on Availability, Reliability and Security, 2006, p. 988-995.

BUJA, G.; MENIS, R. Conceptual frameworks for dependability and safety of a system. SPEEDAM 2006. In: International Symposium: Power Eletronics, Eletrical Drives, Automation and Motion. 23-26 May. 2006, p. 44-49.

CARROLL, T. Planning to recover your data. In: HILES, A. (Editor) The definitive handbook of Business Continuity Management. 2.ed. Inglaterra, 2007, p. 237-252.

CHAMBERS, L. A Hazard Analysis of Human Factors in Safety Critical Systems Engineering. In: 10th Australian Workshop on Safety Related Programmable Computer. Sidney. 2005, p. 27-41. 
CHARTERS, I. Risk evaluation and control: practical guidelines for risk assessment. In: HILES, A. (Editor) The definitive handbook of Business Continuity Management. 2.ed. Inglaterra, 2007, p. 137-144.

CHIDAMBARAM, J.; et al. A methodology for high availability of data for business continuity planning / disaster recovery in a grid using replication in a distributed database. TENCON 2008 - 2008. In: IEEE Region 10 Conference 19-21 Nov. 2008, p. 1-6.

CLOAREC, J.M. How dependability studies contribute to controlling risk. OCEANS 1994, Brest, France. In: Oceans Engineering for Today's Technology and Tomorrow's Preservations - Proceedings on 13-16 set. 1994, p. 560-564.

CoblT OnLine. Disponível em <http://isaca.org>. Acesso em 25 de Nov. 2009.

CORNISH, M. The business continuity planning methodology. In: HILES, A. (Editor) The definitive handbook of Business Continuity Management. 2.ed. Inglaterra, 2007, p. 105-118.

COURTNEY, N. Developing business continuity strategies for the business or work areas. In: HILES, A. (Editor) The definitive handbook of Business Continuity Management. 2.ed. Inglaterra, 2007, p 161-172.

FERREIRA, F. N. F. Segurança da Informação. Rio de Janeiro: Ed. Ciência Moderna, 2003.

FREIRE, W. (Org); AMORA, D. et.al. Tecnologia e Educação: as mídias na prática docente. Rio de Janeiro: Ed. Wak. 2008.

FREITAS, M. A. dos S. Fundamentos do Gerenciamento de Serviços de TI. Rio de Janeiro: Ed. Brasport, 2010.

GAIARSA D. M. Estágio de Vida da Tecnologia. Extensão do conceito de Technology Readiness Level - TRL (Nível de Prontidão Tecnológica) aplicado a TI. 2007. 74 p. Monografia apresentada a Escola Politécnica da Universidade de São Paulo. São Paulo, 2007.

GASPAR, M.; GOMEZ, T.; MIRANDA, Z. T.I. Mudar e inovar. Distrito Federal: Ed. SENAC, 2010.

GONÇALVES C. E. S. Inclusão digital indígena. Manaus, Universidade do Estado do Amazonas, 19 de outubro 2009. Palestra proferida por ocasião da Semana Nacional de Tecnologia, Manaus, 2009.

GOOD PRACTIVE GUIDELINES, Business Continuity Institute. Disponível em: <http://www.thegci.org/gpgdownloadpage.htm>. Acesso em 03 Nov. 2009.

GUEDES, Gilleanes T.A. UML 2: guia prático. São Paulo: Ed. Novatec, 2007.

HELDMAN, K. Gerência de projetos: guia para o exame oficial do PMI. Rio de Janeiro: Ed. Campus, 2006. 
HILES, A. (Editor). The definitive handbook of Business Continuity Management. 2. ed. Inglaterra, Editado por Andrew Hiles, 2007.

HOWE, J. Project iniciation and management. In: HILES, A. (Editor) The definitive handbook of Business Continuity Management. 2. ed. Inglaterra, 2007, p.119-135.

HOLWELL, S. Soft systems - another Layer to the 'V'? In: INCOSE UK Autumn Assembly 2009. Disponível em $<$ http://www.incoseonline.org.uk/Groups/Bristol/show_Events_Details.aspx?CatID=Gro ups\&EventID=58>.

KAANICHE, M.; LAPRIE, J.C.; BLANQUART, J.P. Dependability engineering of complex computing systems. In: Engineering of Complex Computer Systems, 2000. ICECCS 2000 Proceedings. Sixth IEEE International Conference on 11-14 Sept. 2000, p. 36-46.

KARDEC, A.; NASCIF, J. Manutenção: função estratégica. Rio de Janeiro: Ed. Qualitymark, 2001.

KENSKI, V.M. Educação e Tecnologias: o novo ritmo da informação. Campinas, SP: Ed. Papirus, 2007.

KEPENACH, R.J. Business Continuity Plan Design. Internet Monitoring and Protection, 2007. ICIMP 2007. In: Second International Conference on 01-05 July 2007, p.27.

KIRVAN, P.F. Business continuity for telecommunications. In: HILES, A. (Editor) The definitive handbook of Business Continuity Management. 2. ed. Inglaterra, 2007, p.193-204.

LAM, W. Ensuring business continuity. In: IT Professional Volume 4, Issue 3, MayJune 2002, p. 19-25.

LAPRIE, J. C. Dependability of computer systems: concepts, limits, improvements. 1995. In: Software Reliability Engineering - Proceedings. Sixth International Symposium on (1995), p. 2-11.

LAWLER, C.M.; SZYGENDA, S.A.; Components of Continuous IT Availability \& Disaster Tolerant Computing. In: 2007 IEEE Conference on Technologies for Infrastructure Dependability. 2007 IEEE Conference on 16-17 May 2007, p. 101-106.

LITTO, F. M.; FORMIGA, M.; Educação a distância - o estado da arte. São Paulo, Prentice Hall - Pearson, 2009. 480 p.

MAGALHÃES, I. L.; PINHEIRO, W. B. Gerenciamento de Serviços de TI na prática. São Paulo: Ed. Novatec., 2010.

MUSSON, M. Business continuity strategies for manufacturing and logistics. In: HILES, A. (Editor) The definitive handbook of Business Continuity Management. 2. ed. Inglaterra, 2007, p.185-192. 
NIST - National Institute of Standards and Technology. Disponível em < http://www.nist.gov/threats-vulnerabilities.cfm>. Acesso em 05 abril.2011.

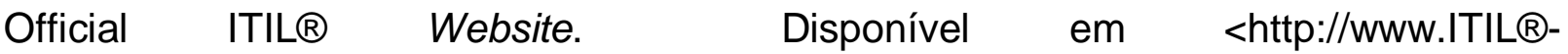
officialsite.com/home/home.asp>. Acesso em 25 março. 2011.

O'HEHIR, M. What is a business continuity planning (BCP) strategy? In: HILES, A. (Editor) The definitive handbook of Business Continuity Management. 2. ed. Inglaterra, 2007, p.27-45.

OLIVEIRA, V. L. Uma análise comparativa das metodologias de gerenciamento de risco FIRM, NIST SP 800-30 e OCTAVE. 2006.181 p. Dissertação (Mestrado). Instituto de Computação, Universidade Estadual de Campinas, Campinas, 2006.

PAI, R.R. et al. Methods toward supply chain risk analysis. Systems, Man and Cybernetics, 2003. In: IEEE International Conference on Volume 5, 5-8 Oct. 2003, p. 4560-4565, vol.5.

PEREIRA, E.C. Infraestrutura tecnológica em cursos na modalidade presencial mediado por tecnologia para o Estado do Amazonas. 2010, 64 p. Dissertação (Mestrado). Escola Politécnica, Universidade de São Paulo, São Paulo, 2010.

RAMAKRISHNAN, R.K.; VISWANATHAN, S. Business strategy and business continuity planning. In: HILES, A.(Editor) The definitive handbook of Business Continuity Management. 2. ed. Inglaterra, 2007, p.97-101.

REBOVICH JR. G. The Evolution of Systema Engineering. SysCon 2008. In: IEEE International Systems Conference, 07-10 April. 2008.

RITTINGHOUSE, J.W.; RANSOME, J. F.; Business Continuity and Disaster Recovery for InfoSec Managers, Ed. Elsevier Digital Press, 2005.

ROBERTS, W. C. Business Continuity Planning for Disasters is Just Good Planning. C.; In: Military Communications Conference, 2006. MILCOM 200623-25 Oct. 2006, p. 1-5.

SAGE, A.P. Systems Engineering Education. IEEE transactions on systems and cybernetics - part c: applications and reviews, Vol. 30, N․ 2, May, 2000.

SILVA, E. L.; MENEZES, E. M. Metodologia da Pesquisa e Elaboração de Dissertação. 3.ed. Florianópolis: Laboratório de ensino a distancia da UFSC, 2001. $121 p$.

SIMMS, J. Business continuity strategies for financial services. In: HILES, A. (Editor) The definitive handbook of Business Continuity Management. 2. ed. Inglaterra, 2007, p.173-184.

SMITH, M.; SHIELDS, P.A. Strategies for IT and communications. In: HILES, A. (Editor) The definitive handbook of Business Continuity Management. 2. ed. Inglaterra, 2007, p.205-236. 
SOFUOGLU, E.; BASOGLU, N. Exploring the characteristics and impact of information technology crisis on a company. 2008. In: PICMET Conference. Capie Town, South Africa. 27-31 July.

SPINA, E. Um método para a melhoria da qualidade de fornecimento da pequena empresa de eletrônica. 1998. 293 p. Tese (Doutorado). Escola Politécnica, Universidade de São Paulo, São Paulo, 1998.

TJOA, S.; JAKOUBI, S.; QUIRCHMAYR, G.; Enhancing Business Impact Analysis and Risk Assessment Applying a Risk-Aware Business Process Modeling and Simulation Methodology Availability, Reliability and Security. 2008. ARES 08. In: Third International Conference on 04-07 March 2008, p. 179-186.

UNIVERSIDADE DO ESTADO DO AMAZONAS. Projeto Pedagógico do curso de Tecnologia em Análise e Desenvolvimento de Sistemas. Manaus: UEA 2009.

- Relatório do Projeto Básico para Ensino a Distância: Ensino Presencial Mediado por Recursos Tecnológicos do curso de Tecnologia em Análise e Desenvolvimento de Sistemas. Manaus, [2008]. 26 p. (Projeto básico e Contrato de Serviço).

ESTADO DO AMAZONAS. Lei n. ${ }^{\circ} 2.637$, de 12 de janeiro de 2001. Cria a Universidade do Estado do Amazonas e dá outras providências. Diário Oficial do Amazonas, Manaus, AM, 2001.

Decreto n. ${ }^{\circ} 21.666$, de $1^{\circ}$ de fevereiro de 2001 . Regulamenta a Lei n. ${ }^{\circ}$ 2.637, de 12 de janeiro de 2001. Diário Oficial do Amazonas, Manaus, AM, 2001.

VANCOPPENOLLE, G. What are we planning for? In: HILES, A.(Editor) The definitive handbook of Business Continuity Management. 2. ed. Inglaterra, 2007, p.3-25.

WALDEN, D.D. The changing role of the systems engineer in a system of system (SOS) environment. 2007. In: 1st Annual IEEE Systems Conference 09-12 April. 2007.

WAN, S.H.C.; YUK-HEE CHAN; Adoption of business continuity planning processes in IT service management. Business-driven IT Management, 2008. BDIM 2008. In: 3rd IEEE/IFIP International Workshop on 07-07 April 2008, p. 21-30.

WESTERMAN, G.; HUNTER, R. O risco de TI: convertendo ameaças aos negócios em vantagem competitiva. São Paulo: Ed. M. Books do Brasil Editora Ltda, 2008.

ZAMBON, E. et al. A Model Supporting Business Continuity Auditing and Planning in Information Systems. Internet Monitoring and Protection, 2007. ICIMP 2007. In: Second International Conference on 01-05 July 2007, p.33.

ZORELLO G.; Metodologias CobIT e ITIL $®$ e as perspectivas do modelo de alinhamento estratégico de TI. XII SIMPEP - Simpósio de Engenharia da Produção. 07-09 nov. 2005. 